\title{
A Review of Cooling Tower Drift Deposition Models
}

Norbert C. J. Chen 


\section{DISCLAIMER}

This report was prepared as an account of work sponsored by an agency of the United States Government. Neither the United States Government nor any agency Thereof, nor any of their employees, makes any warranty, express or implied, or assumes any legal liability or responsibility for the accuracy, completeness, or usefulness of any information, apparatus, product, or process disclosed, or represents that its use would not infringe privately owned rights. Reference herein to any specific commercial product, process, or service by trade name, trademark, manufacturer, or otherwise does not necessarily constitute or imply its endorsement, recommendation, or favoring by the United States Government or any agency thereof. The views and opinions of authors expressed herein do not necessarily state or reflect those of the United States Government or any agency thereof. 


\section{DISCLAIMER}

Portions of this document may be illegible in electronic image products. Images are produced from the best available original document. 
Printed in the United States of America. Available from National Technical Information Service

U.S. Department of Commerce

5285 Port Royal Road, Springfield, Virginia 22161

Price: Printed Copy $\$ 5.50$; Microfiche $\$ 3.00$

This report was prepared as an account of work sponsored by the United States Government. Neither the United States nor the Energy Research and Development Administration/United States Nuclear Regulatory Commission, nor any of their employees, nor any of their contractors, subcontractors, or their employees, makes any warranty, express or implied, or assumes any legal liability or responsibility for the accuracy, completeness or usefulness of any information, apparatus, product or process disclosed, or represents that its use would not infringe privately owned rights. 
ORNL/TM-5357

Contract No. W-7405-eng-26

Engineering Technology Division

A REVIEW OF COOLING TOWER DRIFT DEPOSITION MODELS

Norbert. C. .J. Chen

Manuscript Completed - May 4, 1977

Date Published - June 1977

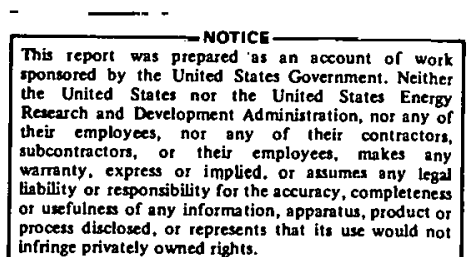

Prepared by the

OAK RIDGE NATIONAL LABORATORY

Oak Ridge, Tennessee 37830

operated by

UNION CARBIDE CORPORATION

for the

ENERGY RESEARCH AND DEVELOPMENT ADMINISTRATION 
THIS PAGE

\section{WAS INTENTIONALLY LEFT BLANK}


CONTENTS

Page

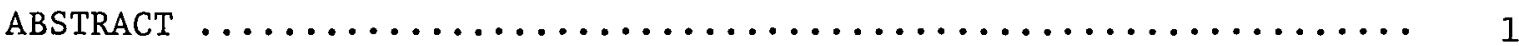

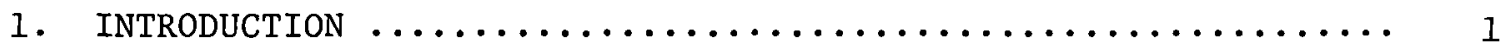

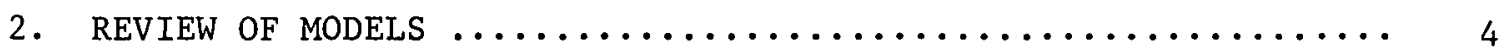

2.1 MODEL BY HOSLER, PENA, AND PENA $-1972 \ldots \ldots \ldots \ldots \ldots \ldots \ldots$. 4

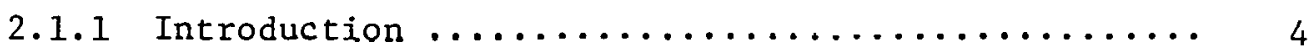

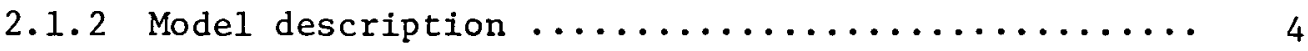

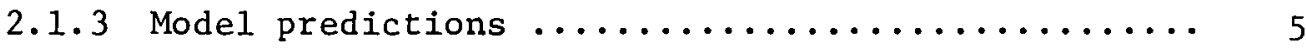

2.1 .4 Discussion of the model $\ldots \ldots \ldots \ldots \ldots \ldots \ldots \ldots \ldots .7$

2.2 MODEL BY ROFFMAN AND GRIMBLE - $1973 \ldots \ldots \ldots \ldots \ldots \ldots \ldots \ldots$

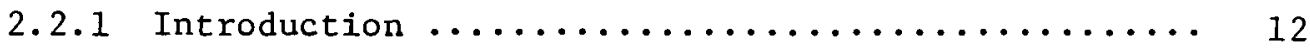

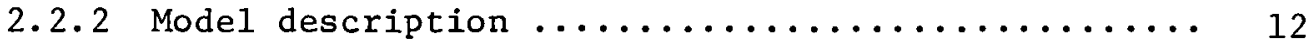

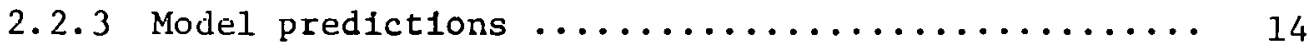

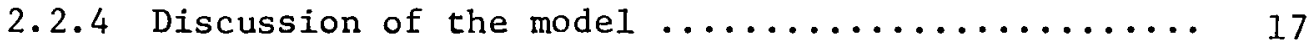

2.3 MODEL BY WINSTROM AND OVARD $-1973 \ldots \ldots \ldots \ldots \ldots \ldots \ldots \ldots \ldots$

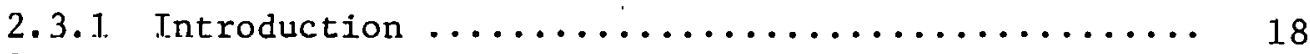

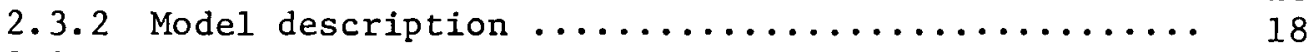

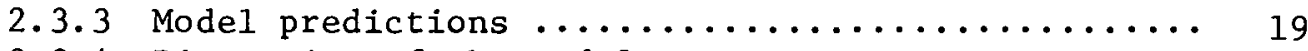

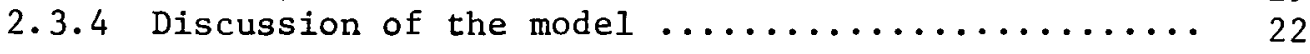

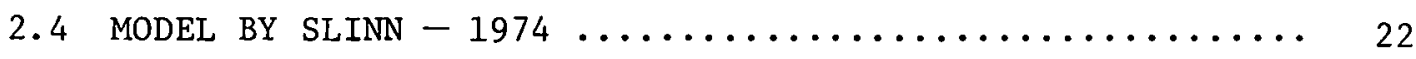

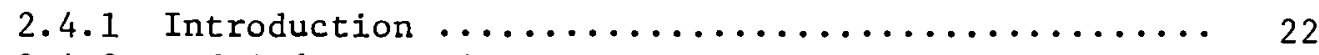

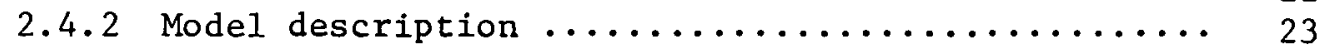

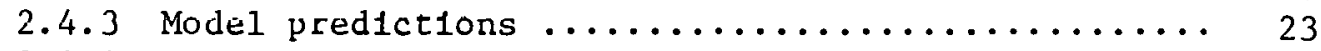

2.4 .4 Discussion of the model $\ldots \ldots \ldots \ldots \ldots \ldots \ldots \ldots . \ldots \ldots$

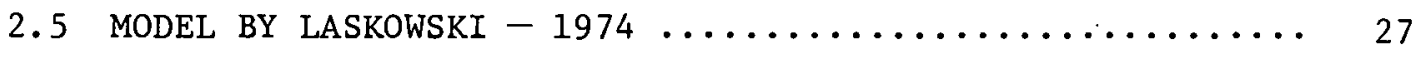

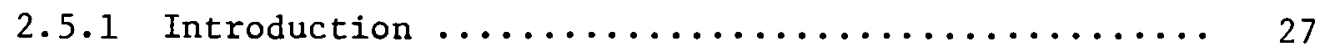

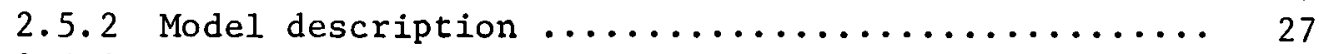

2.5 .3 Model predictions ...................... 30

2.5 .4 Discussion of the model ................ 32

2.6 MODEL BY ISRAEL AND OVERCAMP $-1974 \ldots \ldots \ldots \ldots \ldots \ldots \ldots \ldots \ldots$

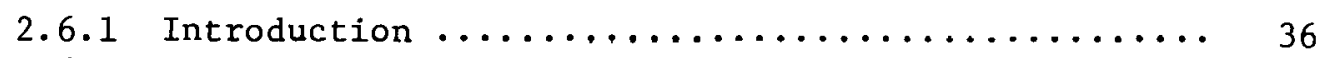

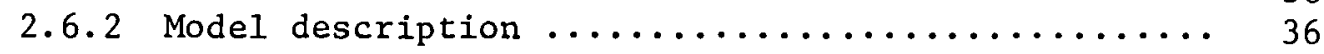

2.6 .3 Model predictions ........................ 38

2.6 .4 Discussion of the model ..................... 38

2.7 MODEL BY HANNA $-1974 \ldots \ldots \ldots \ldots \ldots \ldots \ldots \ldots \ldots \ldots \ldots \ldots \ldots \ldots \ldots$

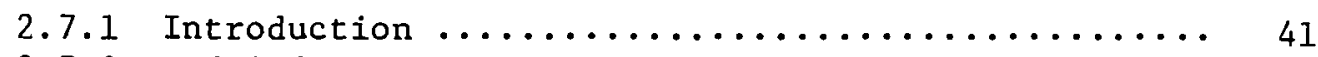

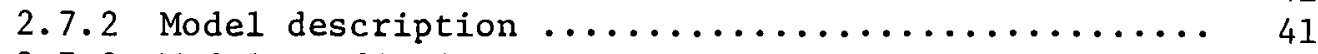

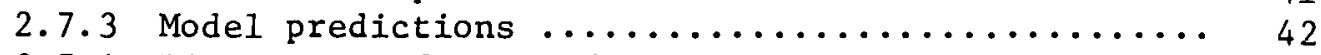

2.7 .4 Discussion of the model ................. 43 
2.8 MODEL BY TSAI AND JOHNSON $-1974 \ldots \ldots \ldots \ldots \ldots \ldots \ldots \ldots . \ldots \ldots 4$

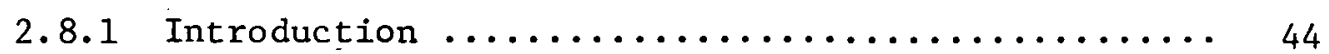

2.8.2 Model description ..................... 44

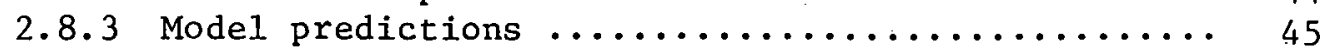

2.8 .4 Discussion of the model ............... 47

2.9 MODEL BY OAK RIDGE NATIONAL LABORATORY $-1975 \ldots \ldots \ldots \ldots .49$

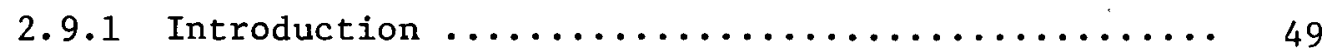

2.9.2 Model description ...................... 49

2.9 .3 Model predictions ...................... 50

2.9 .4 Discussion of the model ................ 50

2.10 MODEL BY RAO, LAGUE, AND EGAN - $1975 \ldots \ldots \ldots \ldots \ldots \ldots \ldots . \ldots 4$

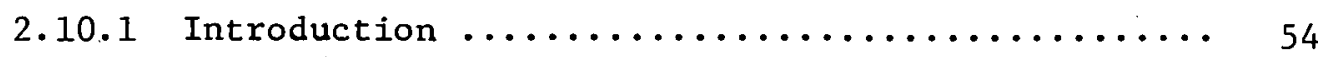

2.10 .2 Model description ...................... 55

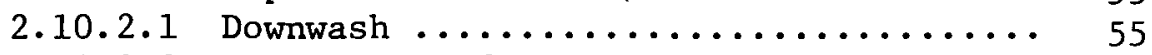

2.10.2.2 Dispersion of small droplets ....... 55

2.10.2.3 Deposition of large drops .......... 56

2.10 .3 Model predictions ...................... 56

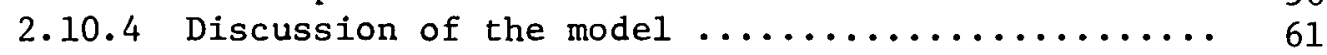

3. MODEL COMPARISONS USING A COMMON SET OF INPUT CONDITIONS $\ldots \ldots .62$

4. GENERAL SUggestions TO IMPROVE THE MODELS $\ldots \ldots \ldots \ldots \ldots \ldots \ldots .75$

4.1 EFFECTS OF THE CENTRIFUGAL FORCE $\ldots \ldots \ldots \ldots \ldots \ldots \ldots \ldots \ldots \ldots$

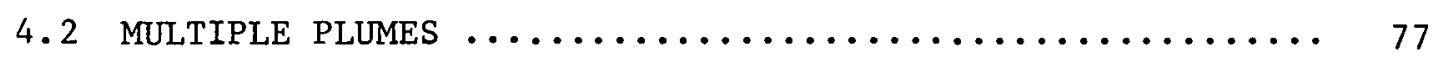

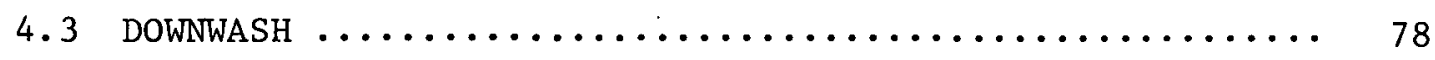

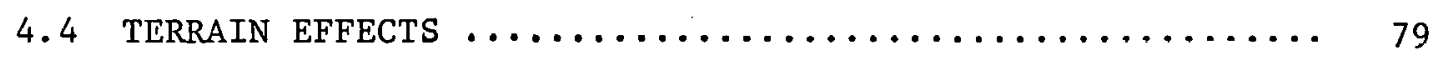

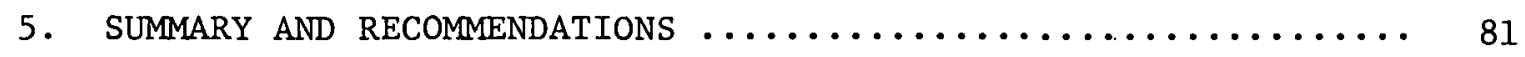

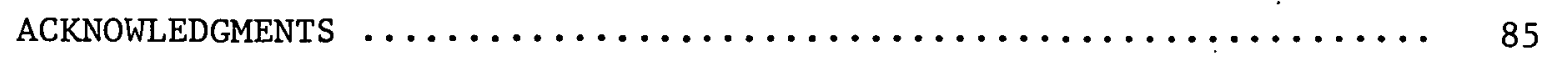

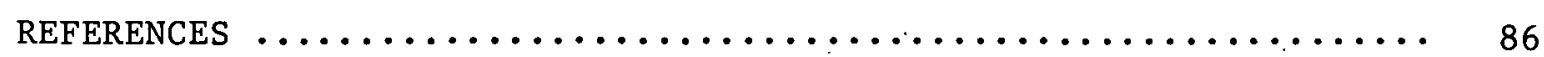


A REVIEW OF COOLING TOWER DRIFTT DEPOSITION MODELS

Norbert C. J. Chen

\section{ABSTRACT}

The behavior, basic assumptions, and limitations of ten different models for calculating the drift deposition rate from wet cooling towers are reviewed and then their predicted results for such deposition with a common set of input parameters are compared. The predicted maximum deposition differs among the models by two orders of magnitude with a wide range in peak location. Comments and suggestions to improve the models are included.

\section{INTRODUCTION}

When a small amount of circulating water in a cooling tower is entrained and carried aloft by the air stream in the form of droplets that contain chemicals in roughly the same concentration as in the cooling water, the droplets, which vary from a few to several thousand microns in diameter, are referred to as drift. Drift is different from fog both in the size of droplets and the method of physical formation, for fog consists of water droplets with diameters less than $20 \mu \mathrm{m}$ and is formed by condensation processes in the atmosphere. In a modern cooling-tower system with efficient drift eliminators, the amount of water lost as drift can be as low as $0.001 \%$.

Drift from cooling towers is of concern because it can corrode and damage structures in the immediate vicinity of the towers, cause a public nuisance if located near parking lots or high-density traffic areas, and endanger local vegetation. The importance of drift deposition is shown in the statement of the major objective for the Chalk Point Cooling Tower Program in Maryland. "... to assess the effect of salt water drift from the Chalk Point Cooling Tower on soils, annual vegetation (especially agronomic crops) and perennial vegetation (woody species) within the deposition area around the tower and to select, improve, and validate salt drift transport and deposition models (or a model) suitable for use in predicting salt drift distribution from natural-draft cooling towers." 1 
Drift deposition involves several interrelated processes: the dynamics and thermodynamics of drops in a rising plume, the drops breaking free from the plume, dispersal by atmospheric turbulence, and evaporation. To estimate drift deposition, the source characteristics of the tower (such as geometry, amount of water circulated, effluent speed, drop-size distribution, drift rate, and salt concentration) must first be known. Then calculations must be made of the plume rise, which in part depends on initial momentum and buoyancy flux and on the ambient atmospheric conditions. And finally, droplet transport, which depends on such meteorological conditions as atmospheric relative humidity and turbulence, temperature and its gradient, and wind vector must be considered.

A number of state-of-the-art reviews on cooling towers have been reported. ${ }^{2-4}$ Generally, these reviews discuss the operating characteristics of cooling towers (with intensive surveys on visible plume length) and briefly describe various models of deposition. However, none of the reviews compare the models for a particular set of identical data - a necessary element for model evaluation. This study attempts to do just that for all currently available mathematical models for drift deposition.

Research has been conducted on this subject for two and one-half decades. The first model of dust deposition known to the author was developed by Bosanquet, Carey, and Halton ${ }^{5}$ In early 1950 and cumsilered only jolid particles of a single size. Formulas and graphs, without derivation, were given for deposition prediction, and good agreement with data was claimed. In 1961, using a modified Sutton diffusion equation, Chamberlain ${ }^{6}$ investigated the deposition of aerosol and vapor clouds. The first attempt at modeling drift deposition from cooling towers was when Hosler, Pena, and Pena ${ }^{7}$ published a ballistic method employing nomograms in 1972 . They included the effects of evaporation but ignored turbulent dispersion. Since then, there have been nine additional models published. In addition, the author is aware of five other unpublished models of drift deposition, but they are proprietary and could not be obtained for this review.

The ten published models are discussed one by one in Chapter 2; in these discussions, particular emphasis is placed on the basic principles of and difficulties encountered with each model. In Chapter 3, an approach is presented for systematically comparing the models using a set of common 
input parameters. The results produced by individual models are not identified; however, discrepancies among predictions are explained whenever possible. In Chapter 4 other effects, such as those produced by centrifugal force in a bifurcated plume, multiple-plume merger, downwash at the lee of a tower, and terrain in a non-flat region, are discussed.

The analysis of drift deposition models cannot be considered complete until the predictions of individual models can be checked against field data. It was hoped that such a comparison could be done against field data obtained at the Chalk Point Cooling Tower Project. Unfortunately, the expected data were not made available at the time of this writing. Finally, a summary of the findings and recommendations based on those findings are given in Chapter 5 . 


\section{REVIEW OF MODELS}

2.1 Model by Hosler, Pena, and Pena - 1972 (Ballistic Method)

\subsubsection{Introduction}

The Hosler, Pena, and Pena method, ${ }^{7}$ one of the earliest drift-deposition models to be widely used, is the first model accounting for droplet evaporation as a function of salt concentration, size and ambient relative humidity. It describes a ballistic trajectory determined by the ambient wind velocity and the droplet fall speed. It considers all droplets to be emitted at the center of the tower top and to escape from the plume when the droplet fall speed exceeds the updraft velocity. The calculations are simplified in practice by the use of graphs and nomograms. Humidity conditions are limited to three classes, making this the only model that can be easily used without an elaborate computer program. Its greatest shortcomings would appear to be the neglecting of turbulent dispersion and the oversimplifying of when droplets escape from the rising plume. The mode1 is conservative in that errors introduced by the various simplifications employed by the model always result in overestimating the deposition.

\subsubsection{Model description}

Hosler, Pena, and Pena make two major assumptions. The first is that droplets are carried up in a rising plume whose updraft decreases linearly with height, from the initial efflux velocity at the tower top to zero at the maximum plume height. The second is that a droplet breaks away from the plume when that droplet's fall speed exceeds the updraft. The maximum height that a droplet can attain (the effective height of emission) then depends primarily on the initial efflux speed and droplet sizes. This height is presented graphically by Hosler, Pena, and Pena. Once the droplets escape from the plume, how much a droplet can be evaporated and how fast it reaches the equilibrium size depend on the droplet's initial size and salt concentration and on the ambient relative humidity. The height at which droplets reach equilibrium size (or equilibrium height) at an ambient temperature of $20^{\circ} \mathrm{C}$ was determined and is shown graphically by 
Hosler, Pena, and Pena. The equilibrium height is temperature dependent, however; and so Pena and Hosler 1 ater ${ }^{8}$ derived a temperature-correction factor for the equilibrium height at temperatures from 0 to $30^{\circ} \mathrm{C}$.

Hosler, Pena, and Pena have classified the degree of evaporation into three categories. They assume that (1) no evaporation will occur for those droplets with an effective height of emission less than the height of equilibrium while the relative humidity is between 90 and $100 \%$; (2) evaporation will produce a drop of saturated solution for those droplets with an effective height of emission larger than the height of equilibrium while the relative humidity is between 65 and $90 \%$; and (3) evaporation will produce dry salt particles for those droplets with an effective height of emission larger than the equilibrium height while the relative humidity is less than $65 \%$. The time for a droplet of a specific size and composition to fall to the ground under different atmospheric conditions can thus be obtained from one of the nomograms prepared by Hosler, Pena, and Pena. With the necessary physical values known, the calculated deposition is derived by uniformly distributing the droplets over an area.bounded by a $22.5^{\circ}$ sector, radiating out from the cooling tower and by the distances traveled by the heaviest and lightest droplets.

\subsubsection{Model predictions}

Once the appropriate degree of evaporation of the droplet has been classified and the respective nomogram selected, the distance at which droplets of different sizes will fall out is determined graphically. For the sakc of simplicity, a limited number of different drop sizes are selected to represent ranges of droplet sizes. Assuming that these "averaged" droplets will fall out uniformly in the corresponding range of drift, contiguous bands of drift fallout appear downwind - the heaviest droplets in the first band, the lightest in the last (most distant) band.

Hosler, Pena, and Pena assume that no turbulence occurs. They predict that the deposition rate $W$ (in $\mathrm{mg} \mathrm{m}^{-2} \mathrm{sec}^{-1}$ ) for droplets of radius $r_{j}$ is

$$
w_{r_{j}}=b \phi Q \tau_{r_{j}} /\left\{\pi u^{2}\left[\left(h_{r_{i}}^{2} / v_{r_{i}}^{2}\right)-\left(h_{r_{k}}^{2} / v_{r_{k}}^{2}\right)\right]\right\},
$$


where

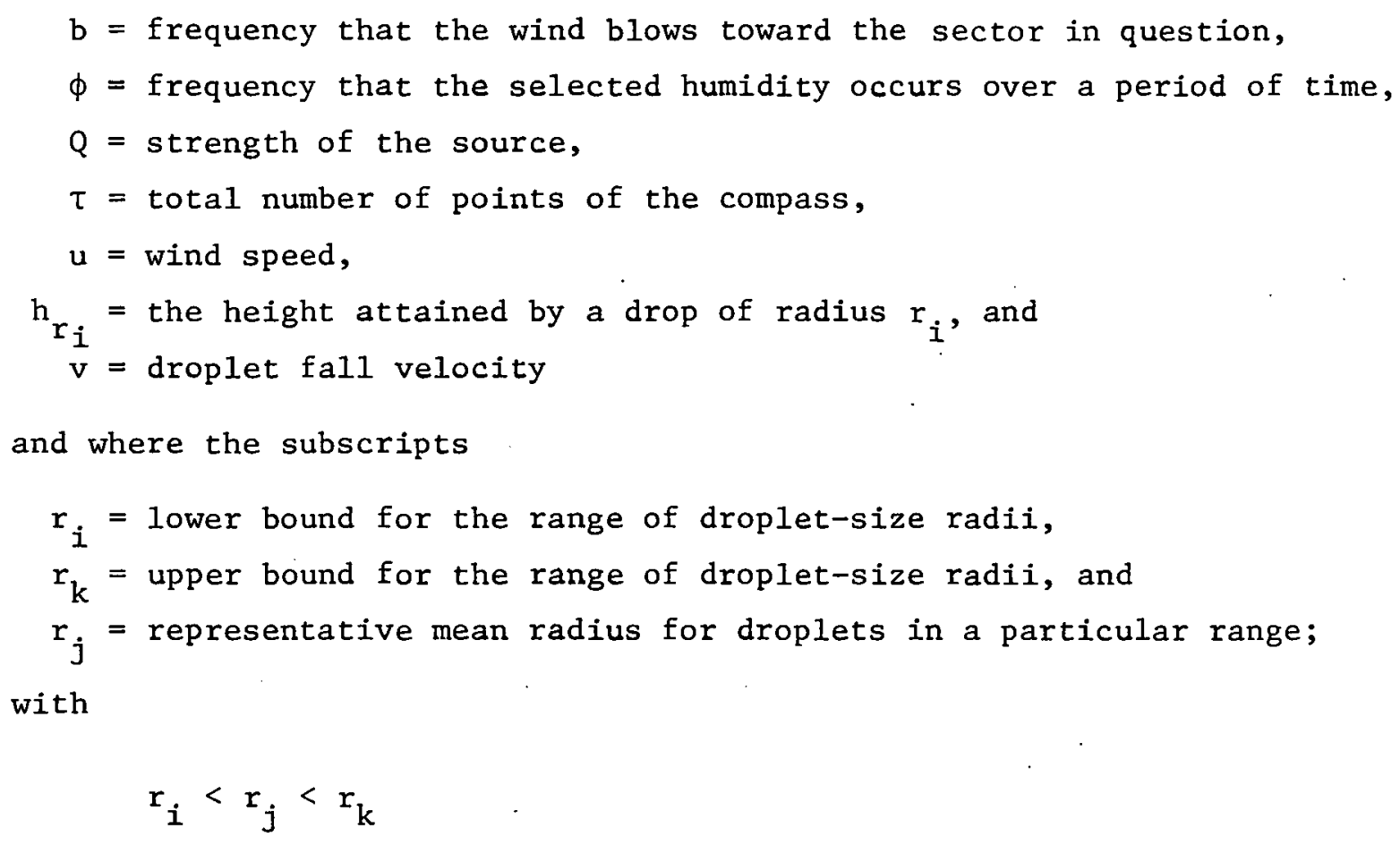

$$
r_{i}<r_{j}<r_{k}
$$

For the purpose of comparing this model with others, the following values were used for the variables:

$$
\begin{aligned}
\mathrm{b}= & 0.125, \\
\phi= & 0.19 \text { for relative humidity between } 0.9 \text { and } 1.0, \\
& 0.61 \text { for relative humidity between } 0.65 \text { and } 0.9 \text {, and } \\
& 0.20 \text { for relative humidity between } 0 \text { and } 0.65 ; \\
Q= & 1.78 \times 10^{4} \mathrm{mg} / \mathrm{sec} \text { of } \mathrm{NaCl}, \\
\tau= & 8, \\
u= & 4.7 \mathrm{~m} / \mathrm{sec} .
\end{aligned}
$$

The size distribution that was assumed for the droplets is as follows:

$\begin{array}{lll}\mathbf{r}(\mu \mathrm{m}) & & \text { Mass }(\%) \\ 50-75 & & 57.5 \\ 75-100 & & 20.0 \\ 100-125 & & 12.7 \\ 125-150 & & 6.8 \\ 150-175 & & 3.0\end{array}$


The model predicts the deposition rate shown by the open circles in Fig. 1 . This deposition rate agrees with the results derived by Sutton's theory ${ }^{9}$ for neutral conditions in which turbulent effects are less significant. In addition, the peak value is within a factor of 2 of that predicted by Sutton's theory for a strong inversion.

\section{1 .4 Discussion of the model}

The assumption that updraft velocity decreases linearly with height is reasonable for a nonbuoyant jet. The jet rises because of its initial. momentum, which is conserved, but the updraft velocity decreases with height as a result of the entrained ambient air. A dry buoyant plume, however, rises because of a density difference between the plume and its

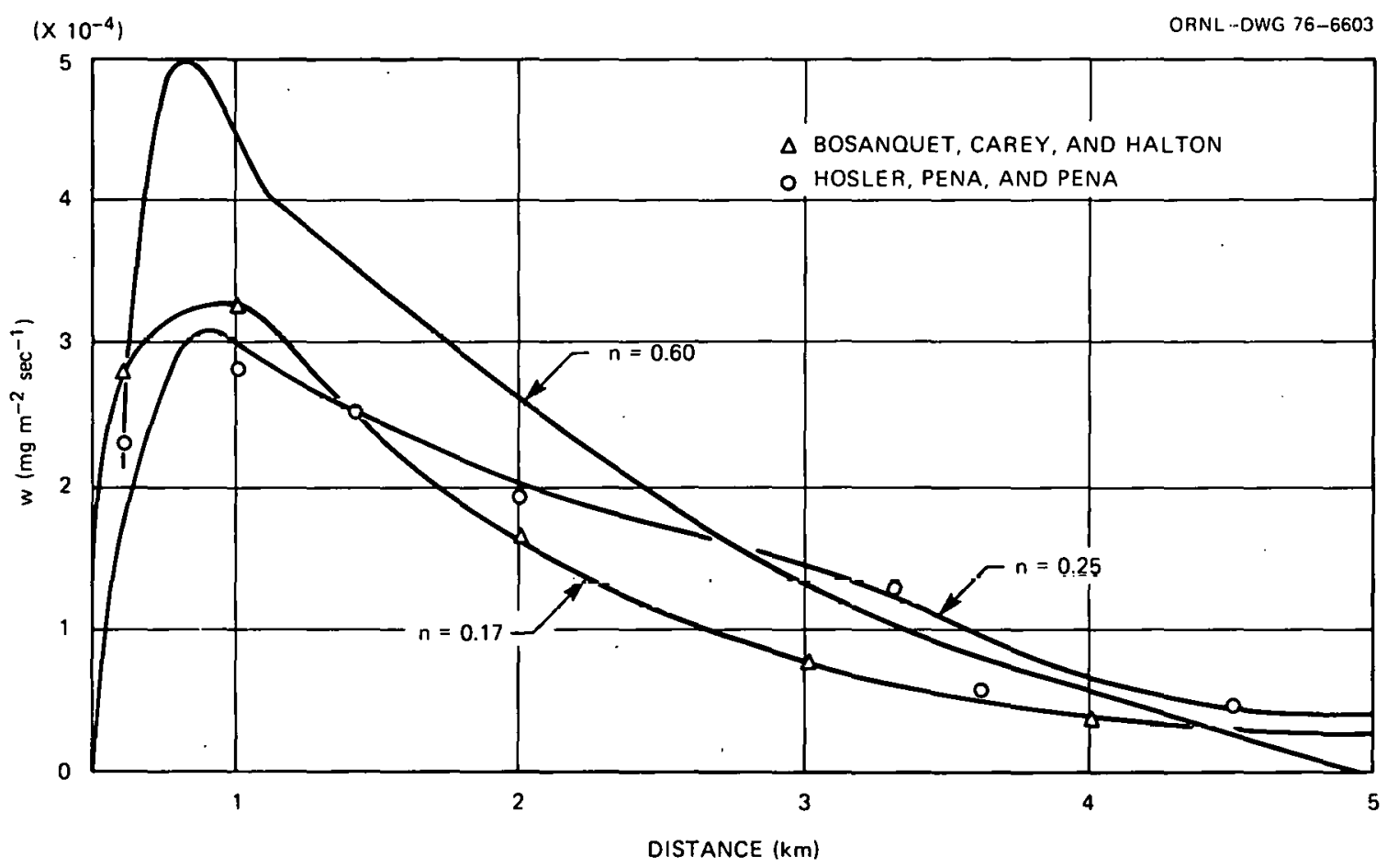

Fig. 1. Comparison of three different deposition models: the set of three solid curves, with $\mathrm{n}=0.17,0.25$, and 0.6 for unstable, neutral, and strong inversion, respectively, is derived from Sutton's theory; the result represented by $\Delta$ is computed from Bosanquet et al. formula; the result represented by $O$ is calculated from Hosler et al. method. Source: J. A. Pena and C. L. Hosler, Fig. 3, p. 582, in "Influence of the Choice of the Plume Diffusion Formula on the Salt-Deposition Rate Calculation," Cooling Tower Environment - 1974, CONF-740302 (1975). 
environment in addition to its initial momentum. The velocity profile of such a buoyant plume is, in general, not linear. If there is a release of latent heat from a wet plume, the updraft will be enhanced and a higher plume rise will be attained than by an otherwise similar dry plume.

A cooling-tower plume behaves more like a wet plume. Its vertical velocity profile is consequently not linear. If a droplet followed a ballistic trajectory, it would actually strike the ground at a distance farther away from the tower than the Hosler, Pena, and Pena model would predict, and salt deposition per unit area would be reduced near the towers. The effect of a stronger updraft may be seen in the idealized comparison of the velocities (and ultimate heights) of wet and dry plumes vs a nonbuoyant jet in a schematic form in Fig. 2(a). Starting at initial velocity wo (at the top of the tower), a jet's updraft velocity w steadily decreases to
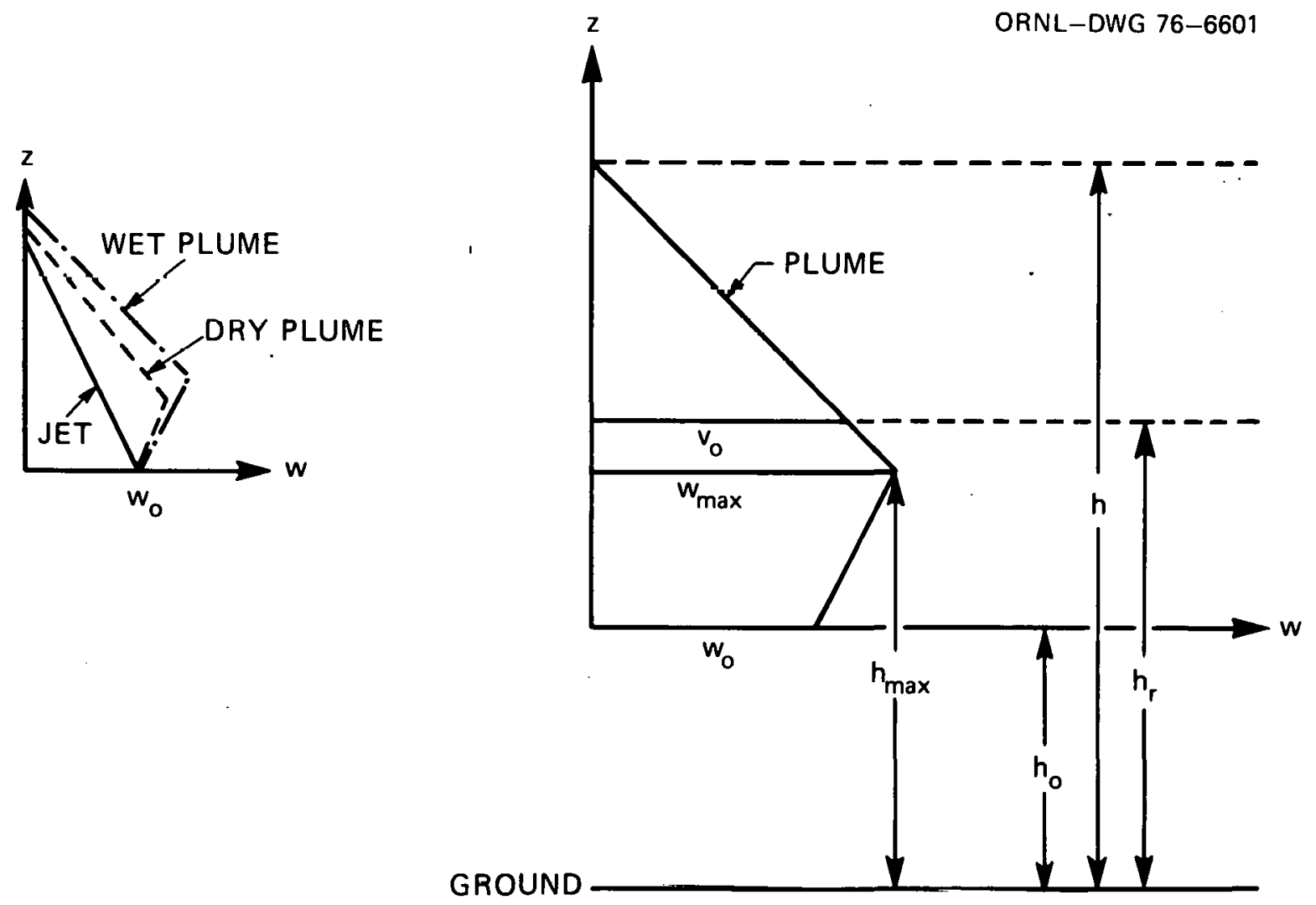

Fig. 2. (a) Comparison of air vertical velocity in a nonbuoyant jet with that in wet and dry plumes, (b) Velocity vs height for a bilinearvelocity (increasing/decreasing) buoyant plume. 
zero. The wet and dry buoyant plumes, on the other hand, initially accelerate and then slow down ultimately reaching a greater height. With this in mind, Hosler, Pena, and Pena defined a correction factor $\phi_{H}$ for the linear velocity profile:

$$
\phi_{H}=\frac{h_{r}-h_{0}}{h-h_{0}}=\frac{w_{0}-v_{0}\left(r_{0}\right)}{w_{0}}=1-\frac{v_{0}\left(r_{0}\right)}{w_{0}} .
$$

This $\phi_{\mathrm{H}}$ is actually a measure of how high a drop can rise; the larger the $\phi_{H}$ factor, the higher the droplets climb. Here the subscript $H$ refers to Hosler et al. In Eq. (2), $h_{r}$ is the height attained by a drop of initial radius $r_{0}, h_{0}$ is the height of the tower, $h$ is the height of the plume, $w_{0}$ is the effluent speed, and $v_{0}\left(r_{0}\right)$ is the fall velocity of a droplet with an initial radius $r_{0}$.

In the following, a new correction factor designated by $\phi_{C}$ will be suggested. With the bilinear profile, when a droplet has initial fall velocity that is less than or equals the initial updraft, it will continue to rise even after it stops accelerating (that is to say after it reaches $h_{\max }$ ) and will only fall out of the plume when its fall velocity exceeds the local updraft. A modified correction factor can be defined to reflect this situation:

$$
\phi_{C}=\frac{h_{r}-h_{\max }}{h-h_{\max }}=\frac{w_{\max }-v_{0}\left(r_{0}\right)}{w_{\max }}=1-\frac{v_{0}\left(r_{0}\right)}{w_{0}}\left(\frac{w_{0}}{w_{\max }}\right) .
$$

Here $h_{\max }$ is the height that the droplet atcains while accelerating because of buoyancy, and $w_{\max }$ is the maximum plume updraft velocity produced by the initial updraft plus the acceleration caused by buoyancy and/or the release of latent heat.

Slinn's analytical expressions ${ }^{10}$ for settling velocity can be used to compare the results of this modified equation with Hosler, Pena, and Pena's $\phi_{\mathrm{H}}$ values. Using

$$
v_{0}=0.8 \times 10^{-2} r_{0}(\mathrm{~m} / \mathrm{sec}) \text { for } r_{0}>50 \mu \mathrm{m}
$$

and

$$
v_{0}=0.25\left(r_{0} / 50\right)^{2}(\mathrm{~m} / \mathrm{sec}) \text { for } \mathrm{r}_{0} \leq 50 \mu \mathrm{m}
$$


in Eq. (3) gives

$$
\phi_{C}= \begin{cases}1-\left(w_{0} / w_{\max }\right) 0.8 \times 10^{-2} r_{0} / w_{0} & \text { for } r_{0}>50 \mu \mathrm{m} ; \\ 1-\left(w_{0} / w_{\max }\right) 0.25\left(r_{0} / 50\right)^{2} / w_{0} & \text { for } r_{0} \leq 50 \mu \mathrm{m} .\end{cases}
$$

Figure 3 compares the $\phi_{\mathrm{H}}$ values calculated by the original Hosler, Pena, and Pena equation with the $\phi_{C}$ values calculated by Chen $f_{c}$ the case $\mathrm{w}_{0} / \mathrm{w}_{\max }=3 / 4$. With small initial updraft and large drops, the $\phi_{\mathrm{C}}$ is double the $\phi_{H}$ value, but at greater initial updrafts the difference is

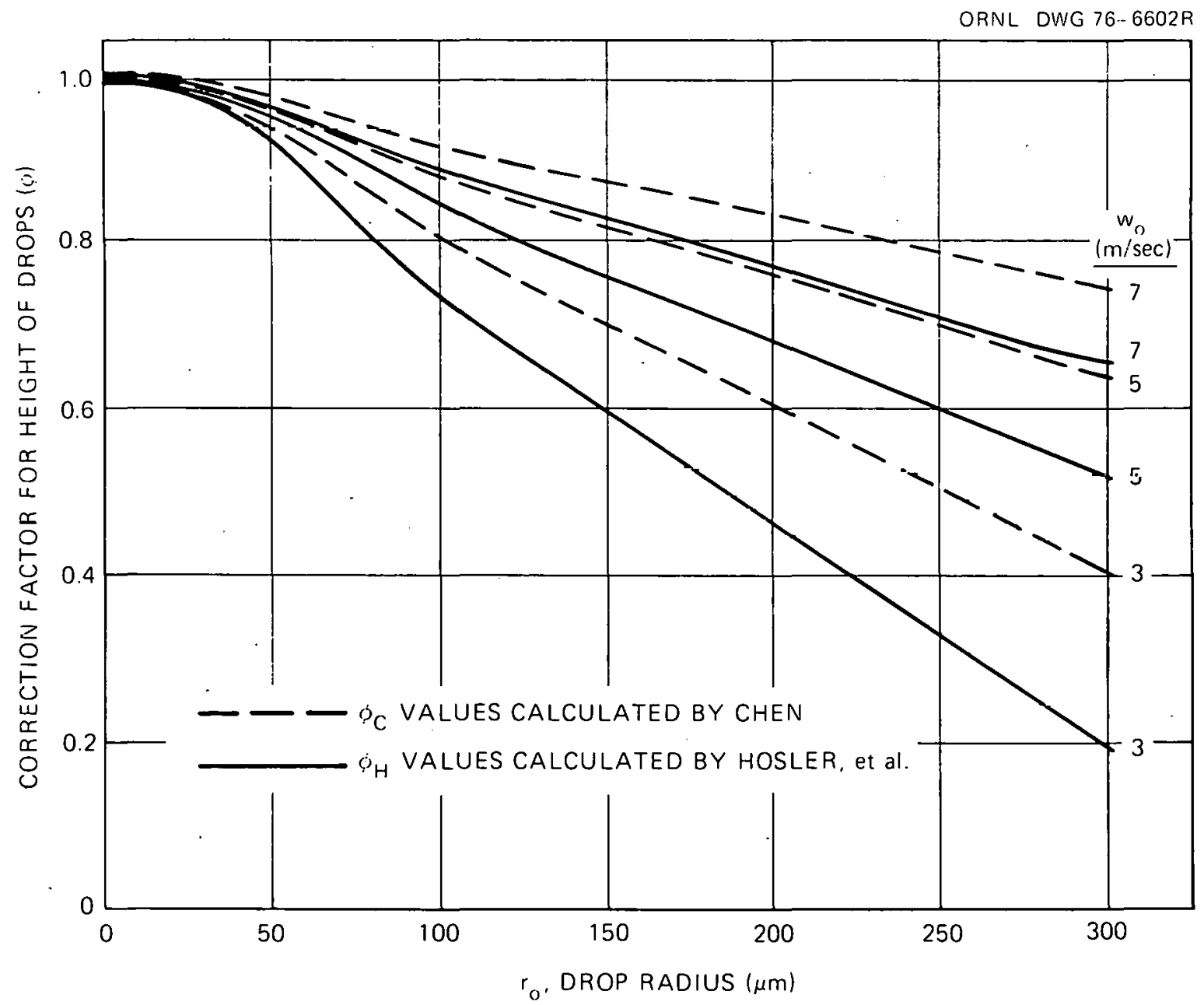

Fig. 3. Comparison of original correction factor, $\phi_{H}$ derived by Hosler,. Pena, and Pena with the modified correction factor $\phi_{C}$ derived by Chen for $w_{0} / w_{\max }=3 / 4$, for various initial updraft and for various drop radii. 
smaller. The bilinear updraft profile seems quite simplified when compared with the much more detailed profiles available from calculations analyzing interacting dynamic and thermodynamic effects or from studies performed by penetrating the plume with aircraft. However, the simplified method does serve to illustrate the differences in the effective heights of the drops. Hosler, Pena, and Pena also greatly simplified the problem of the degree of evaporation achieved by drops of different sizes and salt concentrations as was stated earlier. A change in droplet size is produced by this evaporation which in turn is governed by the difference in water vapor pressure between the drop's surface and its environment. The vapor pressure at a drop surface depends, among other things, on two variables: the droplet's curvature (which usually can be neglected because of the relatively large size of drift droplets) and the solute concentration. The latter is of critical importance because the evaporation rate decreases with increasing concentration for a salt-laden droplet. Since the droplet may evaporate to a saturated solution, the mass of the salt is not negligible in the evaporation process and cannot be ignored in the consideration of evaporation. Insofar as Hosler, Pena, and Pena classify the degree of evaporation into three categories, their approach to evaporation is reasonable in practice.

One of the critical elements in calculating drift transport and deposition is determining where drops break free from a rising plume. In their model, Hosler, Pena, and Pena, reasonably assumed that drops of a given size break free when the fall velocity exceeds the updraft in a rising plume; however, they assumed that updraft speed decreases linearly with height. This seems to be an oversimplified approach and although suggestions have been made by the author to modify the updraft profile, the modified models should be tested against velocity measurements in actual plumes. Finally, Hosler, Pena, and Pena do not take turbulence into consideration. According to Van der Hoven, ${ }^{11}$ the effect of turbulent diffusion of droplets can be neglected only if terminal fall speeds are greater than about $1 \mathrm{~m} / \mathrm{sec}$. However, most of the drops in cooling-tower plumes have fall velocities less than $1 \mathrm{~m} / \mathrm{sec}$, and so an error will be introduced by Hosler, Pena, and Pena's trajectory technique with an increased error for the small sizes. 
2.2 Model by Roffman and Grimble - 1973 (K Theory)

\subsubsection{Introduction}

In Roffman and Grimble's model, ${ }^{3}, 12,13$ the drops are assumed to break free at the full plume rise. The model is based on a diffusion equation that describes the rate of change of the number of droplets per unit volume at full plume rise. This rate of change is calculated as functinns of the drops' radii, atmospheric conditions, changes in droplets' sizes from evaporation or condensation, and changes in salt concentration in the droplets. This method uses eddy coefficients (K's) to characterize atmospheric dispersion of falling droplets. The diffusion equation is solved by assuming constant eddy coefficients over the atmospheric layer of interest. Plume height is calculated by Brigg's formula ${ }^{14}$ as modified by Hanna. ${ }^{15}$ Thus the height reflects the effect of the buoyancy produced by the moisture content and the released latent heat of condensatiun.

\subsubsection{Model description}

Roffman and Grimble apply their diffusion equation at a height where the plume is no longer rising. Using the $\mathrm{K}$ theory they calculate the change in density (in terms of the number of droplets per unit volume) of an average size of drops in a differential volume element. The differential equation governing the rate of change in the number of drift droplets per unit volume is

$$
\begin{aligned}
\frac{\partial N}{\partial t}=u_{i} \frac{\partial N}{\partial x_{i}}+\frac{\partial}{\partial x_{i}}\left(k_{i j} \frac{\partial N}{\partial x_{j}}\right)-\frac{\partial}{\partial R}\left(N \frac{\partial R}{\partial t}\right)-\frac{\partial}{\partial T}\left(N \frac{\partial T}{\partial t}\right) \\
-\frac{\partial}{\partial v_{t}}\left(N \frac{\partial v_{t}}{\partial t}\right)-\frac{\partial}{\partial S}\left(N \frac{\partial S}{\partial t}\right)-\left(\frac{\partial N}{\partial t}\right)_{c r}+\left(\frac{\partial N}{\partial t}\right)_{c a},
\end{aligned}
$$

where

$$
\begin{aligned}
N= & \text { number of drift droplets with radius } R \text { per unit volume }\left(\mathrm{m}^{-3}\right) ; \\
t= & \text { time }(\mathrm{sec}) ; \\
\mathrm{u}_{i}= & \text { the wind velocity component in the axis directions } x, y \text {, and } z \\
& \text { where } \mathrm{x} \text { is positive in the downwind direction, } \mathrm{z} \text { is positive } \\
& \text { vertically upward and } \mathrm{y} \text { is positive laterally in a right-handed } \\
& \text { coordinate system }(\mathrm{m} / \mathrm{sec})
\end{aligned}
$$




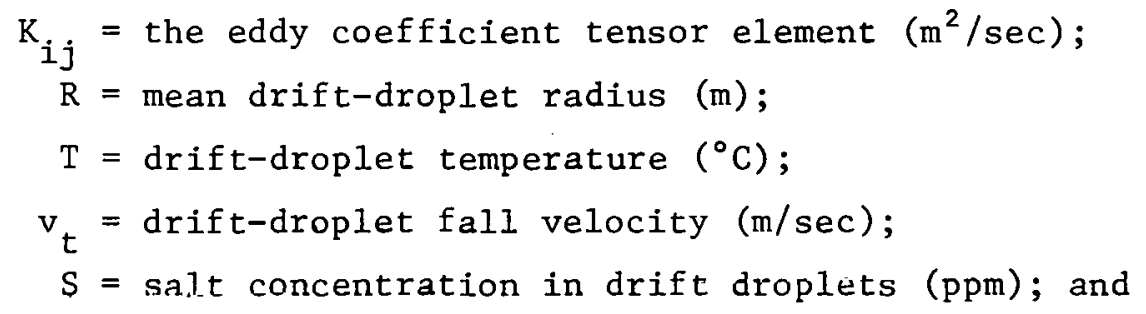
where the subscripts $i j$ are tensor notations.

The subscripts cr and ca refer to the droplets removed by collision and those added by collision, respectively.

The reader should note that in Eq. (5), the advective term should be on the left-hand side; this might be a misprint in the original paper. The authors state that the equation is too complicated to obtain a complete solution because of the large number of variables. In some cases, the functions are not known and a form must be assumed; thus, some simplifications are made. For example, they state that it takes about $2 \mathrm{sec}$ for a droplet with a radius of $200 \mu \mathrm{m}$ to reach an equilibrium temperature with its environment and less time for smaller droplets. Therefore, they neglect temperature variation of the droplet. Other valid assumptions made include ignoring collisions for droplets outside the plume. They also assume that advection is dominant over diffusion in the direction of the wind (which is acceptable for a continuous source). The simplified equation differs from the standard Fickian equation by the inclusion of a term to account for the drop-size change by evaporation or condensation:

$$
u_{x} \frac{\partial N}{\partial x^{\prime}}=K_{y} \frac{\partial^{2} N}{\partial y^{\prime 2}}+K_{z}^{\prime} \frac{\partial^{2} N}{\partial z^{\prime 2}}-\frac{\partial}{\partial R}\left(N \frac{\partial R}{\partial t}\right),
$$

where

$$
\begin{aligned}
\mathrm{u} & =\text { wind velocity } \\
\mathrm{x}^{\prime} & =\mathrm{x}, \\
\mathrm{y}^{\prime} & =\mathrm{y}, \\
\mathrm{z}^{\prime} & =\mathrm{z}-\mathrm{xv}_{\mathrm{t}} / \mathrm{u}, \\
\mathrm{K}_{\mathrm{z}}^{\prime} & =\mathrm{K}_{\mathrm{z}}\left[1+\left(\mathrm{v}_{\mathrm{t}} / \mathrm{u}\right)^{2}\right] .
\end{aligned}
$$

The authors obtain the number of drift droplets per unit volume in terms of Hermite polynomials. Three more equations (mass transfer, heat balance, and Clausius-Clapeyron) are needed to complete the solution. 
The mass transfer equation describing the rate of change in the radius of the droplet is

$$
\frac{\partial R}{\partial t}=\frac{K_{m}\left(\omega_{a}-\omega_{p}\right)}{\rho_{p}}
$$

where

$$
\begin{aligned}
& \mathrm{K}_{\mathrm{m}}=\text { mass transport coefficient }(\mathrm{m} / \mathrm{sec}) \\
& \omega_{\mathrm{a}}=\text { partial density of water vapor in the ambient air }\left(\mathrm{kg} / \mathrm{m}^{3}\right), \\
& \omega_{\mathrm{p}}=\text { partial density of water vapor in the plume }\left(\mathrm{kg} / \mathrm{m}^{3}\right) \text {, and } \\
& \rho_{\mathrm{p}}=\text { water droplet density }\left(\mathrm{kg} / \mathrm{m}^{3}\right) .
\end{aligned}
$$

The other two equations, namely the heat balance equation and the ClausiusClapeyron equation, are referred to in Refs. 12 and 16.

A numerical solution is needed to calculate the diffusion and transport of the drift droplets. Once that has been done, the salt deposition rate is determined as

$$
m_{i}\left(k_{z} \frac{d N}{d z}+v_{t} N\right)=\text { drift deposition rate in } g^{-2} \mathrm{sec}^{-1}
$$

where $m_{i}=\left(\pi R^{3} \rho^{\prime} c\right) 4 / 3$, the mass of salt contained in a drop of radius $R$ with salt concentration $c$ and density $\rho^{\prime}$. ('he factur $w_{i}$ is misoing in the original equation given by Roffman and Grimble. ${ }^{16}$ ) The first term represents the turbulent transport (that is, $\overline{\omega^{\prime} N^{\prime}}=\mathrm{K}_{\mathrm{z}} \mathrm{dN} / \mathrm{d} z$ ); and the second term represents the settling.

\subsubsection{Mode1 predictions}

Calculations were performed by Roffman and Grimble for low- and highdiffusion coefficients representing stable and unstable atmospheric conditions, respectively. The calculated salt deposition rate at ground level along the centerline of deposition is shown in Fig. 4 for a natural-draft cooling tower. For eddy coefficients $\mathrm{K}_{\mathrm{y}}=113$ and $\mathrm{K}_{\mathrm{z}}=77.7 \mathrm{~m}^{2} \cdot \mathrm{sec}^{-1}$ (unstable atmospheric conditions), the maximum deposition rate occurs $1160 \mathrm{~m}$ downwind from the tower; for $\mathrm{K}_{\mathrm{y}}=\mathrm{K}_{\mathrm{z}}=2 \mathrm{~m}^{2} \mathrm{sec}^{-1}$ (stable atmospheric conditions), it occurs $1360 \mathrm{~m}$ downwind. The maximum levels of deposition for these two sets of eddy coefficients are 253 and $4680 \mathrm{~kg} \mathrm{~km}^{-2}$ month ${ }^{-1}$, respectively. 


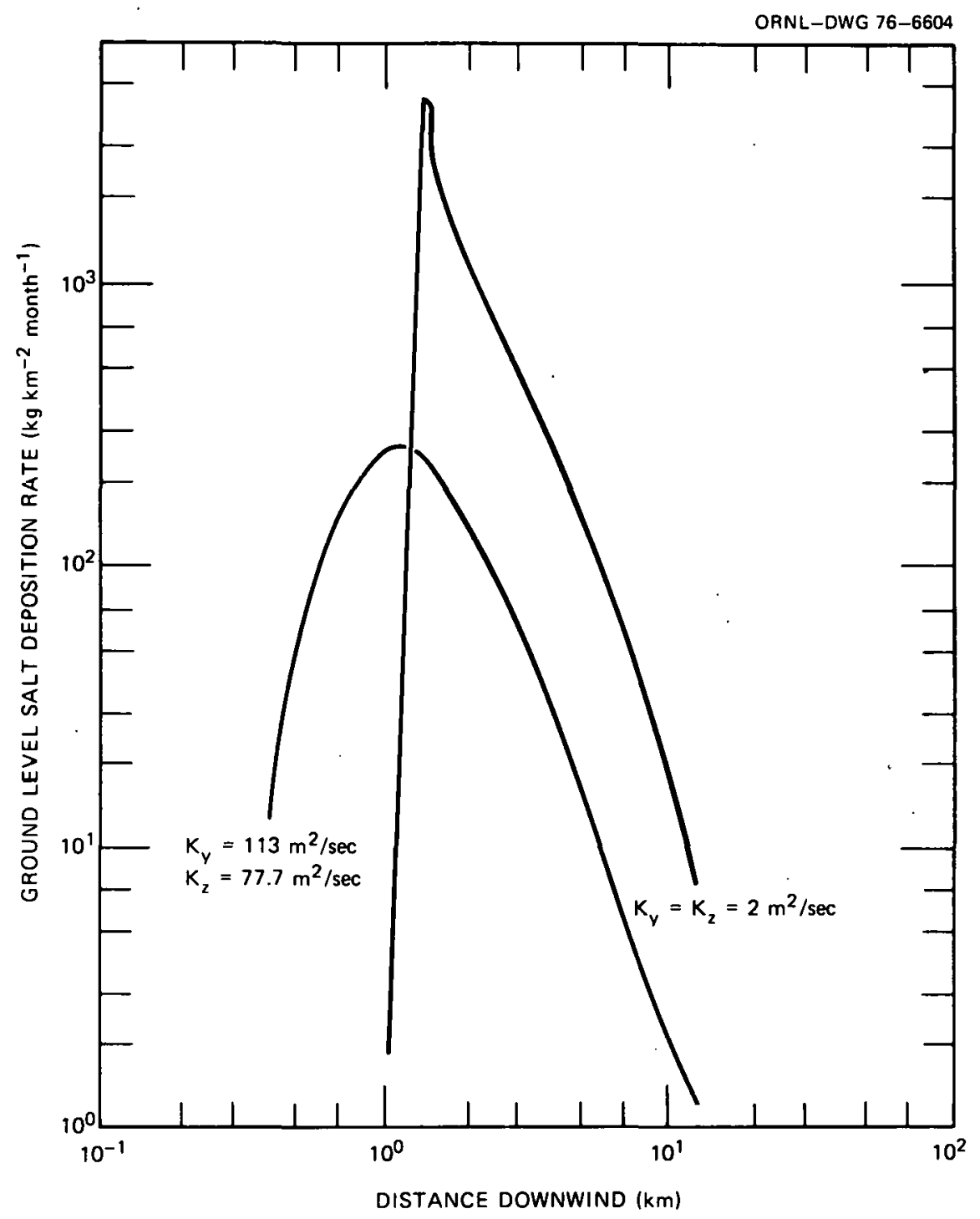

Fig. 4. Ground-1cvel salt deposilion rate from a natural-draft tower as a function of the distance downwind under stable $\left(\mathrm{K}_{\mathrm{y}}=\mathrm{K}_{\mathrm{z}}=2 \mathrm{~m}^{2} /\right.$ $\mathrm{sec})$ and unstable $\left(\mathrm{K}_{\mathrm{y}}=113 \mathrm{~m}^{2} / \mathrm{sec} ; \mathrm{K}_{\mathrm{z}}=77.7 \mathrm{~m}^{2} / \mathrm{sec}\right)$ atmospheric conditions. Source: A. Roffman and R. E. 'Grimble, Fig. 1, p. 13, in "Predictions of Drift Deposition from Saltwater Cooling Towers," paper presented at the annual meeting of the Cooling Tower Institute, Jan. 29-31, 1973, Hous ton.

Roffman and Grimble conclude that "under well-mixed atmospheric conditions, the diffusion mechanism is dominant over the gravity forces, while under stable atmospheric conditions, the gravity forces are dominant over the diffusion." 


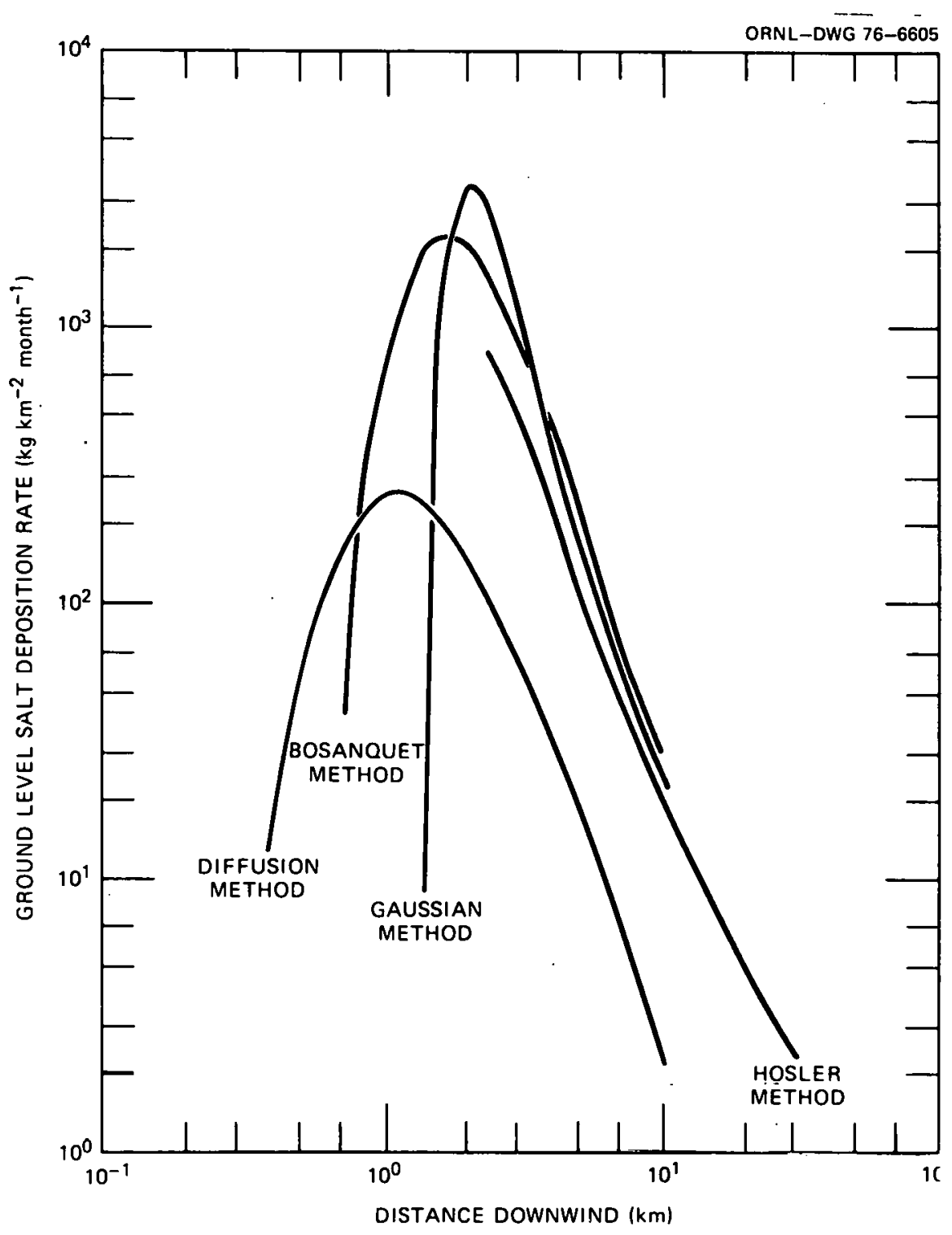

Fig. 5. A comparison of various predictive methods for the groundlevel salt-deposition rate from a natural-draft tower as a function of the distance downwind. Source: A. Roffman and R. E. Grimble, Fig. 3, p. 15, in "Predictions of Drift Deposition from Saltwater Cooling Tower," paper presented at the amnual meeting of the Cooling Tower Institute,. Jan. 29-31, 1973. Houston.

The results calculated by the $\mathrm{K}$ theory (diffusion method) are compared with the results from other models in Fig. 5. There it can be seen that the $\mathrm{K}$ theory yields lower peak deposition than that of the Hosler, Pena, and Pena ballistic method. ${ }^{7}$ Also shown are the results given by Roffman and Grimble for the Bosanquet, Carey, and Halton ${ }^{5}$ model and for a simple Gaussian method. 


\subsubsection{Discussion of the model}

The $\mathrm{K}$ theory is valid for a ground-level source only if the plume is passive and the scale of the turbulence is smaller than the plume cross section. It has been pointed out by Pasquil117,18,19 that the continuous meandering of the plume from an elevated source, in both a horizontal and a vertical plane, is a manifestation of dispersive motions on a scale larger than the plume section itself. l'his part of dispersive action is not included in the $\mathrm{K}$ theory. The assumption that eddy coefficients are constant is questionable. In general, they are varlable with time and in space in a nonisotropic atmosphere, especially near the ground. Near the

ground, $\mathrm{K}_{\mathrm{y}}$ tends to be greater than $\mathrm{K}_{z}$ because of the suppression of the vertical component of turbulence; Roffman and Grimble used 113 and 77.7 $\mathrm{m}^{2} \mathrm{sec}^{-1}$, respectively. Indeed, Roffman and Grimble show that more spread In deposition occurs for stronger turbulence intensity. But the values they used for unstable atmospheres may be too high. An eddy coefficient inside a plume was calculated by $\operatorname{Taft}^{20}$ to be $33 \mathrm{~m}^{2} / \mathrm{sec}$ from considerations of local macroscale and turbulent energy. Taft states, as a result of his calculations, that "the plume-induced levels, however, usually exceed the ambient by a factor of 10 or more ... . These values dwarf the valucs usually predicted by varlous ambient-flow-based formulas for atmospheres of this type." Imperfect knowledge of the turbulent diffusion can therefore easily lead to a discrepancy in drift deposition by an order of magnitude.

It is useful to calculate the amount of salt collerter on the ground and compare it with the total salt emitted from the tower. By summing the predicted deposition by Roffman and Grimble from Fig. 5 over a $22.5^{\circ}$ sector in the first $10 \mathrm{~km}$ downwind, it was found that only about $1 \%$ of the total salt emitted was accounted for by the model as being collected on the ground. Partly this may have been due to the fact that in this method the lowest predicted maximum deposition was located close to the tower. Partly, this may have been due to the cutoff of the calculation at a distance $10 \mathrm{~km}$ downwind.

The low predicted peak of the Roffman and Grimble model in Fig. 5 compared to the other curves probably results from the following assumptions in that model: (1) The effective height equaled the final plume rise for 
large drops. This assumption would tend to underpredict the maximum ground deposition, and this error would be increased for low winds, regardless of stratification. (2) Higher eddy-coefficient values were used in the unstable conditions. (3) Droplets evaporated to dryness at an ambient relative humidity of $70 \%$. (In the Hosler, Pena, and Pena model, a $70 \%$ relative humidity resulted in a saturated solution.)

In Eq. (7), Roffman and Grimble assume that the vapor pressure at the droplet's surface is the plume water vapor pressure at the plume temperature rather than the local ambient temperature. This procedure tends to overestimate the evaporation rate. In conclusion, the Roffman and Grimble model is essentially an application of $\mathrm{K}$ theory, and is the only model that does not employ the ballistic method. It may be the best model for estimating deposition in irregular terrain. However, the eddy coefficient inside a plume (or even in an undisturbed atmosphere) cannot be accurately determined at this time and it is doubtful whether such a complex mathe-. matical effort would be worthwhile at the present time.

\subsection{Model by Wistrom and Ovard - 1973 (Ballistic-Gaussian Method)}

\subsubsection{Introduction}

Because the available information about the Wistrom and Ovard model ${ }^{21}$ is limited, a full evaluation of it was impossible, although certain general observations and conclusions can be made about it. They assume that the breakaway point is at the center of the tower for all droplets, and they use the ballistic method for drops with diameters greater than $100 \mu \mathrm{m}$ and a Gaussian-dispersion method for drops with diameters that are less than or equal to $100 \mu \mathrm{m}$. Droplet evaporation is included, but no details are given.

\subsubsection{Mode1 description}

The trajectories of the larger drift drops are calculated numerically, taking into consideration changes in size resulting from.evaporation, tower operating parameters, and atmospheric conditions. Their paths are followed until the droplets either hit the ground or evaporate to $100 \mu \mathrm{m}$ in diameter. Large drops fall rapidly, and most of them will hit the ground close to the 
tower. Their trajectories are governed mostly by gravity and wind-induced drag forces and are less affected by turbulence, either ambient or plumegenerated.

The behavior of drops smaller than $100 \mu \mathrm{m}$ in diameter is modelled by the Gaussian-dispersion equation with the Pasquill-Gifford stability-class scheme. The trajectories of these small droplets are governed by wind, plume buoyancy, and eddies in the atmosphere. However, the point at which Wistrom and Ovard begin to apply the diffusion equation to small drops is not clear. Moreover, the enhancement of plume rise by multiple sources, such as the efght-cell crossflow mechanical-draft towers that they use in an example, is not mentioned at all.

Wistrom and Ovard go on to state that the small drift droplets entrained in the plume will act as condensation nuclei ${ }^{22}$ and will tend to grow in size as long as a supersaturated condition prevails (most frequently in the winter season). Unfortunately, the effect of this condensation process on plume rise and deposition rate is also not discussed.

\subsubsection{Model predictions}

Wistrom and Ovard presented calculations for some specific conditions. They assumed a stable atmosphere at a $63^{\circ} \mathrm{F}$ dry-bulb temperature and at $50 \%$ relative humidity, a drift-production rate of $0.004 \%$ of the circulating water rate, and a specified droplet-size spectra, which is given in Table 1 and discussed later in this section. However, other input data, such as effluent speed, tower height, tower exit diameter, salt concentration, and plume temperatures, are not givcn. Presumbly, the results announced by Wistrom and Ovard apply to deposition under the plume centerline without taking into consideration the variation with height of wind, temperature, and humidity. After carefully adding the deposition contributed by natural sea spray ${ }^{2}$ to the predicted values (but ignoring effects on plume rise and dispersion due to shoreline environments), the main conclusion is that $70 \%$ of all drift mass falle within the first $500 \mathrm{ft}$ downwind, well within most plant boundaries. The deposition pattern downwind from the tower is shown in Fig. 6. The remaining $30 \%$ of the drift is suspended in the air. 
Table 1. Size and mass distribution of drift particles measured at the top of a mechanical-draft tower with $\mathrm{Hi}-\mathrm{V}$ drift eliminators ${ }^{a}$

\begin{tabular}{|c|c|c|}
\hline $\begin{array}{l}\text { Droplet diameter } \\
(\mu \mathrm{m})\end{array}$ & $\begin{array}{l}\text { Percent of sample } \\
\text { by number }\end{array}$ & $\begin{array}{l}\text { Percent of mass } \\
\text { by droplet size }\end{array}$ \\
\hline 22 . & 24.0 & 0.43 \\
\hline 29 & 36.0 & 1.49 \\
\hline 44 & 26.0 & 3.76 \\
\hline 58 & 6.3 & 2.09 \\
\hline 65 & 4.0 & 1.86 \\
\hline 87 & 1.4 & 1.56 \\
\hline 108 & 0.67 & 1.43 \\
\hline 120 & 0.43 & 1.26 \\
\hline 132 & 0.28 & 1.09 \\
\hline 144 & 0.26 & 1.32 \\
\hline 174 & 0.65 & 5.81 \\
\hline 300 & 0.11 & 5.04 \\
\hline 450 & 0.027 & 4.17 \\
\hline 600 & 0.011 & 4.01 \\
\hline 750 & 0.0055 & 4.00 \\
\hline 900 & 0.0033 & 4.03 \\
\hline 1050 & 0.0024 & 4.57 \\
\hline 1200 & 0.0019 & 5.46 \\
\hline 1350 & 0.0016 & 6.80 \\
\hline 2250 & 0.00095 & 17.99 \\
\hline
\end{tabular}

$a_{G}$. K. Wistrom and J. C. Ovard, Table III in "Cooling Tower Drift; Its Measurements, Control and Environmental Effects," paper presented in the annual meeting of the Cooling Tower Institute, Jan. 29-31, 1973, Houston. 


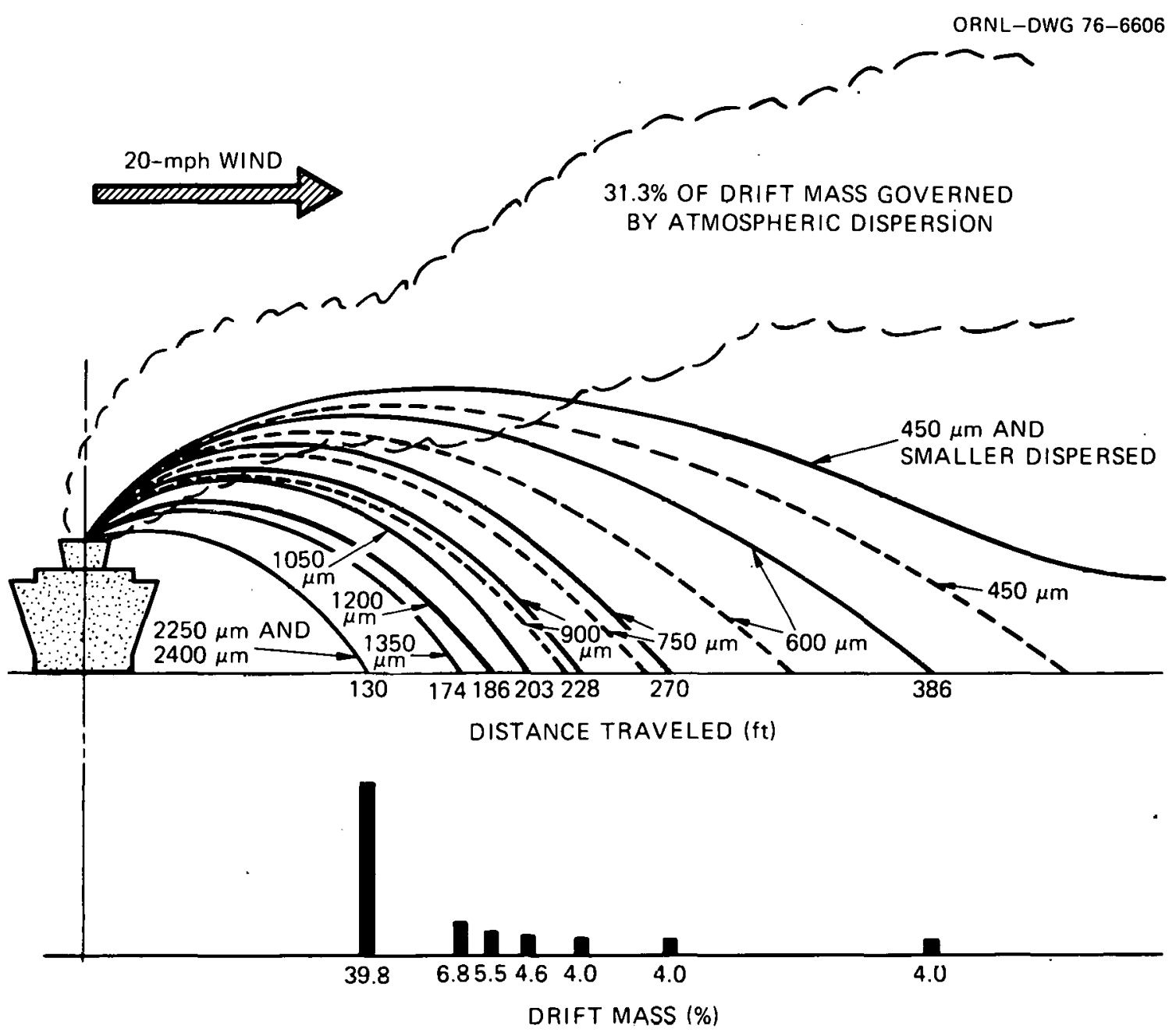

Fig. 6. Droplet trajectorles and fractional drift mass distribution. The solid curves and the dashed curves represent the atmosphere for a drybulb temperature of $63^{\circ} \mathrm{F}$ and a relative humidity of $50 \%$ and for a dry-bulb temperature of $30^{\circ} \mathrm{F}$ and a relative humidity of $80 \%$, respectively. Source: G. K. Wistrom and J. C. Ovard, Fig. 7 in "Cooling Tower Drift, Its Measurements, Control, and Environmental Effects," paper presented at the annual meeting of the Cooling Tower Institute, Jan. 29-31, 1973, Houston.

For a typical winter condition $\left(30^{\circ} \mathrm{F}\right.$ dry-bulb temperature and $80 \%$ relative humidity) Wistrom and Ovard predict the drops to fall slightly closer to the tower lecause the evaporation rate is smaller. This pattern is shown with dashed lines in Fig. $6 .^{*}$

* Recent communication from G. K. Wistrom indicates that the drop size distribution is incorrect because the original calibration between strain size and drop size was in error. A corrected drift prediction is planned to be issued. 


\subsubsection{Discussion of the model}

The practice of combining the ballistic and Gaussian-plume methods is gaining popularity because the ballistic method provides a better calculation technique for large drops (which are less affected by turbulence) and the diffusion method gives better results for small drops (which are more strongly influenced by the ambient turbulence).

In regard to the initial droplet emission, although they take the tower top as the departure point for all droplets, the maximum plume rise (the point at which the plume becomes passive) would seem to be more appropriate as the effective source height in applying the Gaussian equation.

To test the applicability of the ballistic method, consider a droplet with a diameter of $1350 \mu \mathrm{m}$ with a fall velocity $\left(v_{f}\right)$ of $16.5 \mathrm{ft} / \mathrm{sec}$. Assuming no evaporation, the point of impact would be $\left(h_{s} / v_{f}\right) u=178 \mathrm{ft}$, as predicted by the model and shown in Fig. 6 for a stack height $\left(h_{s}\right)$ of 100 $\mathrm{ft}$ and a wind speed (u) of $20 \mathrm{mph}$. In a dry atmosphere evaporation is more rapid and the droplet's size and vertical velocity decrease rapidly. Thus, the trajectories of the small droplets tend to be flattened as they approach the ground. According to Wistrom and Ovard, drops that are initially smaller than $450 \mu \mathrm{m}$ in diameter will evaporate to $100 \mu \mathrm{m}$ or less before reaching the ground. As shown in Fig. 6, the slope close to the ground tor such a droplel lias leen estimated to bo of the nrier nf $1 / 40$ or less, as predicted by the model for an atmosphere of $63^{\circ} \mathrm{F}$ dry-bulb temperature and at $50 \%$ relative humidity.

\subsection{Model by Slinn - 1974 (Ballistic-Gaussian Method)}

\section{4 .1 Introduction}

Slinn ${ }^{10}$ analyzed the salt-deposition problem as the interaction of several statistically distributed variables: droplet-size, turbulence and droplet breakaway points. Slinn assumed that large droplets were emitted at the center of the cooling tower top and that small droplets were emitted at the ful.1 plume rise. He determines which one of the variables dominate the fallout rate from the plume and therefore can be used as a descriptor and predictor for salt deposition. 


\subsubsection{Model description}

In the following description, the influence of the distribution of drop sizes and influence of turbulence are not discussed. The interested reader is referred to Ref. 10. Only the influence of the distribution of breakaway points, which was first studied by SIinn, is discussed.

For estimating the breakaway points, Slinn proposes that drops are removed from a buoyant plume by two mechanisms. For small drops (diameters less than $100 \mu \mathrm{m}$ ), the slip between air and drop motion is ignored and the drops are presumed to rise with the plume. Thus, turbulent transport of small drops is represented by $K \operatorname{grad}(f \mathrm{dr}$ ), where $K$ is a turbulent diffusivity and $\mathrm{f} d r$ is the number of drops per unit volume whose radii are between $r$ and $r+d r$. If the largest eddy of the plume-generated turbulence has a radius of $R_{0}$ (the initial plume radius) and a characteristic turbulence speed of $w_{0}$ (the initial effluent speed), then $K=(\delta / 2) w_{0} R_{0}$, where $\delta$ is a numerical constant (for which slinn suggests a value of $10^{-2}$ ). Thus $\mathrm{K}=0.75 \mathrm{~m}^{2} / \mathrm{sec}$ for a natural-draft cooling tower with $\mathrm{w}_{0}=5 \mathrm{~m} / \mathrm{sec}$ and $\mathrm{R}_{0}=30 \mathrm{~m}$. This value might be lower than that of an undisturbed atmosphere.

For drops of diameter greater than $100 \mu \mathrm{m}$, slip is included. Because of their weight, some drops in this class will not exactly follow the fluid as they swirl out and then become reentrained by the plume and thereby droplets will be sprayed out from the boundary of the plume. This flux of droplets crossing the plume boundary is expressed as $(\varepsilon / 2) v_{s} f d r$, where $v_{S}$ is the fall velocity and $\varepsilon$ is a constant that Slinn assumes is of the order of unity.

\subsubsection{Model predictions}

An example illustrating the different processes is provided by Slinn ${ }^{10}$ to predict the crosswind integrated chromiym deposition downwind of a single cooling tower of height $h$, source strength $Q_{0}$ (grams of chromium per sec) and initial buoyancy flux $F_{0}$. Slinn assumed a gamma distribution for the number distribution of the large droplets and designated the fraction of the total salt that is carried by the large drops as $\kappa(=1 \%)$. Then the fraction of the salt deposited in the large-drop mode on a strip of ground 
from $x$ to $x+d x$ is

$$
\gamma d x=\frac{\kappa}{\Gamma(6)}\left[\frac{\bar{u} h}{v_{s}(b) x}\right]^{6} \exp \left[\frac{\bar{u} h}{v_{s}(b) x}\right] \frac{d x}{x}
$$

where $\bar{u}$ is the mean wind speed, $v_{s}(b)$ is the settling velocity of drops of radius $b(b=100 \mu \mathrm{m}$ was used by Slinn), $\mathrm{x}$ is the downwind distance, and $\Gamma$ is the gamma function.

For small droplets, Slinn assumes the breakaway point to be at the maximum plume rise. By using a Gaussian distribution model, the crosswind integrated fraction of material that is deposited on a strip from $x$ to $\mathrm{x}+\mathrm{dx}$ is given by:

$$
\begin{aligned}
\gamma d x= & \frac{d x}{\sigma_{z}}\left[(1-k) /(2 \pi)^{1 / 2}\right]\left[v_{s}\left(\bar{r}_{m}\right) / \bar{u}\right] \\
& \times \exp \left\{\left(-1 / 2 \sigma_{z}^{2}\right)\left[h+1.6\left(F_{0}^{1 / 3} x^{2 / 3} / \bar{u}\right)-v_{s}\left(\bar{r}_{m}\right) x / \bar{u}\right]^{2}\right\},
\end{aligned}
$$

where $\sigma_{z}$ is the standard deviation of the thickness of the plume and $v_{s}\left(\bar{r}_{m}\right)$ is the settling velocity of drops of a mean radius $\bar{r}_{m}$.

Finally, not having an accurate evaluation of breakaway points, slinn assumed that a fraction $\beta$ of the small drops break free from the plume at the top of the tower and that their diffusion can be ignored. 'The result=ing deposition flux is

$$
\gamma \mathrm{dx}=\frac{\mathrm{dx}}{\mathrm{x}}[\beta(1-k) / 5 !]\left[\overline{\mathrm{uh}} / \mathrm{v}_{\mathrm{s}}(\mathrm{a}) \mathrm{x}\right]^{3} \exp \left\{-\left[\overline{\mathrm{uh}} / \mathrm{v}_{\mathrm{s}}(\mathrm{a}) \mathrm{x}\right]^{1 / 2}\right\}
$$

The value chosen for $\beta$ makes a significant difference in the predicted deposition pattern. Figure 7 shows two curves, one in which $\beta=1 \%$ and the other in which $\beta=0.1 \%$. The figure also shows the influence of changing the value of $v_{s}\left(\bar{r}_{m}\right)$ from $25 \mathrm{~cm} / \mathrm{sec}$ to $5 \mathrm{~cm} / \mathrm{sec}$. This reflects the importance of evaporation effects.

Slinn concluded that for drops larger than $50 \mu \mathrm{m}$ in radius, the dropsize distribution has a dominant influence on the deposition rate and location, and for smaller drops, turbulence diffusion has a comparable influence on the deposition at about 5 to 10 tower heights downwind. 


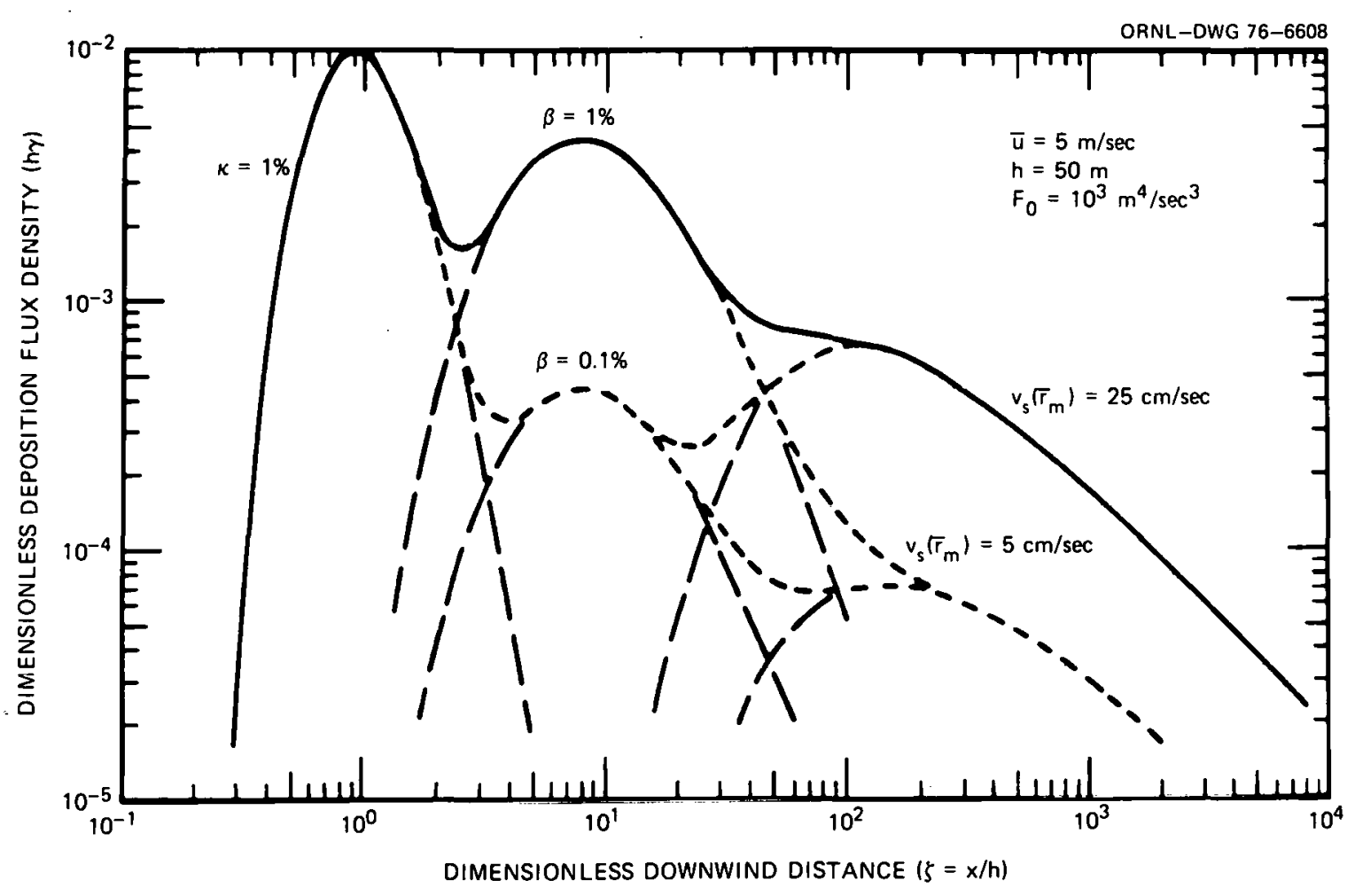

Fig. 7. Illustrative results for specific values of the parameters in Eqs. (8)-(10). The value $\beta$ is the fraction of the small drops that are assumed to break free at the top of the cooling tower, and $K$ is the fraction of the drift that is in the large drops. Source: W. G. N. Slinn, Fig. 6, p. 496, "An Analytical Search for the Stochastic-Dominating Process in the Drift Deposition Problem," Cooling Tower Environment - 1974, CONF740302 (1975).

\subsubsection{Discussion of the model}

As can be seen from this model and the others that precede it, one of the major problems in predicting deposition is determining where the droplets break away from the plume. Although Slinn directly addressed this aspect, he did not resolve its uncertainties. His method does not evaluate droplet breakaway from the plume any more accurately than other methods. Three basic approaches to the problem of defining the breakaway point are illustrated in Fig. 8. One (assumed by Wistrom and Ovard) is that all drops break free at the mouth of the tower and that deposition is dependent on the ballistic trajectories of the different sizes of drops [Fig. 8(a)]. The second (assumed by Roffman and Grimble) is that all drops escape at tull. plume rise regardless of size [Fig. 8 (b)]. And the third (assumed 


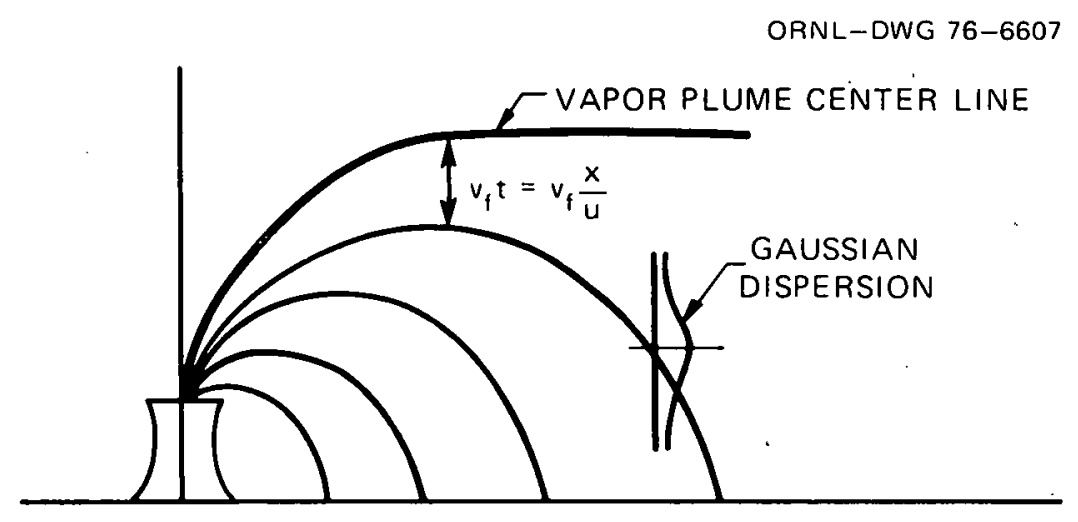

(a)

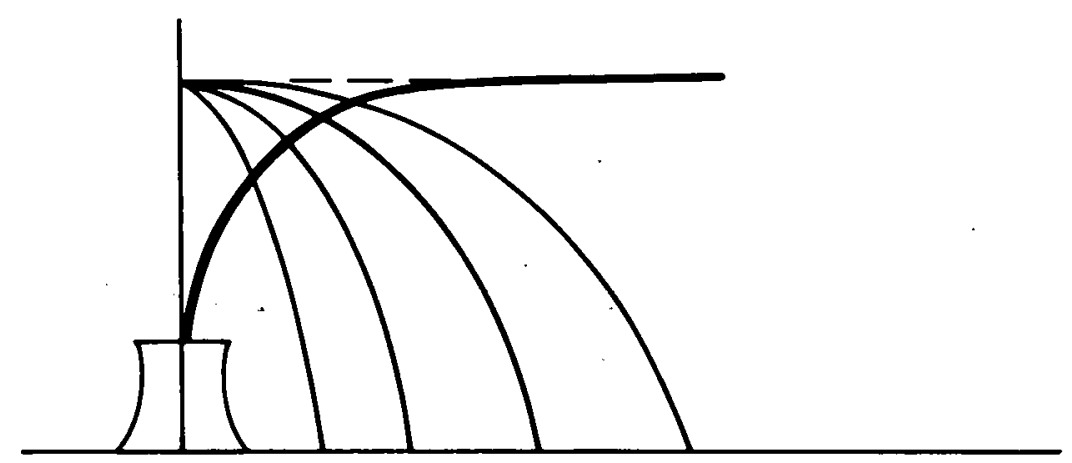

(b)

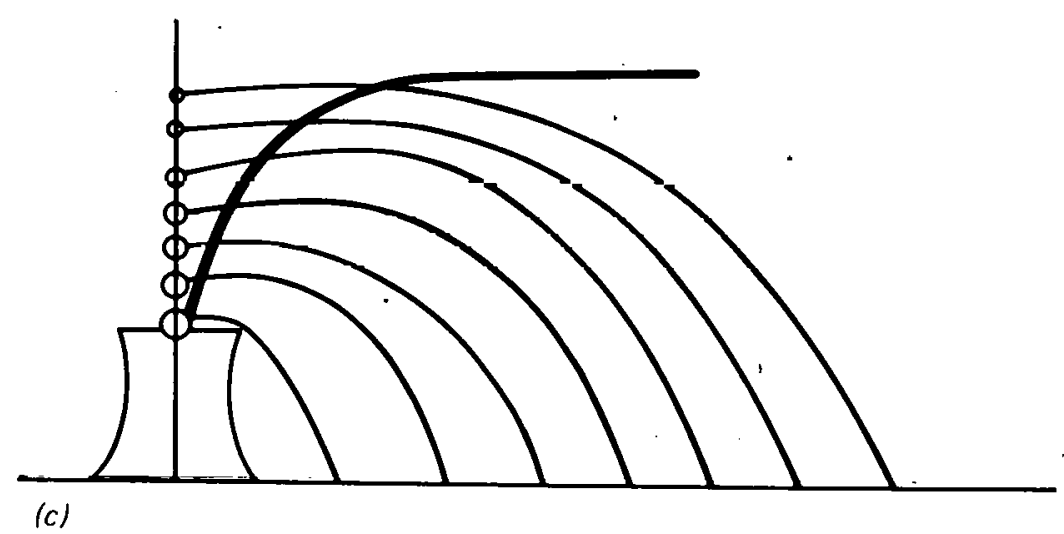

Fig. 8. Schematic illustration of drift breakaway points: (a) all droplets emitted at the tower top, (b) all droplets emitted at the maximum plume rise, and (c) droplets emitted from the plume as the fall velocity exceeds the updraft.

by Hosler et al.) is that the drops escape from the plume at discrete points at which the drops' fall velocities exceed the updraft [Fig. 8(c)]. In reality, drops probably break free all along the plume's trajectory, following none of the above simplified models exactly. 


\subsection{Model by Laskowski - 1974 (Ballistic-Gaussian Method)}

\subsubsection{Introduction}

The Laskowski model ${ }^{24}$ also combines the ballistic and Gaussian plume methods. This model assumes that all drift particles are emitted at the center top of the tower and follows the behavior of drift drops of selected initial size and salinity as these drops travel from the drift eliminator through the plume and the ambient air until the drops either hit the ground or reach a size sufficiently small to remain suspended in the atmosphere. Unlike most other models in which a simple Gaussian drop plume descends in accordance with the fall velocity, the trajectory of a droplet is computed from hydrodynamic equations coupled with conservation of mass and energy equations. The effects of precipitation washout and of the aerodynamic wake are said to be included. Laskowski uses Briggs'14 or Slawson and Csanady's ${ }^{25}$ plume-rise formulas, depending on the meteorological conditions.

\subsubsection{Model description}

Laskowski gives the following generalized equation for the motion for a single drop traveling in a plume, in the atmosphere, or in a uniform upward motion inside the tower:

$$
\rho_{L}\left(\pi D_{p}^{3} / 6\right) \frac{d \vec{v}}{d t}=\rho_{L}\left(\pi D_{p}^{3} / 6\right) \vec{g}-\rho_{\text {air }}\left(\pi D_{p}^{2} / 4\right) C_{D} \frac{|\vec{u}-\vec{v}|(\vec{u}-\vec{v})}{2}+\vec{F}
$$

where $D_{p}, \vec{u}, \vec{v}, t, \rho_{L}, \rho_{\text {air }}, \vec{g}, C_{D}$ are drop diameter, wind velocity, drop velocity, time, density of liquid, density of alr, gravity force, and drag coefficient, respectively, and $\vec{F}$ is any other force.

The term on the left-hand side of Eq. (11) represents the inertial force, and the first and second terms in the right-hand side represent gravity and drag forces, respectively.

Inside the tower, a uniform upward air motion is assumed. Within the plume, vertical speed is dcrived from eilher Briggs' or Slawson and Csanady's plume-rise equations, depending on thermal stratification and wind conditions. 
Fick's law of diffusion ${ }^{26}$ is applied by Laskowski to the mass transport to the gas phase around the drop:

$$
\frac{d m_{p}}{d t}=k_{x m}\left(\pi D_{p}^{2}\right)\left(x_{A_{0}}-x_{A_{\infty}}\right)+x_{A_{0}}\left(\frac{d m p}{d t}+\frac{d m a i r}{d t}\right),
$$

where

$$
\begin{aligned}
& \mathrm{m}_{\mathrm{p}}=\text { mass of water in the drop, } \\
& \mathrm{m}_{\mathrm{air}}=\text { mass of air, } \\
& \mathrm{k}_{\mathrm{xm}}=\text { mass-transfer coefficient for drops, } \\
&=\frac{2 \rho_{i r} D_{\mathrm{AB}}}{\mathrm{D}_{\mathrm{p}}}\left(1+0 \cdot 3 \mathrm{~N}_{\mathrm{R}}^{1 / 2} \mathrm{~N}_{\mathrm{Sc}}{ }^{1 / 3}\right), \\
& D_{\mathrm{AB}}=\text { coefficient of diffusion of water vapor in air } \\
& \mathrm{N}_{\mathrm{R}}=\text { Reynolds number, } \\
&=\mathrm{D}_{\mathrm{p}}\left|\mathrm{u}_{\mathrm{alr}}-\mathrm{v}_{\mathrm{drop}}\right| \rho_{\text {air }} / \mu_{\text {air }}, \\
& \mathrm{N}_{\mathrm{Sc}}=\text { Schmidt number } \\
&\left.=\text { ( } \mu / \rho D_{\mathrm{AB}}\right) \text { air } \\
& \mathrm{x}_{\mathrm{A}_{0}}=\text { mole fraction of water vapor at the droplet surface in air, } \\
& \mathrm{x}_{\mathrm{A}}=\text { mole fraction of water vapor in air, remote from the droplet. } \\
& \text { The first term in Eq. (12) represents the rate of mass transfer by } \\
& \text { diffusion, and the second term represents the rate of mass transfer by } \\
& \text { bulk flow. }
\end{aligned}
$$

Laskowski assumes that the drops neither break up nor coalesce in the vertical air currents in the tower. But since the growth or evaporation rate of the drops in the plume and in the atmosphere is controlled not only by the rate at which water vapor can diffuse but also by the rate at which heat can transfer, Laskowski applies an energy equation that is similar to the one given by Mason ${ }^{27}$ and Fletcher: ${ }^{22}$

$$
\mathrm{T}-\mathrm{T}_{\text {drop }}=\frac{D_{\mathrm{AB}} \mathrm{H}\left(\Delta \mathrm{x}_{\mathrm{A}}\right)}{\mathrm{K}_{\text {air }}} \rho_{\text {air }},
$$

where

$$
\begin{aligned}
\mathrm{T} & =\text { air temperature around the droplet local environment, } \\
\mathrm{T}_{\mathrm{drop}} & =\text { droplet temperature, }
\end{aligned}
$$




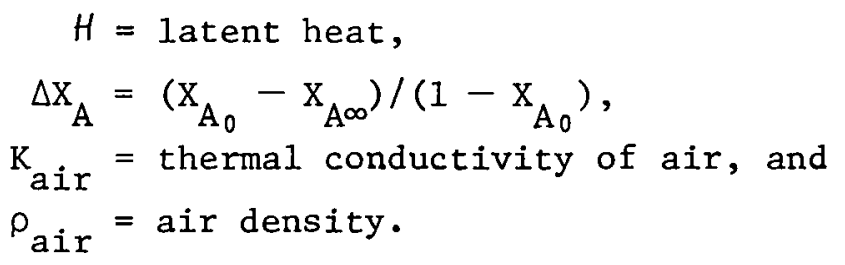

Assuming the mass of salt remains unchanged in spite of the change in drop size, Laskowski derives the following relation between water mass in the drop and salt concentration:

$$
\frac{\mathrm{dm}}{\mathrm{dt}}=-\left(\mathrm{m}_{0} / \mathrm{c}^{2}\right) \frac{\mathrm{dc}}{\mathrm{dt}}
$$

where $\mathrm{m}_{0}$ is the mass of salt in drop and $c$ is the salt concentration.

By numerical integration of Eqs. (11), (12), (13), and (14), simultaneously, Laskowski obtains drop velocity, size, and position with respect to time, thus constructing the subsequent drop trajectory. Breakaway from the plume is established by checking a drop's coordinates with the plume height and radius. Again, it should be noted that Brigg's plume-growth formula is used to account for sensible heat.

To simplify the computation, Laskowski assumes that the plume is well mixed with the ambient air at a distance of ten tower heights, and she argues that all the drift drope that contribute to the ground deposition should fall out of the plume within this distance. She further assumes that a drop attains terminal velocity $10 \mathrm{sec}$ after it leaves the plume. Laskowski considers deposition from large droplets to occur in a pieshaped area originating at the tower and expanding downwind with a transect of $22.5^{\circ}$. Furthermore, she conslders deposition to be uniform within the bounds of the sector and the limiting distances for impact of a particular droplet size. However, for small droplets (which are more influenced by the atmospheric turbulence), a tilted Gaussian plume model is used to describe the vertical distribution of the drops (see Fig. 9). The heights of the center of gravity axis of drift droplet.are divided by the value of $\sigma_{z}$, corresponding to the particular stability condition under consideration. At each selected distance, $x$, the $z / \sigma_{z}$ is calculated and the corresponding area under the curve obtained. This area is subtracted from one-half the area of the normal curve. The resultant value corresponds to the fraction of salt deposited between the tower and the distance under consideration. 


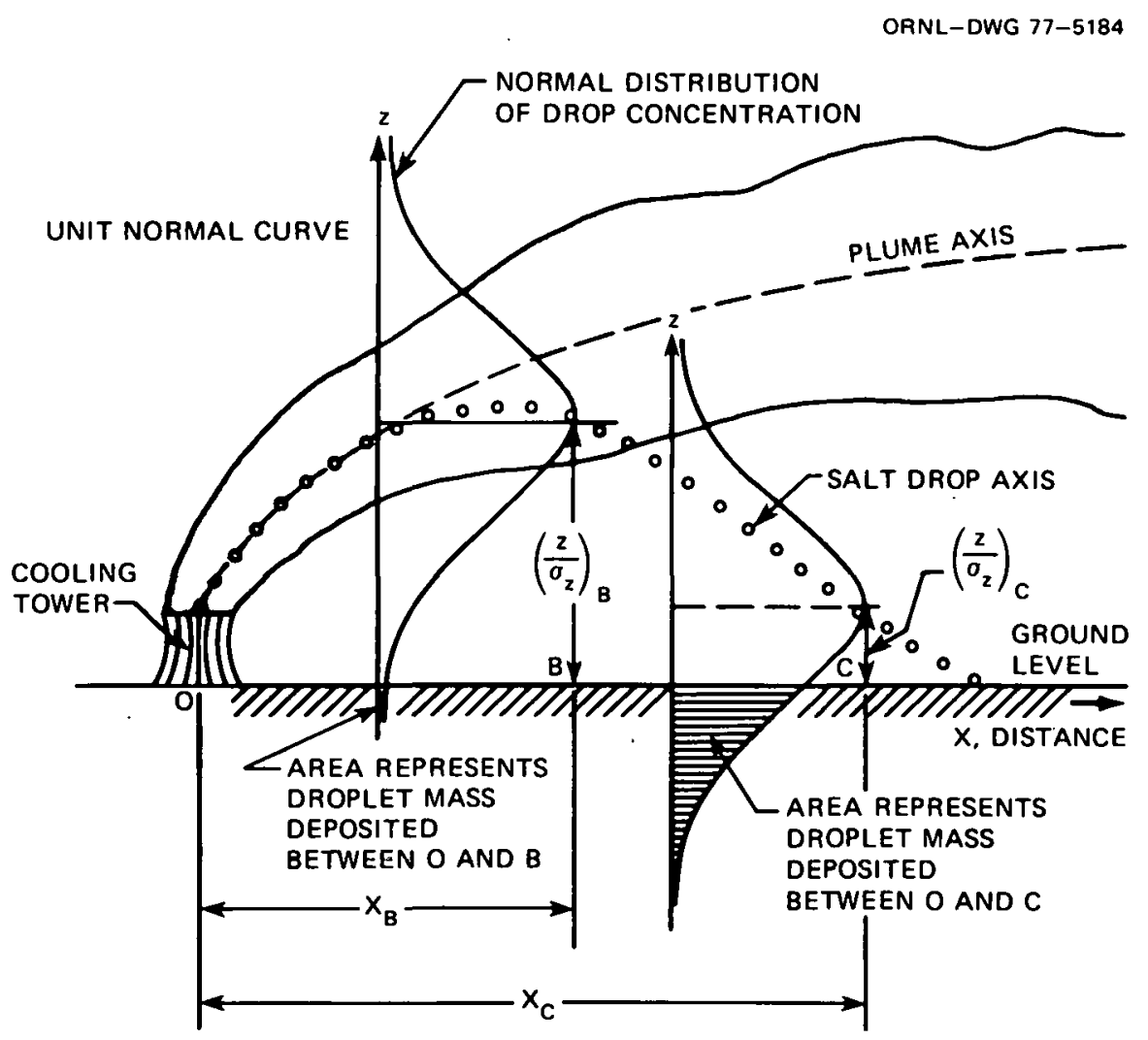

Fig. 9. Method for calculating drift deposition due to the atmospheric turbulence.

\subsubsection{Model predictions}

Laskowski ${ }^{28}$ has used this model to predict the drift deposition patterns for a number of cases; these are described in Table 2, and the results obtained are shown in Figs. 10 through 12 . The model indicates that deposition rate is quite sensitive to the predominance of large drops (see Fig. 10). It also shows that the representation of low wind speed (0-6 $\mathrm{m} / \mathrm{sec}$ ) affects the predicted deposition more for a droplet distribution with a small mass fraction in the heaviest drops $(0.8 \%)$, as shown in Fig. 11 , and less for a droplet distribution with a large mass fraction in the heaviest drops $(7 \%)$, as shown in Fig. 12. Studies by Laskowski of the effects of tower height, atmospheric stability representation, relative humidity, and the location for the drop-size measurement show that these variables are less influential. 
Table 2. Drop-size distribution ${ }^{a}$

\begin{tabular}{|c|c|c|c|c|c|c|c|c|c|c|}
\hline \multirow[b]{2}{*}{$\begin{array}{l}\text { Diameter } \\
\text { interval } \\
(\mu \mathrm{m})\end{array}$} & \multirow[b]{2}{*}{$\begin{array}{l}\text { ReFresentative } \\
\text { diameter chosen } \\
\qquad(\mu \mathrm{m})\end{array}$} & \multicolumn{3}{|c|}{ Case 1} & \multicolumn{2}{|c|}{ Case 2} & \multicolumn{2}{|c|}{ Case 3} & \multicolumn{2}{|c|}{ Case 4} \\
\hline & & $\begin{array}{c}\text { Mass mean } \\
\text { diameter } \\
\text { for interval } \\
\quad(\mu \mathrm{m})\end{array}$ & $\begin{array}{c}\text { Mass } \\
\text { fraction }\end{array}$ & $\begin{array}{l}\text { Mass fraction } \\
\text { for curves } \\
\text { of F1g. } 10\end{array}$ & $\begin{array}{c}\text { Mass mean } \\
\text { diameter } \\
\text { for interval } \\
(\mu \mathrm{m})\end{array}$ & $\begin{array}{l}\text { Mass } \\
\text { fraction }\end{array}$ & $\begin{array}{l}\text { Mass mean } \\
\text { diameter } \\
\text { for interval } \\
\quad(\mu \mathrm{m})\end{array}$ & $\begin{array}{c}\text { Mass } \\
\text { fraction }\end{array}$ & $\begin{array}{l}\text { Mass mean } \\
\text { diameter } \\
\text { for interval } \\
\quad(\mu \mathrm{m})\end{array}$ & $\begin{array}{l}\text { Mass } \\
\text { fraction }\end{array}$ \\
\hline $10-70$ & 50 & 56 & 0.22 & 0.20 & 56.5 & 0.25 & 56 & 0.2 & 52 & 0.22 \\
\hline $70-125$ & 100 & 94 & 0.42 & 0.46 & 95 & 0.47 & 94 & 0.4 & 96 & 0.28 \\
\hline $125-175$ & 150 & 141 & 0.21 & 0.24 & 143 & 0.19 & 144 & 0.23 & 144 & 0.19 \\
\hline $175-260^{b}$ & 200 & 200 & 0.13 & 0.10 & 200 & 0.076 & 199 & 0.11 & 197 & 0.12 \\
\hline $260-320^{c}$ & 280 & 280 & 0.012 & & 280 & 0.01 & 255 & 0.044 & 269 & 0.12 \\
\hline$>320^{d}$ & 450 & 362 & 0.008 & & 352 & 0.004 & 359 & 0.015 & 410 & 0.07 \\
\hline
\end{tabular}

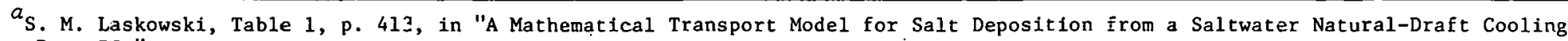
Tower, Part II," paper presented at the Symposium on Atmospheric Diffusion and Air Pollution, American Meteorological Society, Sept. 9-13, 1974, Santa Barbara, Calif.

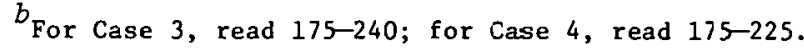

For Cáse 3, read 240-320; for Case 4, read 225-325.

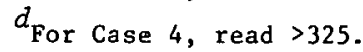




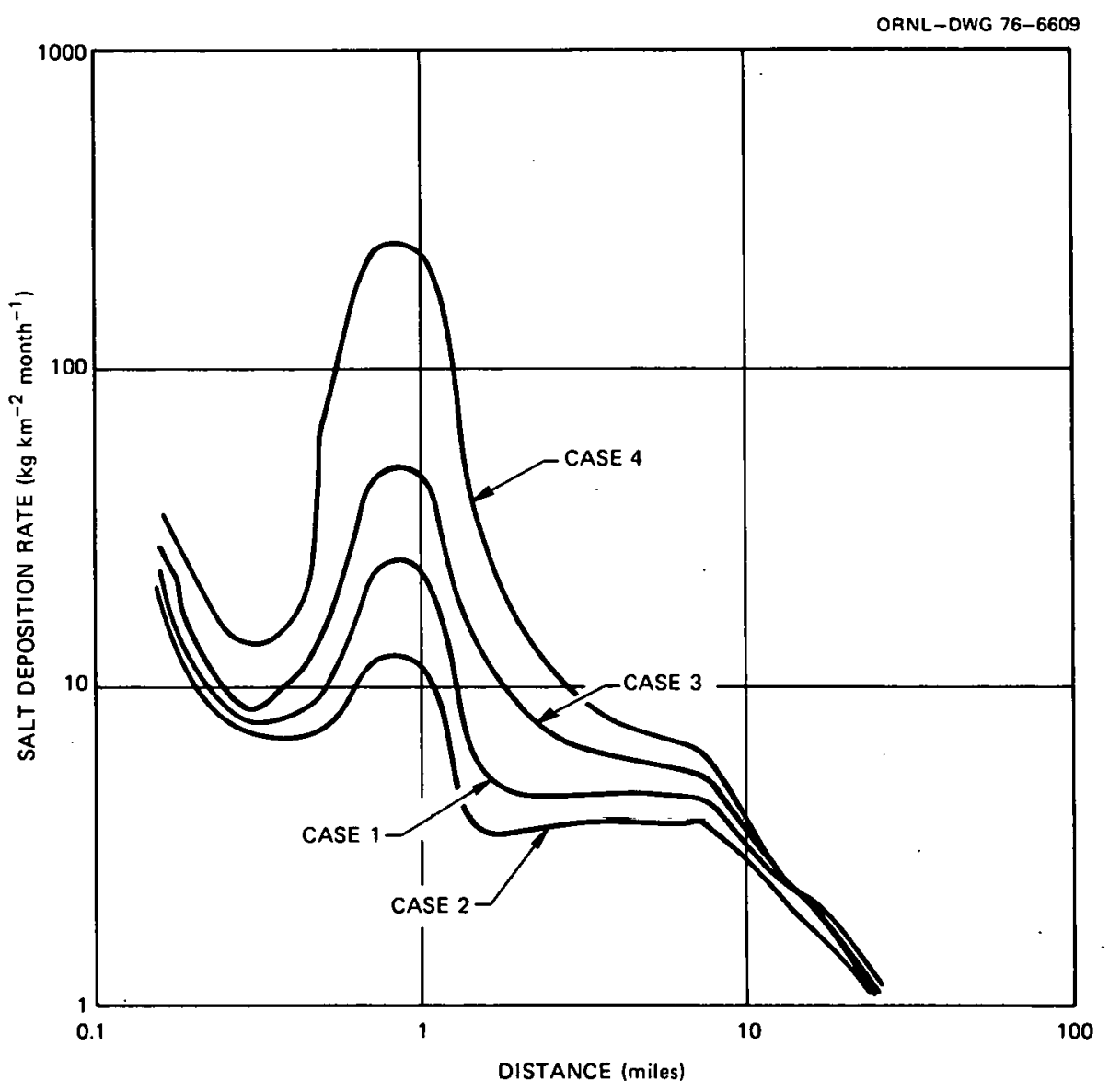

Fig. 10. Salt-deposition rate vs distance from the tower as a function of drop-size distribution. The data concerns one $22.5^{\circ}$ sector at a selected site for one month with a drift rate of $0.001 \%(14.0 \mathrm{~kg}$ of sali per hour). For the drop-size distribution, see Table 2. Source: S. M. Laskowski, Fig. 2, p. 413, in "A Mathematic Transport Model for Salt Deposition from a Saltwater Natural-Draft Cooling Tower, Part II," paper presented at the Symposium on Atmospheric Diffusion and Air Pollution, American Meteorological Society, Sept. 9-13, 1974, Santa Barbara, Calif.

\section{5 .4 Discussion of the model}

The Laskowski model is more complicated and makes more assumptions than the previously considered models.

Laskowski assumed that no droplet breakup or coalescense occurs in the vertically rising air stream within the cooling tower. However, it was shown by Foster ${ }^{29}$ that coalescence of drops will in fact change the drop spectrum between the eliminator and the tower exit. Foster concluded that a number of large drops are produced in the tower at the expense of the mass flux of the smaller drops. 


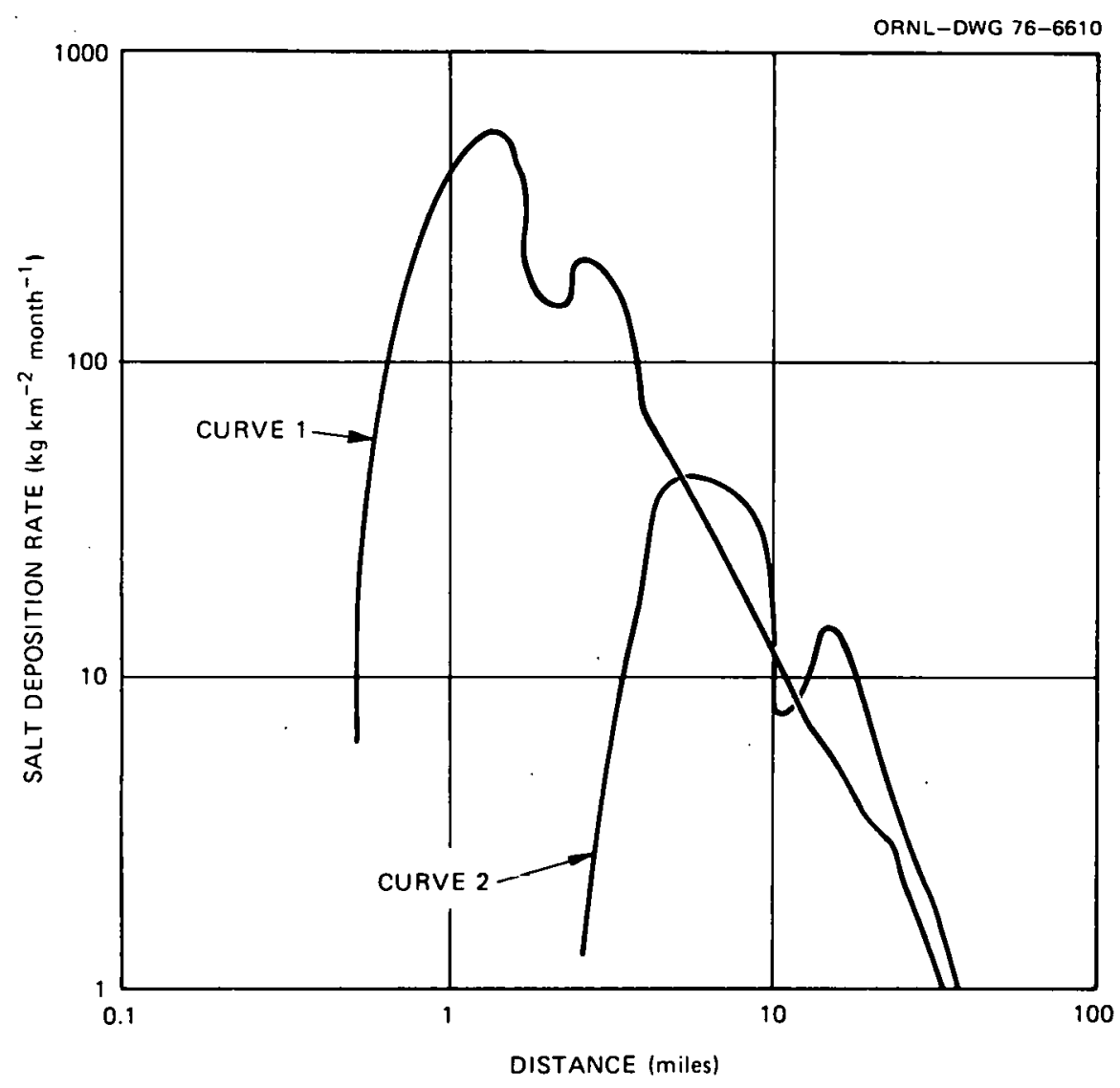

Fig. 11. Effect of low wind-speed representation $(0-6 \mathrm{~m} / \mathrm{sec})$ on deposition rate for droplets with a size distribution from Case 1 of Table 2 . The data concerns one $22.5^{\circ}$ sector at a selected site for one month with a drift rate of $0.00325 \%(186.0 \mathrm{~kg}$ of salt per hour). Curve 1 results. from a four-group wind representation of $1.0,2.3,3.5$, and $5.0 \mathrm{~m} / \mathrm{sec}$. Curve 2 is from a one-group wind representation of $3.5 \mathrm{~m} / \mathrm{sec}$. Source: S. M. Laskowski, Fig. 8, p. 417, in "A Mathematical Transport Model for Salt Deposition from a Saltwater Natural-Draft Cooling Tnwer, Part II," papcr preseinled at the Symposium on Atmospheric Diffusion and Air Pollution, American Meteorological Society, Sept. 9-13, 1974, Santa Barbara, Calif.

Laskowski does not point out that there is an upper limit for $c$ in Eq. (14); the saturation concentration of salt in water for the particular temperature. The saturation concentration of salt in water at room temperature $\left(25^{\circ} \mathrm{C}\right)$ is $26 \%$. Thus, care should be used in this respect when applying Eq. (14).

Laskowski assumes that the droplets will fall at their terminal velocity $10 \mathrm{sec}$ after they leave the plume. This seems arbitrary. The drop 


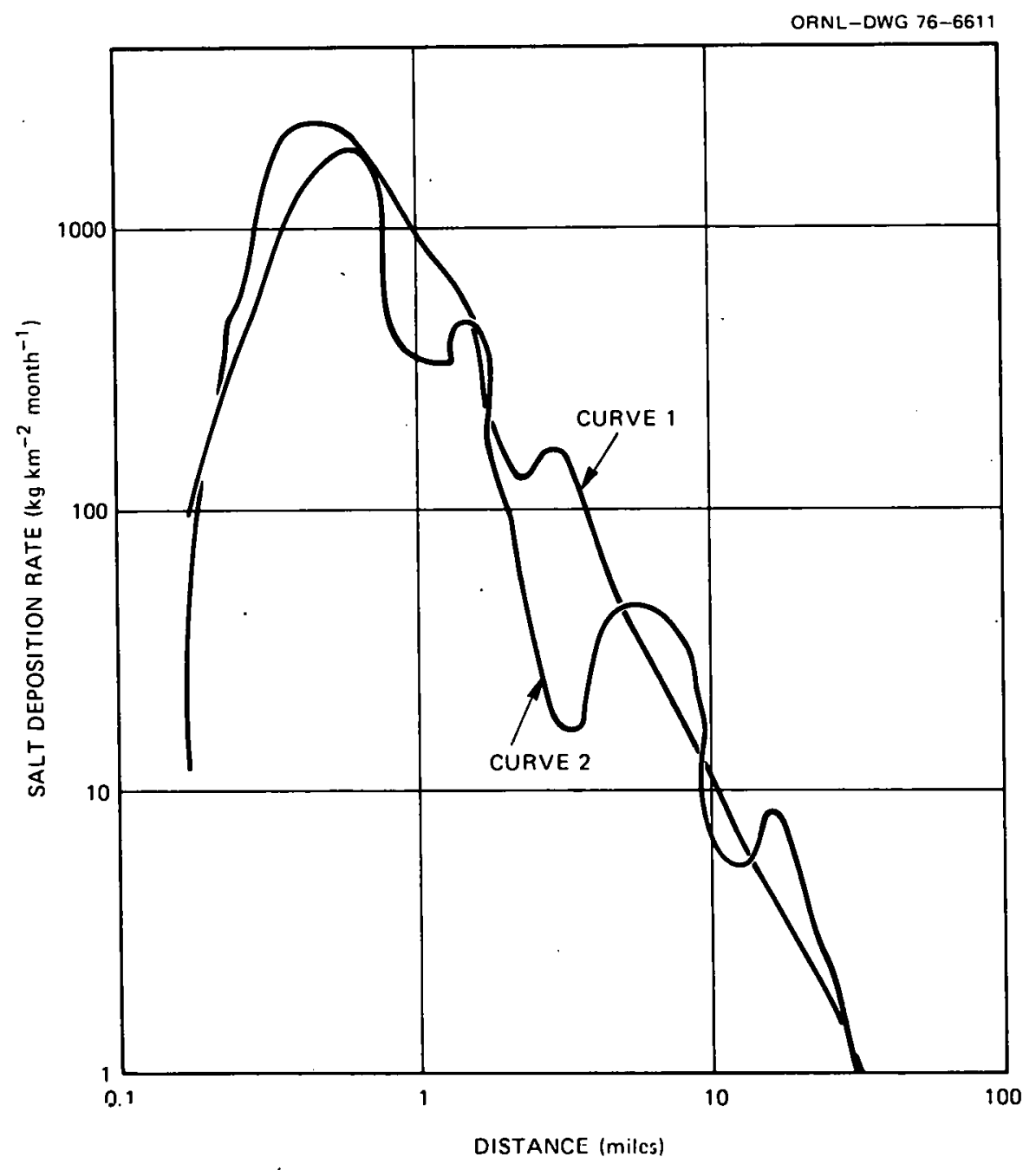

Fig. 12. Effect of low wind-speed representation $(0-6 \mathrm{~m} / \mathrm{sec})$ on deposition rate for droplets with a size distribution from Case 4 of Table 2 . The data concerns a $22.5^{\circ}$ sector at a selected site for one month with a drift rate of $0.00325 \%$ ( $186.0 \mathrm{~kg}$ of salt per hour). Curve 1 results from. a four-group wind representation of $1,2.3,3.5$, and $5 \mathrm{~m} / \mathrm{sec}$; Curve 2 is from a one-group wind representation of $3.5 \mathrm{~m} / \mathrm{sec}$. Source: $\mathrm{S}$. M. Laskowski, Fig. 9, p. 4.7, in "A Mathematical Transport Model for Salt Deposition from a Saltwater Natural-Draft Cooling Tower, Part II," paper presented at the Symposium on Atmospheric Diffusion and Air Pollution, American Meteorological Society, Sept. 9-13, 1974, Santa Barbara, Calif.

might keep evaporating and decreasing in size and weight, thus decreasing its terminal velocity, depending on the drop's original size, the salt concentration within the droplet and the ambient relative humidity. In some instances, equilibrium might be reached more quickly than $10 \mathrm{sec}$, especially if the relative humidity is low. 
To account for the fact that a cooling tower is not a point source, Laskowski mudlfies the source term by defining a "virtual point source" from which the downwind distance $(x)$ is determined. This empirical "virtual point source" was derived from photographs of the growth of an actual plume.

Laskowski claims that effects due to wake and precipitation washout are also accounted for, but the paper does not describe these considerations nor their effects and so it is not possible to evaluate their impacts here. These impacts could be significant. For example, a high wind speed ( $>25 \mathrm{mph}$ at the top of the tower) might produce a wake behind the tower that would bend the plume toward the ground, thus increasing deposition there and shifting the peak deposition point closer to the tower.

Some of the results predicted by Laskowski are not immediately apparent. As shown in Fig. 10, the peak deposition rate is highly dependent upon the presence of larger drops ( $>320 \mu \mathrm{m}$ diam), but it is not clear why a dip is produced near the tower. If it is assumed that a class of droplets diffuses with a Gaussian distribution, the height and the width of the bell-shaped curve of deposition rate would indicate the maximum deposition and the spread due to turbulence, respectively. The larger the droplets, the closer they will. fall to the tower and the higher the peak of the curve; the smaller the width of the curve, the less influence turbulence has on the droplets. The resulting deposition rate can be regarded as a superposition of the individual bell-shaped curves generated by particular size ranges of droplets, whether the curves be isolated or overlapped.

Figs. 11 and 12 also contain some puzzling results, such as a doublevalued deposition rate at certain downwind distances. In Fig. 11, the peak value of the average deposition can be changed by an order of magnitude by changing the detailed low-wind-speed representation (from 0 to $6 \mathrm{~m} / \mathrm{sec}$ ) for a drop-size distribution with no large drops. On the other hand, for a size distribution with a greater mass fraction of large drops, rhanging the low-wind-speed representation (from 0 to $6 \mathrm{~m} / \mathrm{sec}$ ) makes no difference in the peak value of the average deposition (see Fig. 12). 


\subsection{Model by Israel and Overcamp - 1974 (Gaussian Method)}

\subsubsection{Introduction}

The Israel and Overcamp model ${ }^{30}$ also involves a downward-sloping Gaussian plume model, which is modified by including a fraction of the image source as suggested by $\mathrm{Csanady}^{31,32}$ to satisfy the mass conservation. All droplets are assumed to be emitted at the center of the tower top and to escape from the plume at a height where the fall velocity equals the updraft. The updraft is calculated from the plume formula derived by slawson and Csanady. ${ }^{25}$ A Brookhaven National Laboratory (BNL) four-category stability class ${ }^{*}$ is used to select $\sigma$ values to simulate turbulent dispersion. Here $\sigma$ is the standard deviation of the width or thickness of the plume. The evaporation equation used is the same as that of the Hosler, Pena, and Pena model.

\subsubsection{Model description}

Israel and Overcamp apply a "2/3-1aw" plume-rise formula:

$$
z=\left(3 / 2 \beta^{2}\right)^{1 / 3}\left(F^{1 / 3 / u}\right) x^{2 / 3} \text {, }
$$

where $z$ is the rise above the tower, $x$ is the downwind distance, $u$ is the mean windspeed, $\beta$ is the entrainment coefticient, and $F$ is the initial buoyancy flux. By differentiating Eq. (15) with respect to time, the plume updraft at any $z$ is given by

$$
\mathrm{w} \simeq\left(2 / 3 \beta^{2}\right)^{1 / 2}(\mathrm{~F} / \mathrm{zu})^{1 / 2}
$$

For a droplet with a fall velocity $v_{D}$, the maximum height $\Delta h_{D}$ above the tower is obtained by setting $\mathrm{w}=\mathrm{v}_{\mathrm{D}}$, setting $z=\Delta \mathrm{h}_{\mathrm{D}}$, and transposing:

$$
\Delta \mathrm{h}_{\mathrm{D}} \simeq\left(2 / 3 \beta^{2}\right)\left(\mathrm{F} / \mathrm{uv}_{\mathrm{D}}^{2}\right)
$$

* The atmospheric stability is an indicator of turbulence that is dependent primarily on net radiation and wind speed. There are six stability classes according to the Pasquil118,19 classification scheme. There are four stability classes according to Smith and Singer. ${ }^{33}$ For more details, the paper by Turner ${ }^{34}$ should be consulted. 
Equation (17) essentially provides a plot of maximum height vs droplet fall speed, and the effeclive source height is seen to be inversely proportional to the square of the fall velocity, as expected. The largest, fastestfalling drops have a lower effective source height. Israel and Overcamp assume droplet breakaway occurs between one tower exit diameter above the tower and the maximum height of plume rise. Drops are assumed to escape at different heights above the tower axis (see Fig. 8c).

Israel and Overcamp determine drop settling and evaporation in a manner similar to that used by Hosler, Pena, and Pena. They then use averaged values (initial plus final states/2) of such variables as fall speed to simplify calculations. The deposition rate for a size range of droplet centered about a diameter $\mathrm{D}_{j}$ is the product of the ground-level concentration and the settling speed of the droplet:

$$
\Delta_{j}(x)=\frac{E_{j} v_{D_{j}}^{\prime}\left(1+\alpha_{0}\right)}{2 \pi \sigma_{y} \sigma_{z} u} \exp \left(-y^{2} / 2 \sigma_{y}^{2}\right) \exp \left[-\left(H_{D_{j}}-x \bar{v}_{D_{j}} / u\right)^{2} / 2 \sigma_{z}^{2}\right],
$$

where $E_{j}$ is the source strength of droplets with a mean diameter $D_{j}, \bar{v}_{D_{j}}$ is the mean settling speed, $v_{D_{j}}^{\prime}$ is the impacting velocity, $y$ is the crosswind distance, $\sigma_{y}$ and $\sigma_{z}$ are the ${ }^{j}$ plume standard deviations in crosswind and vertical directions respectively, $\alpha_{0}$ is the fraction of the image source to be retained, as suggested by Csanady, and $H_{D_{j}}$ is the sum of the tower height and the height attained by a drop above the tower top $\left(\Delta h_{D}\right) \cdot{ }^{31,32}$ Israel and Overcamp then calculated total deposition by summing the different depositions contributed by droplets of various sizes.

In a more recent version, a number of modifications were made by Overcamp: ${ }^{35}$

1. substitution of Brigg's stable plume rise formula for his neutral one to better estimate the maximum rise of the plume:

$$
z_{\max }=2.9(F / \text { us })^{1 / 3} \text {, }
$$

where $s$ is the restoring acceleration per unit vertical displacement for adiabatic motion in atmosphere. 
2. substitution of the formula for the image source strength coefficient by one proposed by Overcamp ${ }^{36}$

$$
\alpha_{0}(x)=1-\left\{2 v_{d} /\left[v_{d}+v_{s}+\left(\frac{u H-v_{s} x}{\sigma_{z}}\right) \frac{d \sigma_{z}}{d x}\right]\right\}
$$

where $v_{s}$ is the settling velocity, and $v_{d}$ is the deposition velocity.

3. the use of the Pasquil1-Gifford dispersion coefficients for $\sigma_{z}$ and $\sigma_{\mathrm{y}} ;$ and

4. calculation of sector-averaged deposition instead of centerline.

\subsubsection{Model predictions}

Sample calculations were carried out by Israel and Overcamp to show the effects of the initial size of the drops and of the selection of mean wind velocity. Figure 13 shows the centerline deposition rates in which contributions due to the first six largest-drop intervals are indicated. It is seen that deposition for the $425-\mu \mathrm{m}$ interval has a sharp peak around $500 \mathrm{~m}$ from the tower and has a narrow width. However, the deposition is spread over a greater area for small drops as a result of turbulent mixing and other causes. The total deposition is found by summing over all dropsize intervals, as shown by the curve labelled "total" in Fig. 13. Figure 14 shows the effect of wind speed on centerline depusition. On the nne. hand, a high wind tends to suppress the plume rise and to increase the close-in deposition; on the other hand, it will carry drops over a longer distance and reduce the close-in deposition. These two opposite effects compete with each other, and in Fig. 14 an overall decrease in the deposition is found as wind speed increases for the particular case studied.

The major conclusion drawn by Israel and Overcamp is that when turbulent dispersion is taken into consideration, the predicted deposition close to the tower is greater than that predicted by the ballistic method.

\subsubsection{Discussion of the model}

As was noted above, the point at which droplets are considered to break away from the plume is crucial to any deposition estimate. The effective 


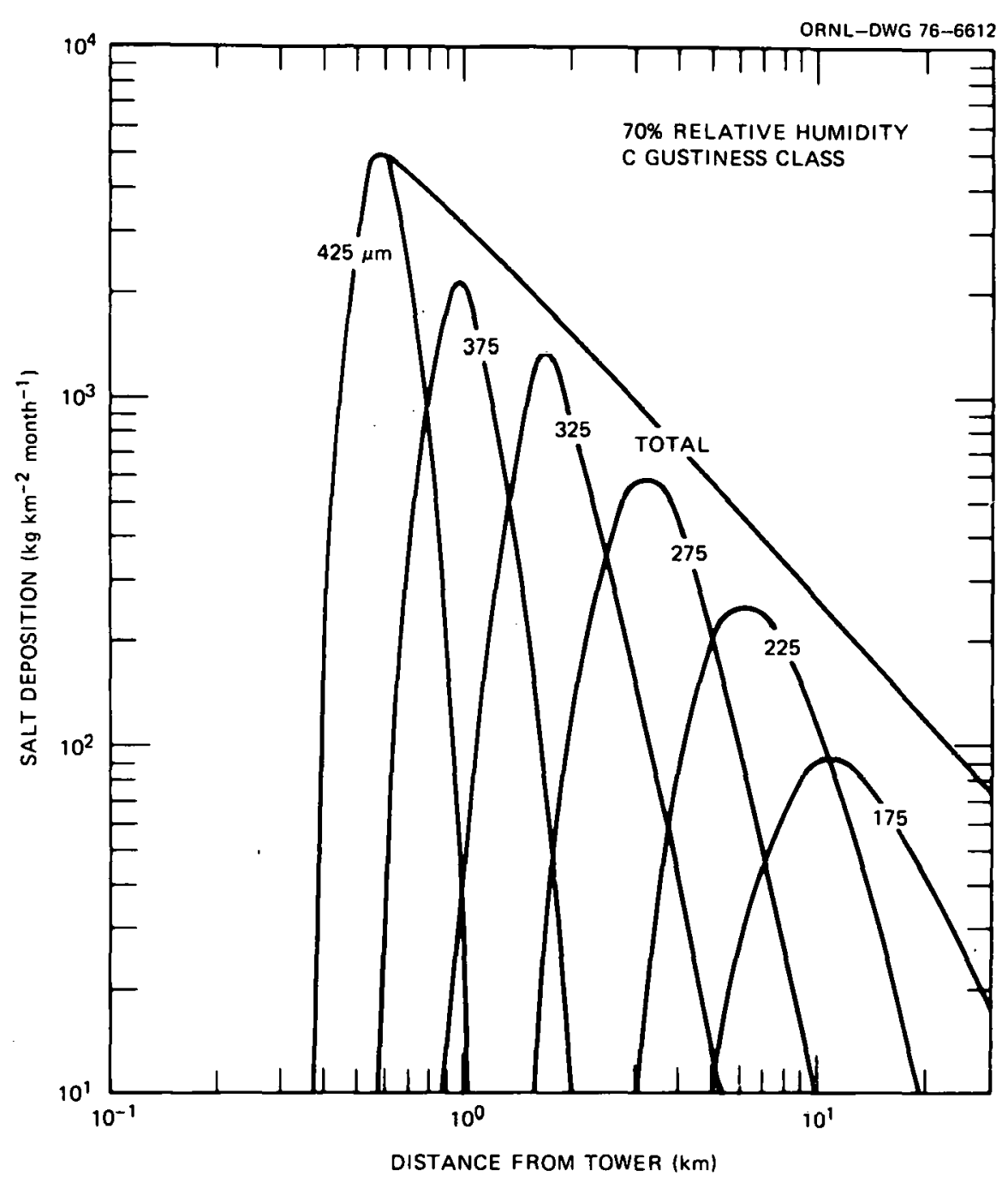

Fig. 13. Effect of droplet size on centerline salt deposition.

Source: G. W. Israel and T. J. Overcamp, Fig. 4, p. 625, "Drift Deposition Model for Nacural-Draft Cooling Tower," in Cooling Tower Envrionment - 1974, CONF-740302 (1975).

rise of droplets derived from the plume-rise equation in this model seems to be a reasonable assumption in view of the limited knowledge of tropletremoval processes.

The use of a tilted Gaussian plume model in Israel and Overcamp's treatment for large droplets in the deposition estimate may be unnecessary, because the behavior of large droplets is dominated by settling rather than by diffusion. 


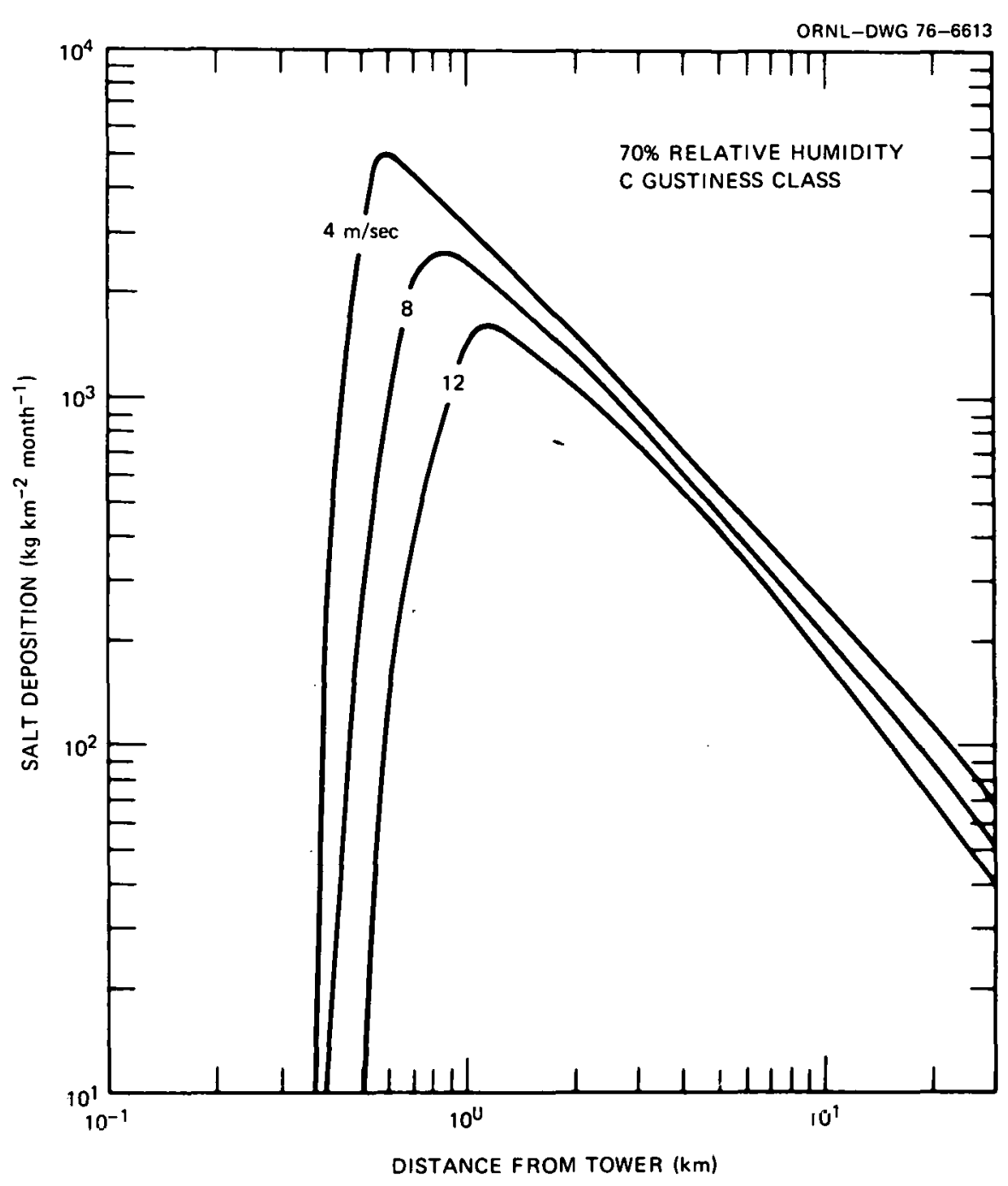

Fig. 14. Effect of wind speed on centerline salt deposition. Source: G. W. Israel and T. J. Overcamp, Fig. 5, p. 626, "Drift Deposition Model for Natural-Draft Cooling Towers," in Cooling Tower Environment - 1974, CONF740302 (1975).

In consideration of mass conservation, Israel and Overcamp adopt Csanady's theory by deriving an analytic solution for the image-sourcestrength coefficient for a downward-sloping Gaussian plume model. The theory is extended to cover the case in which the settling velocity does not equal the deposition velocity as expressed in Eq. (20). The solution, as written in Eq. (18), satisfies an integral mass-conservation equation specifying that the change in the airborne flux in the downwind direction equals the cross-wind integrated deposition on the ground. The detail is 
beyond the scope of this review. The paper by Overcamp ${ }^{36}$ should be consulted.

\subsection{Model by Hanna - 1974 (Ballistic-Gaussian Method)}

\subsubsection{Introduction}

The Hanna model ${ }^{37}$ is basically a ballistic method that considers droplcts to be emitted from the center of the top of the tower and to break away from the plume when they have gravitationally fallen out of the plume's radius. Droplet evaporation and turbulent dispersion are included, but the details of the latter are not clear.

\subsubsection{Model description}

The specific purpose of Hanna's model was to predict the chromate deposition from a bank of mechanical-draft cooling towers; however, with modification the model can be generalized to predict the deposition associated with natural-draft cooling towers. A mechanical-draft cooling tower forces droplets out of the tower with greater momentum, so Hanna adopted an equation derived by Briggs ${ }^{38}$ to describe the transition from momentum-dominated to buoyancy-dominated rise. That equation is extended by Hanna to include latent heat effects.

According to Hanna's description of plume rise, entrainment of ambient air causes the plume to grow differently at different stages. According to the model, the plume grows as $\mathrm{dR} / \mathrm{dz}=0.5$ in the "bent-over" rising stage and $\mathrm{dR} / \mathrm{dx}=0.05$ during the stage of the final rise. The parameters $R$ and $z$ are plume radius and height above the tower exit. In neutral and unstable atmospheres, the plume ceases to rise at a distance defined by

$$
\mathrm{x}^{*}=50 \mathrm{~F}^{5 / 8}, \quad \text { for } \mathrm{F}<55 \mathrm{~m}^{4} / \mathrm{sec}^{3} \text {, }
$$

where $x^{*}$ is in meters and $F$ is the buoyancy flux per cell in $\mathrm{m}^{4} / \mathrm{sec}^{3}$.

Hanna follows the trajectory of a drop from its emission from the center of the cell. Thence, the droplet rises or falls depending on whether or not the updraft is stronger than the droplet's gravitational settling. Hanna determines the breakaway point and its height for a particular drop size by calculating the plume-rise rate, the fall rate of the droplet, and 
the time it would take for the droplet to fall the distance from the plume's centerline to its periphery.

Hanna assumes that the plume rapidly cools off to the ambient temperature and that the droplet can be assumed to be at ambient temperature and that its saturation vapor pressure can be assumed to be that for the ambient temperature for the entire time that the droplet is in or out of the plume. Thus the problem of energy transport between the droplet and its environment can be ignored.

Once the drift droplets leave the plume, according to Hanna's model, the extent of evaporation depends largely on the droplet's initial size and salt concentration and on the ambient relative humidity. The Stokes law for small droplet sizes and Engelman's table, ${ }^{39}$ derived from Gunn and Kinzer's experiment for larger drops, ${ }^{40}$ are used by Hanna to calculate the fall speed.

The model provides the impact distance and final size for each drop. If drops do not reach the ground, their final locations and sizes are listed. For drops with fall velocities less than $1 \mathrm{~cm} / \mathrm{sec}$, dry deposition is assumed to occur and the fall speed considered to be $1 \mathrm{~cm} / \mathrm{sec}$.

Hanna ${ }^{41}$ further suggests that if the final droplet diameter is less than $200 \mu \mathrm{m}$, the drops will diffuse according to the Gaussian plume model. However, it is not clear at what distance from the tower Hanna applied the Gaussian model for drops that begin with diameters grealer than 200 l.um hut. evaporate to diameters less than $200 \mu \mathrm{m}$.

\subsubsection{Model predictions}

The predicted chromate deposition rate as a function of downwind distance following approximately a "-3/2 power" is presented by the solid curve in Fig. 15. It is assumed that the deposition rate out to a distance of $50 \mathrm{~m}$ from the tower is due to emission from a single cell (water flux, 170 gps) and that the deposition rate at distance greater than $500 \mathrm{~m}$ is a result of the merging of the plumes from all cells (water flux, $20 \times 170$ gPs). Deposition rates are interpolated between the curve for a single cell at a distance equal to $50 \mathrm{~m}$ and the curve for 20 cells at a distance equal to $500 \mathrm{~m}$. 


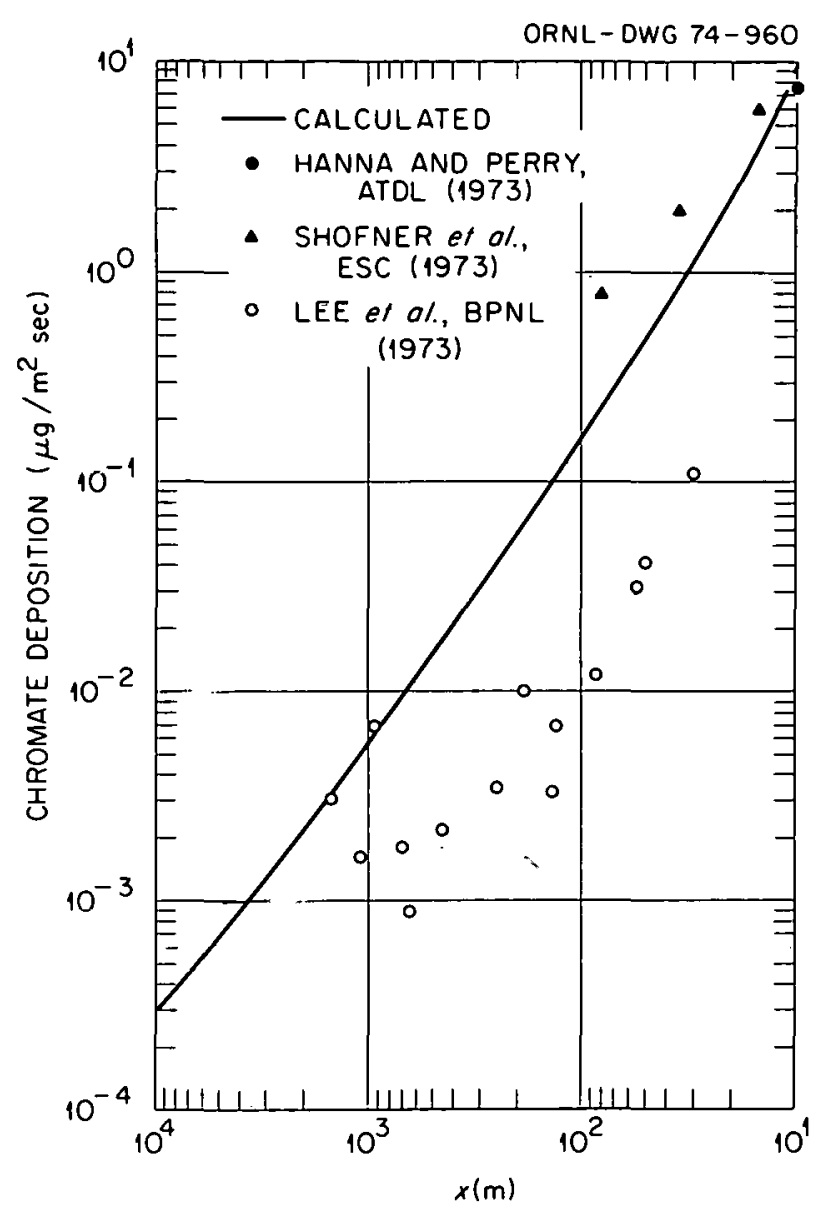

Fig. 15. Chromate deposition rate, observed and calculated, during the June 1973 experiment. Source: S. R. Hanna, Fig. 8, p. 301, in "Meteorological. Effects of the Mechanical-Draft Cooling Towers of the Oak Ridge Gaseous Diffusion Plant," Cooling Tower Environment - 1974, CONF740302 (1975).

\section{7 .4 Discussion of the model}

In his consideration of droplet evaporation, Hanna's simplification that the solute mass is small in comparison with the solution mass is well justified given the conditions under consideration where chromate concentration is as low as $20 \mathrm{ppm}$. However, for a salt concentration of $3 \%$, such as when seawater is used in a conling system, the solute mass cannot be assumed to be small, and an adjustment to the method would have to be made.

The model prediction is compared with the actual measurements taken from K-3l mechanical-draft cooling tower of Oak Ridge Gaseous Diffusion Plant in Fig. 15. When these data are compared, the following factors 
should be kept in mind: The diameter of a cell is $6.8 \mathrm{~m}$. This is a finite source as far as the near field is concerned and the results there should be viewed cautiously. Furthermore, frequent downwash is found within the first $70 \mathrm{~m}$ from the tower. Because these two major factors are not included in the model, the predicted values in the near field should be too low. Furthermore, in the far field it is assumed that the neighboring plumes from the cells in a bank merge beyond a distance of about $500 \mathrm{~m}$, but the mechanism of merging is not mentioned in the model. Further complications not accounted for by the model may arise if the cool air above a creek induces a downdraft, as may happen in this case $\sim 250 \mathrm{~m}$ from the towers. Circumstances also affected the gathering of the data (such as the failure of the drift-collecting pans to be located directly underneath the plume centerline most of the time). These anomalies contribute to uncertainties in the data that should be taken into consideration when the data are used to evaluate the model's predictions.

\subsection{Model by Tsai and Johnson - 1974 (Ballistic Method)}

\subsubsection{Introduction}

The Tsai and Johnson mode1 $1^{4}$ assumes all droplets to be emitted at the center of the tower top and to escape from the plume when the droplet's fall velocity exceeds its updraft. The droplets are then conslueied to follnw a ballistic trajectory. Droplet evaporation is included; whether turbulent effects are accounted for is not specified.

\subsubsection{Model description}

Tsai and Johnson estimate the dispersion of drops using the turbulentjet models of Fan $^{43}$ and Abraham ${ }^{44}$ for conditions of low-to-moderate winds and Brigg's plume-rise equation ${ }^{14}$ for other conditions.

The model assumes that a drop falls from the plume when the droplet's fall velocity equals the plume-rise velocity, which is one of the parameters generated by their plume-rise model. The effective height of emission is shown schematically in Fig. 16.

Tsai and Johnson calculate the terminal velocity of droplets with the Stokes law for drops with diameters of less than $80 \mu \mathrm{m}$ and with the empirical results derived by Gunn and Kinzer ${ }^{40}$ for larger drops. 


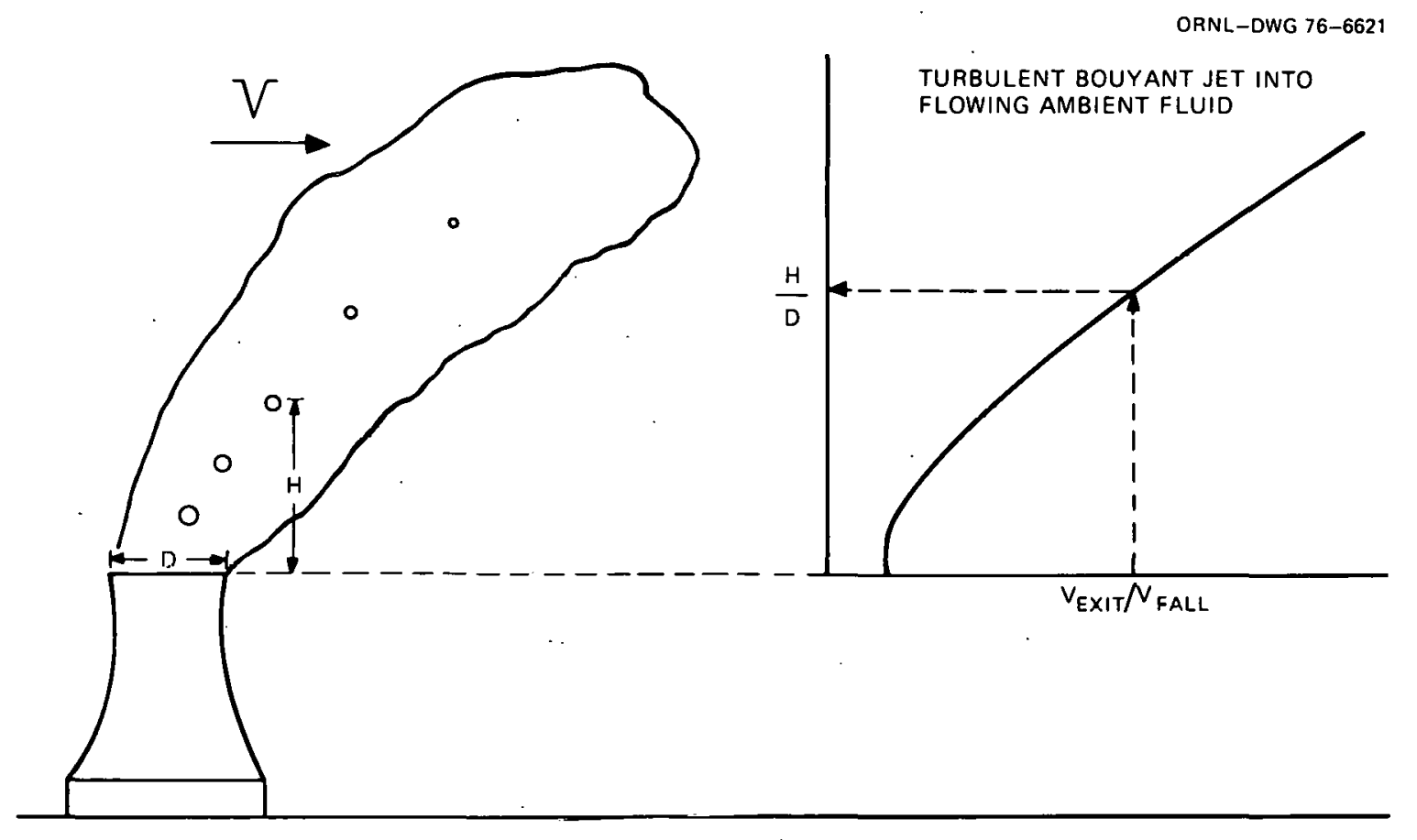

Fig. 16. Initial droplet rise in tower plume. Source: Fig. 5.1-19 in Environmental Report - Montague Nuclear Power Station Units 1 and 2, Supp1. 1, Northeast Nuclear Energy Co. (Aug. 16, 1974). Drift Model developed by Stone and Webster Engineering Corp.

For drop evaporation, Tsai and Johnson follow an empirical equation for mass diffusion. ${ }^{45}$ The cutoff relative humidity is assumed to be $40 \%$ For a droplet to result as a dry particle. The energy transfer between a drop and its environment, along. with temperature dependence of saturated vapor pressure, is not considered.

The plume is conoidered to disperse in such a way as to cover a $22.5^{\circ}$ sector downwind from the tower. The deposition in that sector is averaged incrementally downwind and uniformly across the sector according to Tsai. 46 The average areas then are small subdivisions bounded by the $22.5^{\circ}$ sector edges and the two impact distances traveled by the largest and the smallest droplets in that particle-size range.

\subsubsection{Model prediction}

In Tsai and Johnson's predicted deposition, labeled as "S and W" in Fig. 17, the curve is smoothed from a step-like histogram (a characteristic of the ballistic method) by an area mean. It is seen that the 


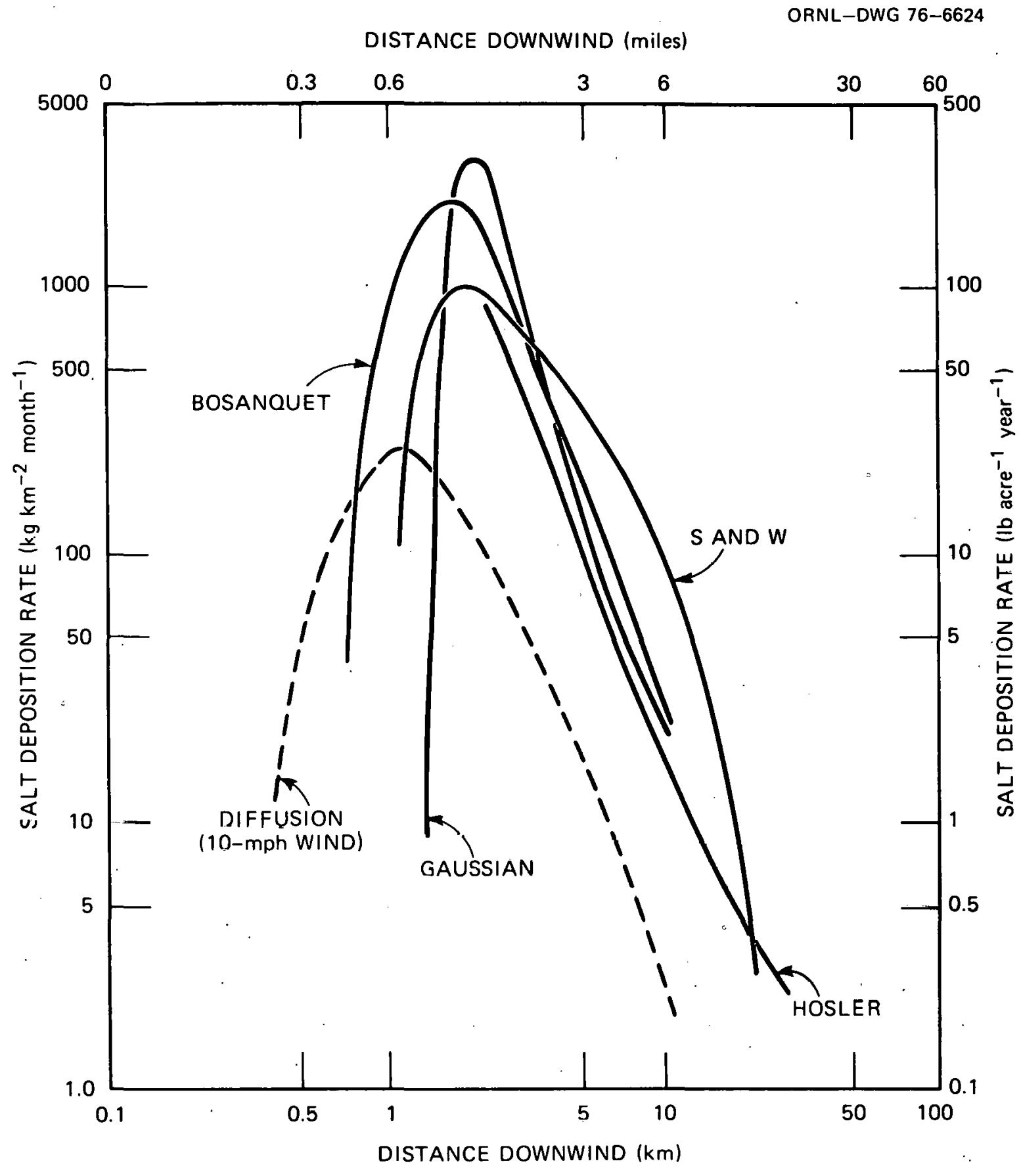

Fig. 17. Drift model comparison for a natural-draft tower. Source: Y. J. Tsai and D. H. Johnson, Fig. 3.6-1.4 in "Cooling Tower Drift Model, paper presented at the Fifth Annual Pittsburgh Conference on Modeling and Simulation, Apri1 24-26, 1974. Pittsburgh. 
predicted maximum deposition by Tsai and Johnson falls within the two extremes; the maximum peak deposition predicted by the Gaussian method and the minimum peak deposition predicted by the $\mathrm{K}$ theory (diffusion method). However, Tsai and Johnson predict a higher deposition than any other models, say, between $4 \mathrm{~km}$ to $20 \mathrm{~km}$. In addition, the model also predicts droplet trajectory and equilibrium diameter as shown in Fig. 19.

\subsubsection{Discussion of the model}

Because of lack of field data, Tsai and Johnson compared their predictions with those simulated by other models, such as the Bosanquet method, Gaussian dispersion method, Hosler et al. method, and the diffusion model developed by Roffman and Grimble. It should be noted that the results of Roffman and Grimble apply to a maximum deposition on the plume centerline, whereas the results of Tsai and Johnson apply to a $22.5^{\circ}$ sector average. Whether identical input data, such as drift-drop spectrum and atmospheric stabllity, are used for comparison is not discussed.

The terminal velocities of drops (see Fig. 18) vary as the square, the first power, and the square root of the diameter, depending on whether the

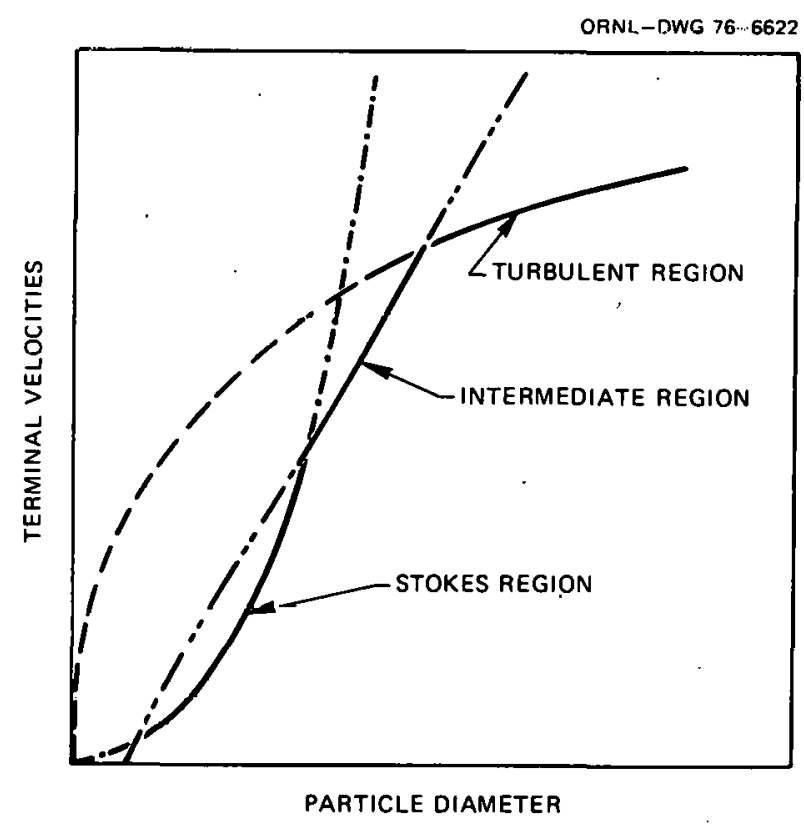

Fig. 18. Laws of free-falling particles. Source: J. M. Dallavalle, Micrometrics, 2d ed., p. 21, Pitman, New York, 1968. 
motion is in the Stokes region, the intermediate region, or the turbulent region. 47 However, the fall velocity, as computed by Tsai and Johnson (see Fig. 19) indicates an opposite curvature to the result predicted by the Stokes law. If a higher fall velocity is assigned to the small drops, as implied in Tsai and Johnson's calculations shown in Fig. 19, overprediction in deposition might be expected.

Another uncertainty is the height of droplet emission. It was demonstrated by Eq. (17) in Section 2.6.2 that the droplet's rise above the tower top is inversely proportional to the square of the fall velocity of that particle. In contrast to Tsai and Johnson's curve (see Fig. 16), a right-halved branch of a parabola concave upward should be shown. It is not clear to what extent the predicted deposition rate will be affected by this error.

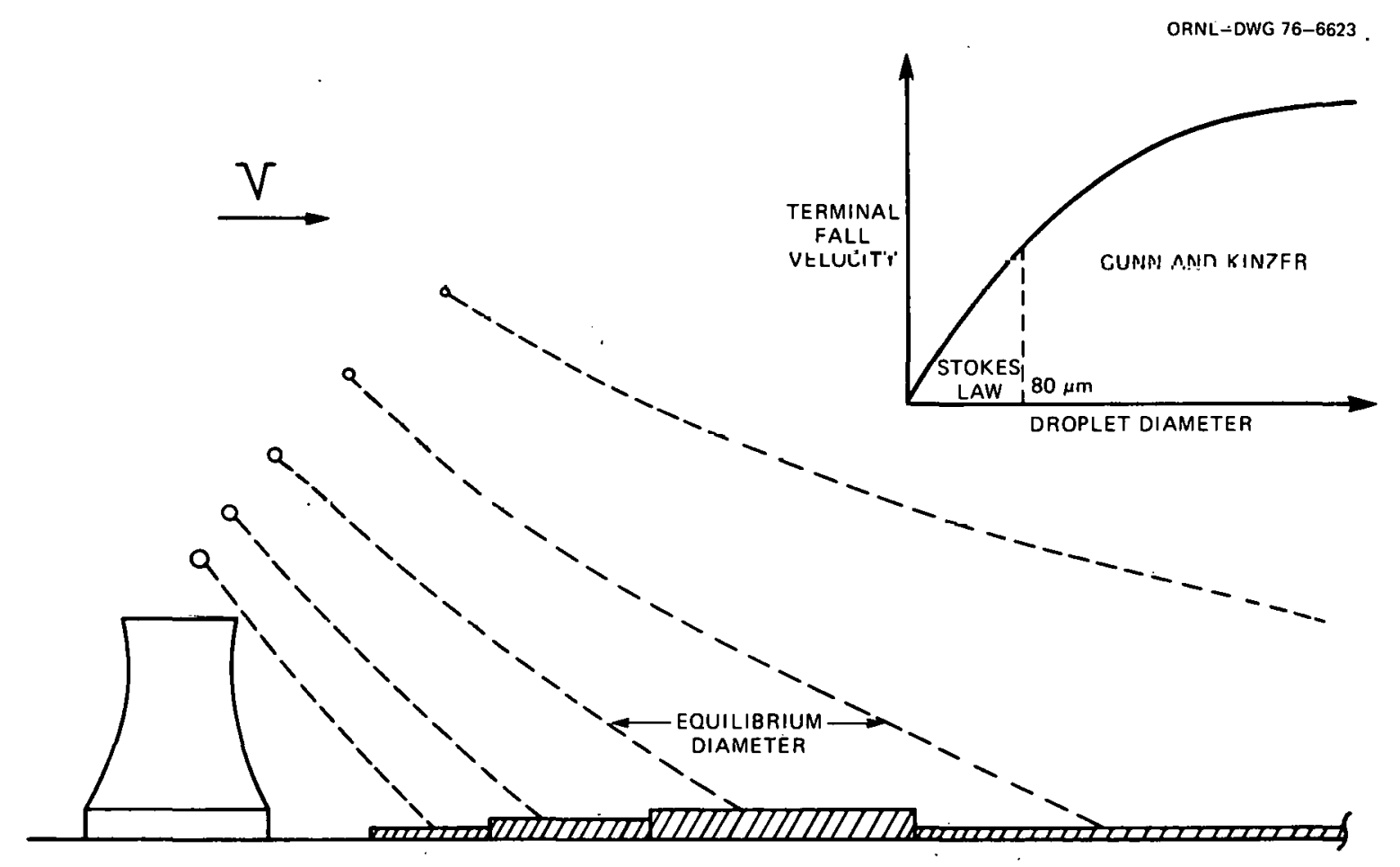

Fig. 19. Droplet trajectory. Source: Fig. 5.1-20 in Ervironmental Report - Montague Nuclear Power Station Units 1 and 2, Supp1. 1, Northeast Nuclear Energy Co. (Aug. 16, 1i74). Drift model developed by Stone and Webster Engineering Corp. 
2.9 Model by Oak Ridge National Laboratory - 1975 (Ballistic Method)

\subsubsection{Introduction}

The Oak Ridge Fog and Drift Model (ORFAD) ${ }^{48,49}$ predicts certain longterm environmental impacts, such as fog, ice, airborne salt concentration, and drift deposition rate, of wet cooling towers, provided tower characteristics and weather data are available. Only its treatment of the drift deposition rate will be considered here.

The ORFAD model assumes that all droplets are emitted at the center of the tower top and uses a ballistic method to predict their behavior. Turbulence effects are ignored, and the droplet breakaway point is not specified. The treatment of evaporation is similar to that of Hosler, Pena, and Pena. ${ }^{7}$

\subsubsection{Model description}

The ORFAD program calculates plume rise according to the dry plume rise formula suggested by Briggs. This formula is suitable for various conditions of environmental stability and gives a conservative estimate of deposition. However, ORFAD could be modified to account for plume-rise enhancement caused by latent heat effects (as suggested by Hanna ${ }^{15}$ ). The program assumes that $25 \%$ of the waste heat is removed as sensible heat and $75 \%$ is removed as latent heat.

The droplets are assumed to fall to the ground by a ballistic.trajectory. The horizontal velocity of the droplets is assumed to be that of the mean wind speed, and the fall velocity is determined by the Stokes law for small pure-water droplets and by empirical data for large drops. A correction for salt concentration is made. To simplify calculations of the drop evaporation, the three discrete humidity categories introduced by

Hosler, Pena, and Pena ${ }^{7}$ are employed: no evaporation for relative humidity $\left(\mathrm{H}_{1}\right)$ above $76 \%$, evaporation to a saturated solution for relative humidity range $\left(\mathrm{H}_{2}\right)$ from 50 to $76 \%$, and evaporation to dry particles for a relative humidty $\left(\mathrm{H}_{3}\right)$ below $50 \%$.

Again, the plume is envisioned as dispersing in a $22.5^{\circ}$ sector downwind. This downwind sector is divided into 19 areas, each area a little farther downwind than the one before. The diamcters of the droplets that 
would fall in each area are calculated and the mass fraction of the emitted droplets is found for each of these drop-size ranges. The average deposition per unit of time is then calculated by considering the mass to be uniformly distributed over the area.

\subsubsection{Model predictions}

For drift, the program prints out the annual rate of deposition per unit area of dissolved solids from the drift (grams per year per square meter of horizontal surface) and the yearly averages. The amount of drift deposited on the surface in liquid form is not calculated or printed. Contour maps of the drift deposition also can be generated by the program.

This model has been examined by considering the drift deposition from the K-31 mechanical-drift cooling tower of the Oak Ridge Gaseous Diffusion Plant. The weather data from the Knoxville airport, which is only 30 miles away, were used in the ORFAD calculations along with the data given in Table 3. The predicted salt deposition along the northeast transect, over which the wind blows about $13.5 \%$ of the time, is presented in Fig. 20. Unfortunately, direct measurements of salt deposition have not been available; * the salt deposition is converted into a prediction of chromium concentration in grass. ${ }^{50}$ Figure 21 shows the measured and predicted chromium concontration along the northeast transect from the $\mathrm{K}-31$ mechanical-draft cooling towers. ${ }^{51}$ The predicted deposition decreases monotonically by a factor of 300 over a distance of $1 \mathrm{~km}$, namely $150 \mathrm{~g} / \mathrm{m}^{2} \cdot 2$ month at $50 \mathrm{~m}$ from the tower to $0.5 \mathrm{~g} / \mathrm{m}^{2} \cdot 2$ month at $1 \mathrm{~km}$ from the tower.

\subsubsection{Discussion of the model}

The ORFAD model uses the tripartite humidity categories in Ref. 7 to describe the evaporation process. Pena and Hosler, on the basis of more recent experimental evidence, revised ${ }^{8}$ the makeup of these categories to $1.0>\mathrm{H}_{1} \geq 0.9,0.9>\mathrm{H}_{2} \leq 0.65$, and $0.65>\mathrm{H}_{3}$. This shift in the predicted evaporative behavior would (possibly significantly) change the

* There were direct measurements in deposition by Atmospheric Turbulence and Diffusion Laboratory of NOAA, Battelle Pacific Northwest Laboratories and Environmental Systems Corporation. The imperfection of the data was discussed in Section 2.7 .4 of this report. 
Table 3. ORFAD input parameters (K-31 tower ORGDP $)^{a}$

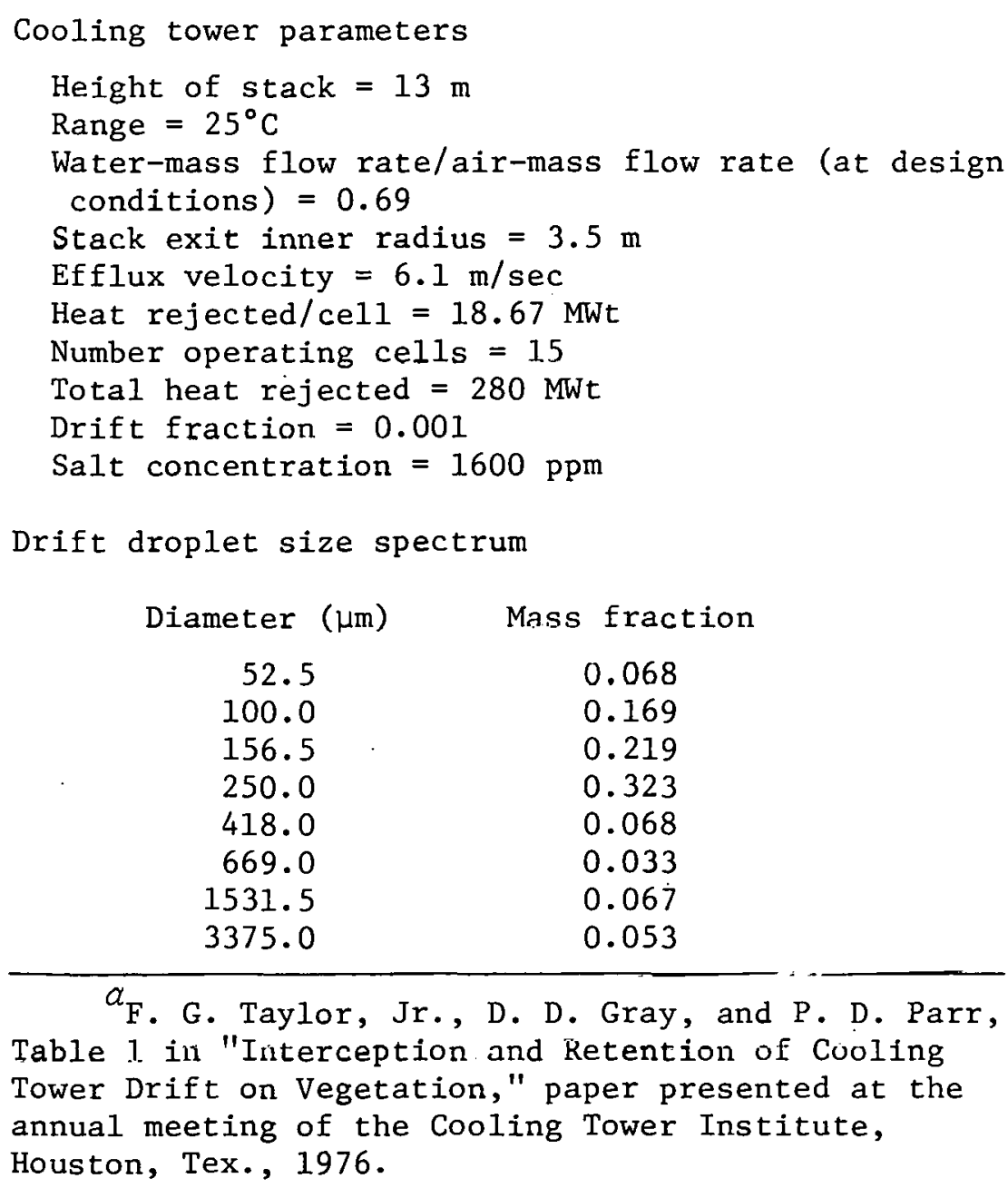

extent of evaporation, subsequent particle size, and fall speed of some drops, and perhaps should be taken into consideration in the use of ORFAD. The height for evaporating droplets to reach equilibrium size is temperature dependent. The original values are constructed by Hosler, Pena, and Pena at $20^{\circ} \mathrm{C}$. For temperatures at $0^{\circ} \mathrm{C}$ and $30^{\circ} \mathrm{C}$, the correction factors are 2.03 and 0.76 , respectively.${ }^{8}$, It is recommended that such corrections should be incorporated. The author was informed that this has been corrected In a revised version of ORFAD. 


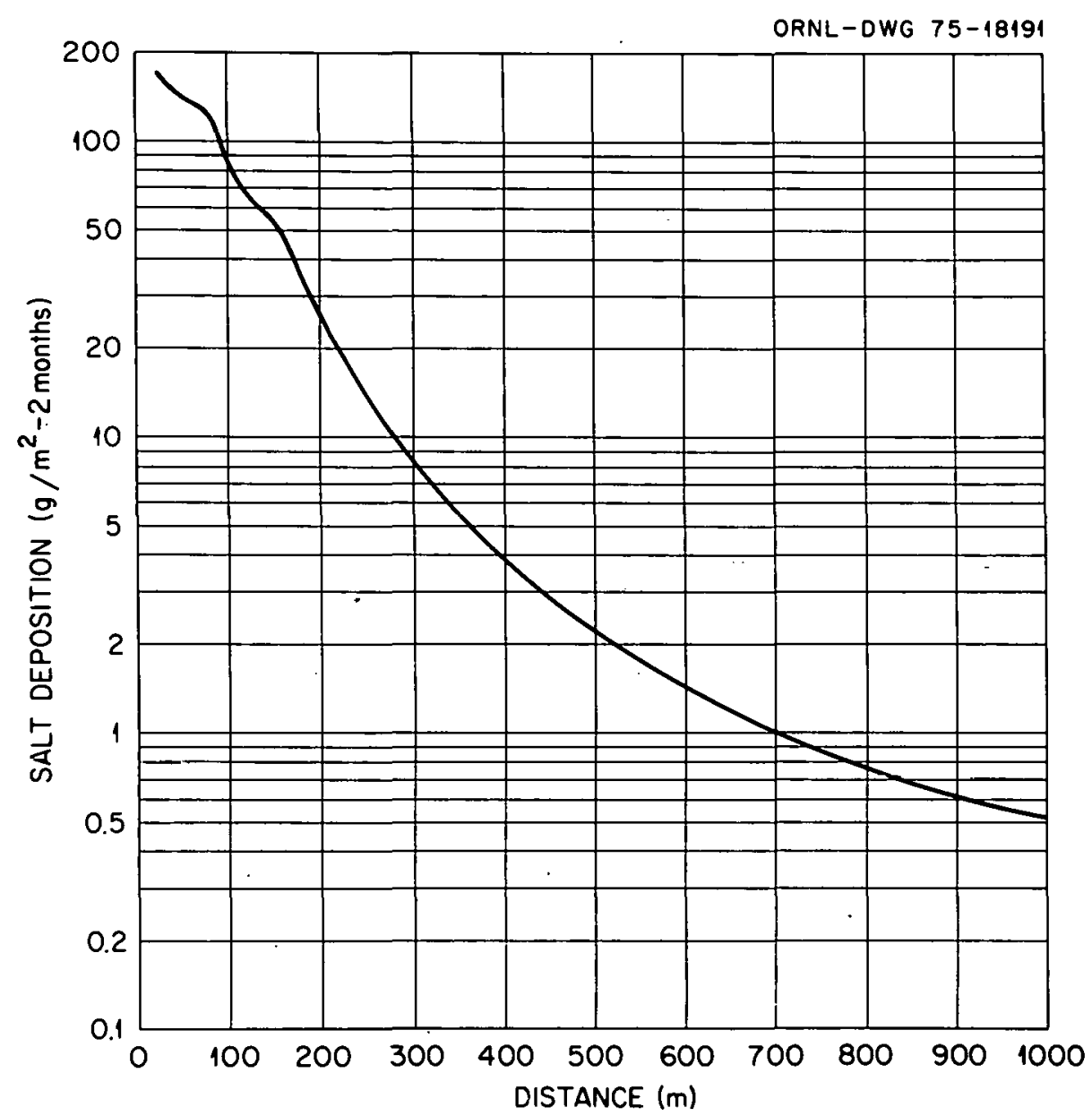

Fig. 20. Smoothed, predicted salt-deposition rate along the norcheast transect at the Oak Ridge Gaseous Diffusion Plant. Source: $F$. G. Taylor, D. D. Gray, and P. D. Parr, Fig. 1 in "Interception and Retention of Cooling Tower Drift on Vegetation," paper presented at the annual meeting of the Cooling Tower Institute, 1976, Houston.

The ratio between sensible and latent heat is highly dependent upon temperature. The assumed value in the model, $0.25 / 0.75=1 / 3$, is reasonable for summer months; but the situation is entirely different in winter months, when the value is more likely to be unity.

When multiple towers are present, ORFAD multiplies the deposition of one tower by the number in operation. This amounts to superimposing the plumes and ignores any dynamic interactions among plumes.

One drawback of ORFAD is that it does not take account of turbulent effects on deposition. As discussed in earlier reviews of the Hosler, 


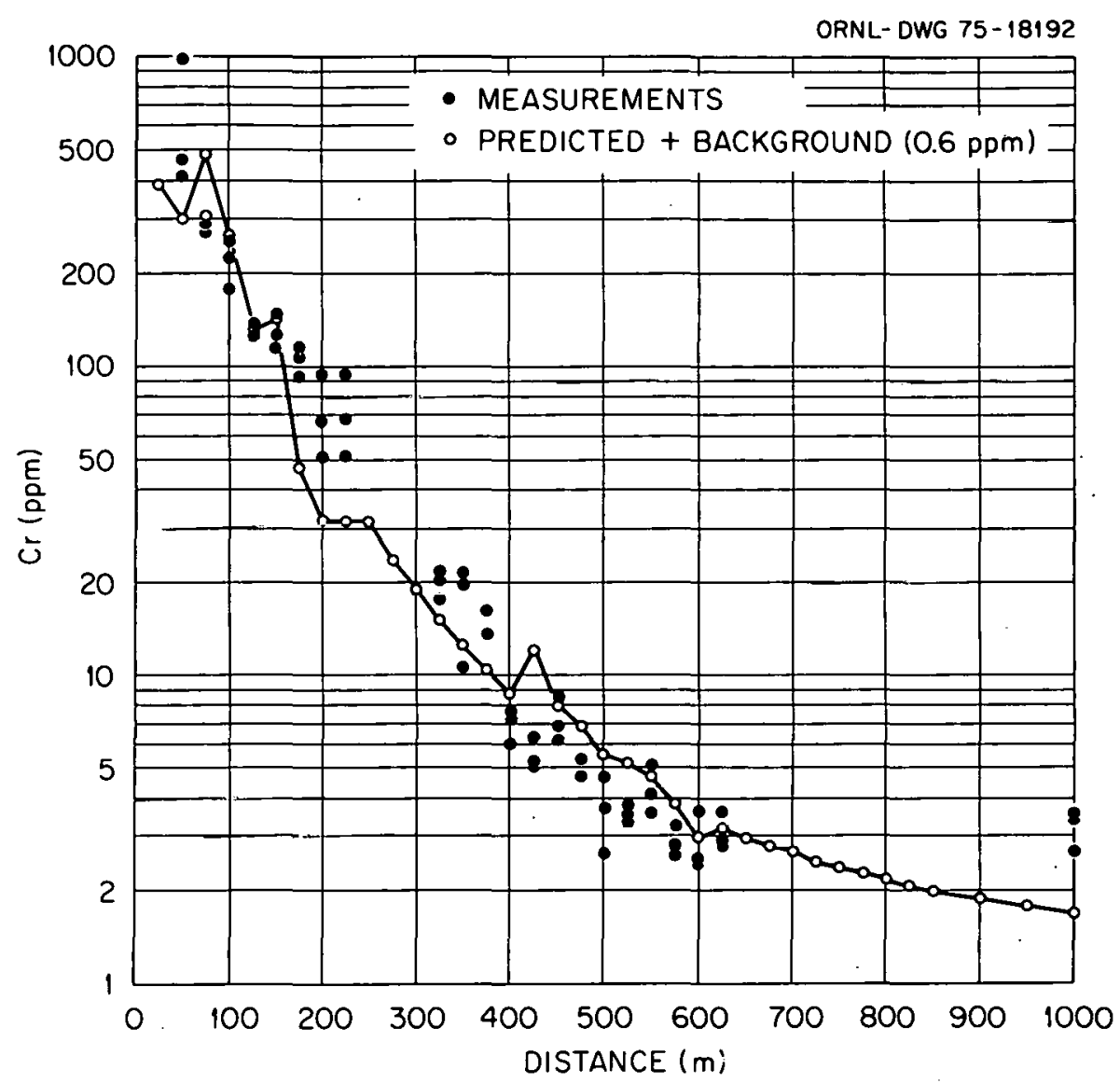

Fig. 21. Predicted and measured chromium concentrations along the northeast transect at the Oak Ridge Gaseous Diffusion Plant. Source: F. G. Taylor, D. D. Gray, and P. D. Parr, Fig. 2 in "Interception and Retention of Cooling Tower Drift on Vegetation," paper presented at the annual meeting of the Cooling Tower Institute, 1976, Houston.

Pena, and Pena model, this effect is important for small droplets and cannot be ignored. A related factor that has not been considered in this (or any other) model is nonuniform terrain. Irregular terrain could very well cause an increase in mechanical turbulence. On some occasions, this might cause unusual plume rise and lead to a pronounced effect on the magnitude and location of maximum ground deposition. For example, local circulations might occur as a result of mountain-valley terrain or shoreline environments. Other variables that might be considered are the height variation of the ambient wind profile, the visible plume length, and the downwash.

The ORFAD prediction has been compared to data from field measurements at the K-31 tower of the Dak Ridge Gaseous Diffusion Plant (Fig. 21). The 
general agreement beyond $100 \mathrm{~m}$ is always within a factor of 2 . The measured deposition is higher than that predicted downwind in the range frum 200 to $350 \mathrm{~m}$. This may be because plumes touch down frequently. However, downwash frequency is low in October, when the measurements were taken. Furthermore, the touchdown has been found to be within the first $70 \mathrm{~m}$ from the towers. ${ }^{37}$ The alternate reason might be the downdraft induced by the creek, which is located between 200 and $350 \mathrm{~m}$ from the bank of the cells. As the temperature contrast between the land and the water causes a circulation, a downdraft results. In addition, wind might blow through breaks in the 20-year-old fill. If this indeed happened, there would be a lot more measurable deposition than the model predicts. The computed values closer than about $100 \mathrm{~m}$ should be disregarded, due to the finite source effect of towers. It should be noted that more deposition data, both in mechanical- and natural-draft cooling towers, are needed to validate all models.

An attempt has been made ${ }^{51}$ to compare the ORFAD drift predictions with observations of chromium concentrations in grass. A number of assumptions were necessary in doing this; among the least certain of those assumptions are the time to reach steady-state chromium concentration in grass and the chromium interception rate by the grass. Although both of these numbers were suggested by experimental results, the values used must be regarded cautiously. Nevertheless, the agreement was encouraging, and further work to improve ORFAD and to compare it with additional field data should be undertaken.

\subsection{Model by Rao, Lague, and Egan - 1975 (Ballistic-Gaussian Method)}

\subsection{0 .1 Introduction}

Rao, Lague, and Egan's drift deposition model, ${ }^{52}$ which is based on the original formulations on drift prediction by Austin of MIT, applies a ballistic method for large drops (diam $>250 \mu \mathrm{m}$ ) and a ballistic-Gaussian method for small drops (diam $<250 \mu \mathrm{m})$. All droplets are assumed to be emitted at the center of the tower top. Large droplets are considered to break away from the plume when the droplet falls one tower-exit radius 
from the plume centerline. It is not clear where small droplets are considered to break away from the plume and to diffuse according to the tilted Gaussian model. Droplet evaporation is empirically treated. When downwash occurs, its effects on all particle sizes are included. The model is deslgned to use the plume rise, growth rate, and updraft profile that are generated from a buoyant, wet, and bentover cooling-tower-plume model. ${ }^{5}$

\subsection{0 .2 Model description ${ }^{*}$}

2.10.2.1 Downwash. Rao, Lague, and Egan assunie that downwash occurs whenever the wind speed exceeds two-thirds of the efflux speed, a criterion derived by Briggs ${ }^{4}$ for smokestacks. Corrections are made to account for the effect on effective plume height produced by the slight downwash.

Deposition due to downwash is calculated as the product of deposition velocity and ground-level concentration. The deposition velocity is a weighted average of the fall velocities of saturated drops over the range of drop sizes considered. The ground-level concentration is derived from a Gaussian method with an assumed $\sigma_{z}$ to simulate large eddies formed in the wake of the tower complex. Turner ${ }^{55}$ stability classes of the $\sigma_{z}$ values are used in the model. The turbulence in a wake region is assumed to decrease with increasing distance from the tower:

\begin{tabular}{cl}
$\begin{array}{c}\text { Downwind distance } \\
\text { (tower heights) }\end{array}$ & \multicolumn{1}{c}{$\begin{array}{c}\text { State of } \\
\text { turbulence }\end{array}$} \\
\hline 2 & Most unstable \\
6 & Moderately unstable \\
16 & Slightly unstable \\
20 & Neutral \\
\hline
\end{tabular}

2.10.2.2 D1spersion of small droplets. The center of gravity of the small drops falls relative to the plume axis a distance that is proportional to the fall velocity of the droplets. Unlike most other models (in which fall

\footnotetext{
* Because of proprietary rights, Rao, Lague, and Egan have requested
} that neither their equations nor certain of their results be repronlused in this report. 
velocity remains constant as long as the drop stays inside the plume and varies in the atmosphere), Rao, Lague, and Egan's model relies on empirical formulas for fall-velocity calculations. These formulas are based on the original droplet size, initial salt concentration, and relative humidity. These formulas consider drops to behave differently before and after the maximum plume rise. The initial plume rise causes an upward trajectory until the droplet reaches the full plume rise, after which the drop's trajectory slopes downward. When the plume becomes passive, a normal or Gaussian distribution is superimposed on the mean droplet trajectory to simulate atmospheric dispersion. The scheme is similar to Laskowski's model (see Sect. 2.5).

\subsubsection{Deposition of large drops. Because the trajectory of large} drops is dominated more by gravity than by turbulent diffusion, Rao,

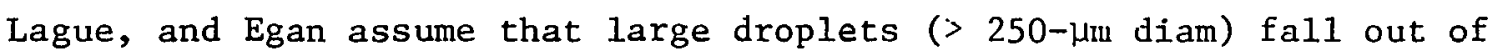
the plume when the droplet has fallen one tower-exit radius. The effective height at which the droplet leaves the plume is assumed to be inversely proportional to the square root of the droplet fall velocity. Depending on the time required for the droplet to reach saturation, Rao, Lague, and Egan use the Austin empirical formulation for evaporation to calculate the impact distance. Deposition is computed by distributing uniformly the mass fraction of a given droplet size range over an arted bounded by a $22.5^{\circ}$ sector radlating from the tower and by the maximum and minimum impact distances for the range of droplet sizes.

The depositions from the three contributions (the downwash, the small droplets, and the large droplets) are combined to give the total deposition for each combination of relative humidity and wind rose.

\subsubsection{Model predictions}

Rao, Lague, and Egan find that "the most critical factors affecting long-term patterns and overall magnitudes of the deposition are the tower drift characteristics and the directional frequencies of the observed winds." Some of the calculated deposition rates for a salt concentration of $0.23 \%$ are presented in Figs. 22 through 25. Figures 22 and 23, representing far- and near-field deposition patterns respectively, are for a 


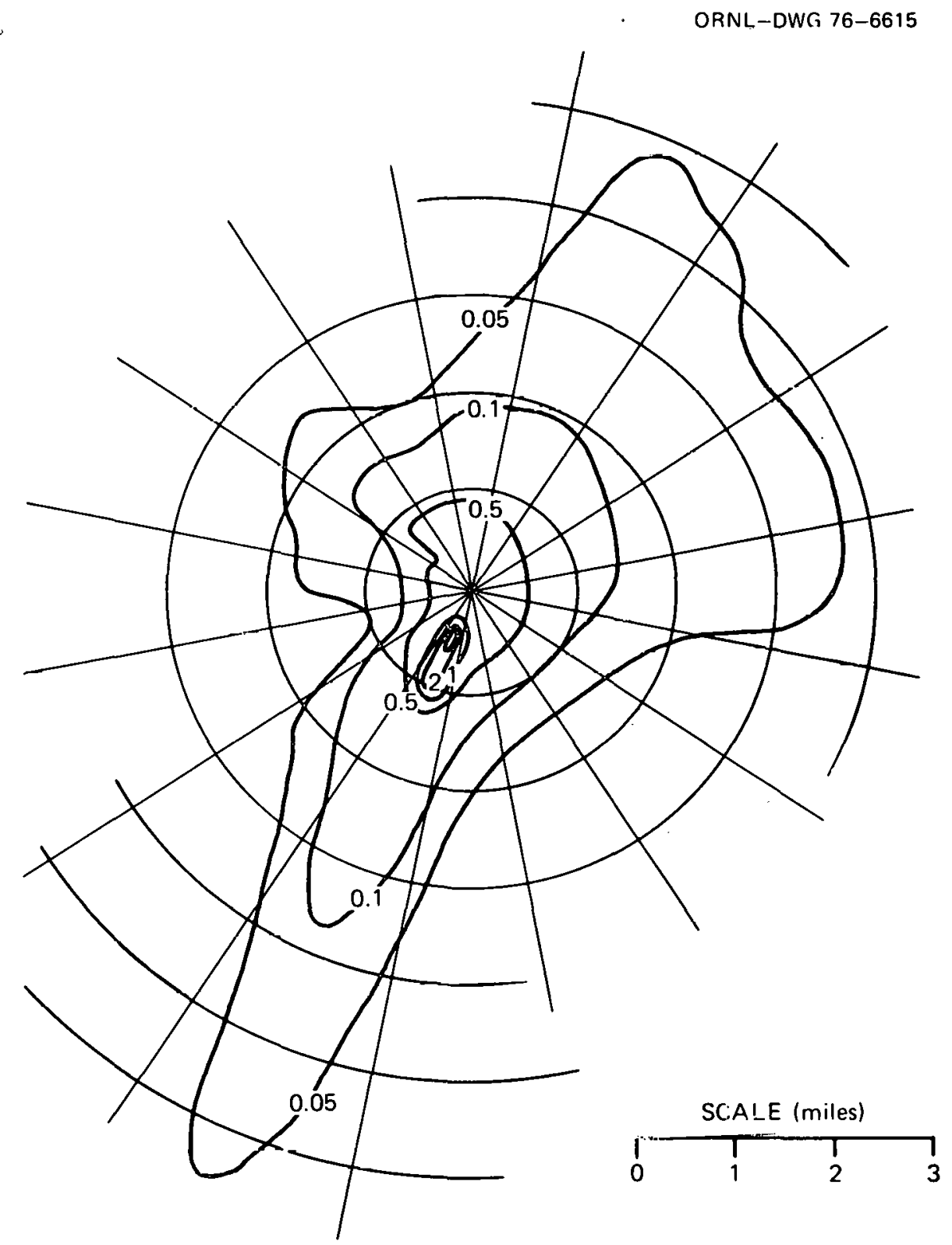

Fig. 22. Isopleths of drift-deposition rate (lb/acre/month) for June 1975 , with $0.006 \%$ assumed drift rate, 0-15 km. Source: K. S. Rau, J. E. Lague, and B. A. Egan, Fig. 3-1, p. 3-9, in "Cooling Tower Drift Model Description," Appendix B of A Study of Environmental. Impacto Associatod with Couling Tower uperation at the Proposed Prairie, Wisconsin, Power Plant, Wisconsin Electric Power Co., ERT/P-1235 (1975). 


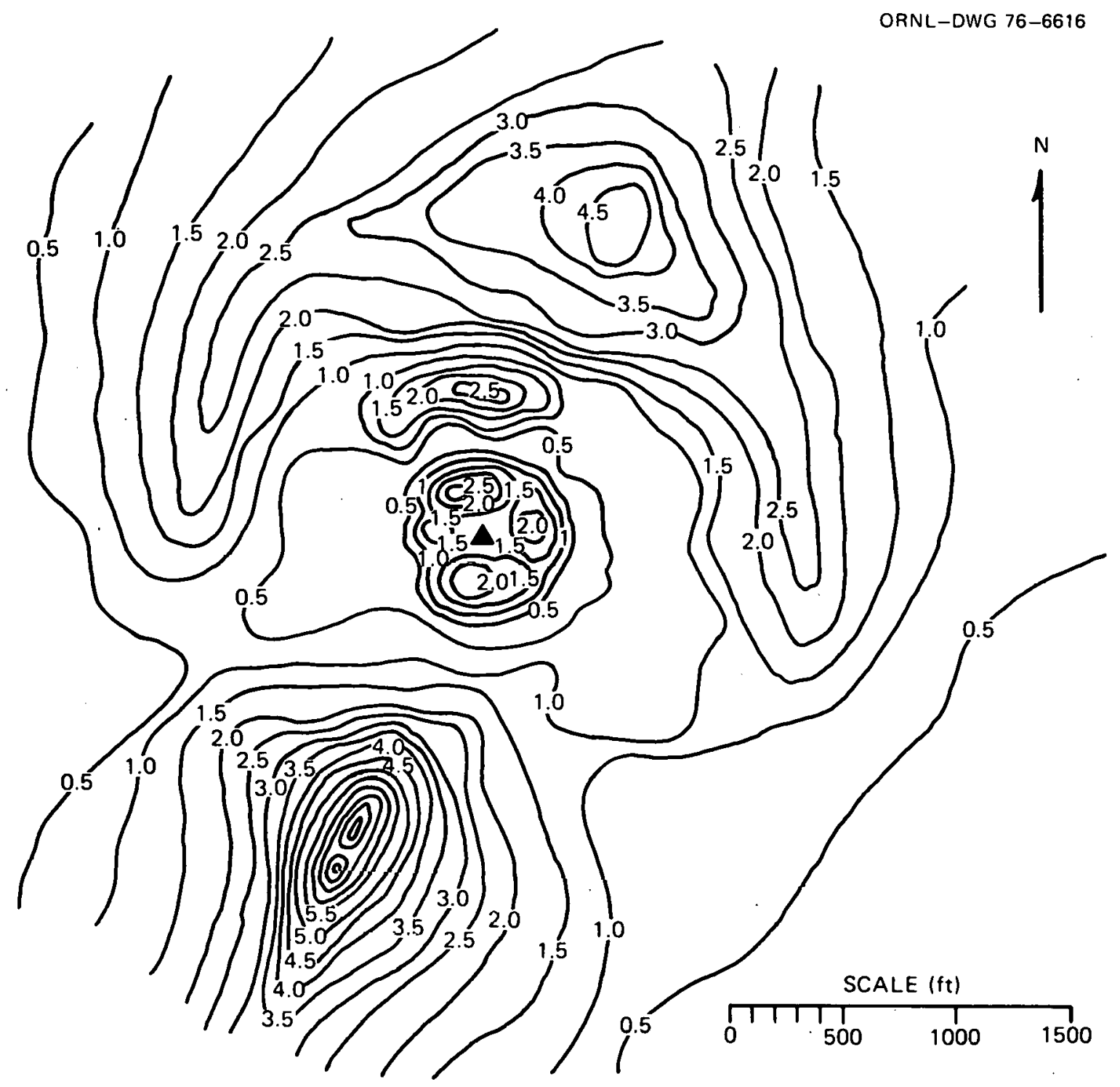

Fig. 23. Isopleths of drift-deposition rate (1b/acre/month) for June 1975 , with $0.006 \%$ assumed drift rate, $0-750 \mathrm{~m}$. Source: K. S. Rao, J. S. Lague, and B. A. Egan, Fig. 3-1(a), p. 3-10, in "Cooling Tower, Drift Mode1 Description," Appendix B of A Study of Environmentai Impacts Associated with Cooling Tower Operation at the Proposed Prairie, Wisconsin, Power Plant, Wisconsin Electric Power Co., ERT/P-1235 (1975). 


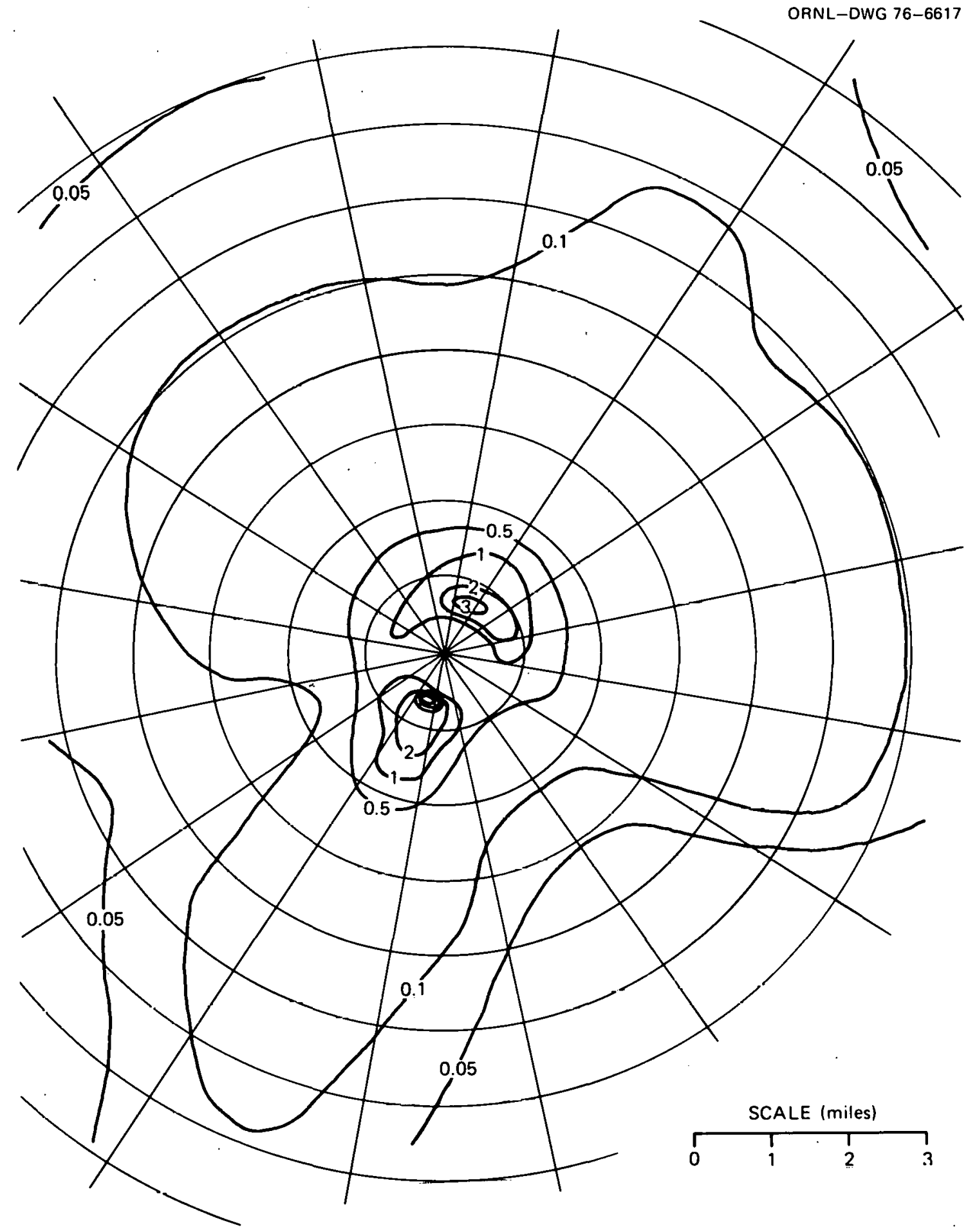

Fig. 24. Isopleths of drift-deposition rate (lb/acre/month) for June 1975 , with $0.02 \%$ assumed drift rate, 0-15 $\mathrm{km}$. Source: K. S. Rao, J. S. Lague, and B. A. Egan, Fig. 3-5, p. 3-14, in "Cooling Tower Drift Model Description," Appendix B of A Study of Environmental Impacts Associated with Cooling Tower Operation at the Proposed Prairie, Wisconsin, Power Plant, Wisconsin Electric Power Co., ERT/T-1235 (1975). 


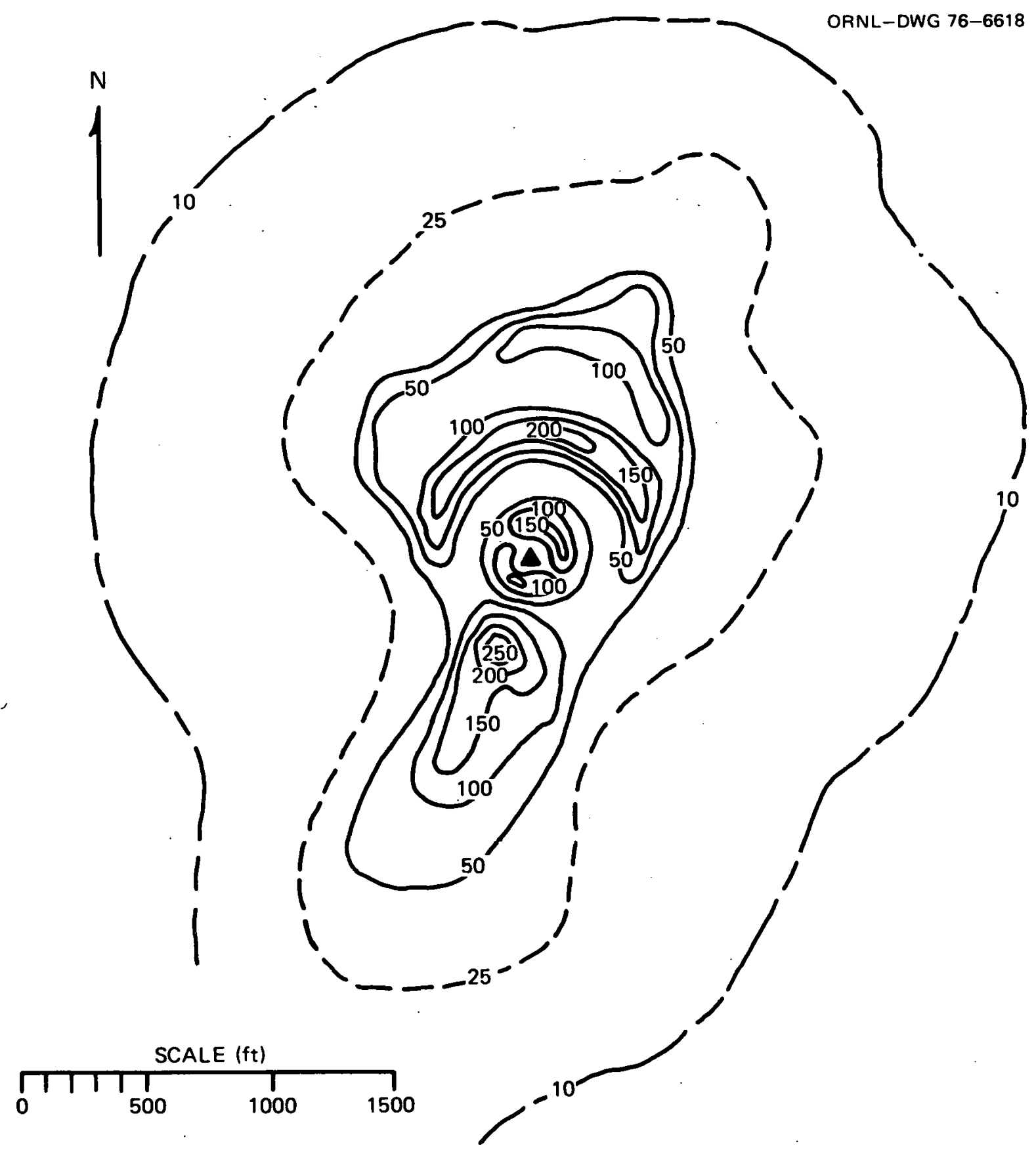

Fig. 25. Isopleths of drift-deposition rate (1b/acre/month) for June 1975 , with $0.02 \%$ assumed drift rate, $0-750 \mathrm{~m}$. Source: K. S. Rao, J. S. Lague, and B. A. Egan, Fig. 3-5(a), p. 3-15, in "Cooling Tower Drift Model Description," Appendix B of A Study of Environmental Impacts Associated with Cooling Tower Operation at the Proposed Prairie, Wisconsin, Power Plant, Wisconsin Electric Power Co., ERT/P-1235 (1975). 
drift rate of $0.006 \%$ and show a strong dependence on a persistent northeasterly wind in June. A peak is found to occur at 500 to $600 \mathrm{~m}$ (.31 to .38 mile) southwest of the tower at a rate of $896 \mathrm{~kg} / \mathrm{km}^{2} / \mathrm{month}(8 \mathrm{lb} / \mathrm{acre} /$ month). Figures 24 and 25 are results for the same conditions, except with a drift rate of $0.02 \%$. Note that a peak in deposition occurs somewhat closer to the tower with a deposition rate of $3.14 \times 10^{4} \mathrm{~kg} / \mathrm{km}^{2} / \mathrm{month}$ (280 $\mathrm{lb} / \mathrm{acre} / \mathrm{month})$. In both cases, deposition decreases rapidly beyond $1 \mathrm{~km}(.63 \mathrm{mile})$.

\subsubsection{Discussion of the model}

In calculating deposition contributed by the downwash, Rao, Lague, and Egan assume that the Gaussian dispersion is applicable in the wake of the tower, a highly turbulent region. Distorted flow fields produced by a wake create concentration distributions that are so complicated that predicting them with a simple Gausstan dispersion might not be accurate because it would probably indicate a less uniform distribution than the turbulent mixing in the wake would produce. A thorough discussion of wake effects is given by Halitsky. 56

On the other hand, if the plume is very buoyant (for example, a wet natural-draft cooling tower plume with a low Froude number), the buoyancy force is sufficient to counteract at least part of the adverse pressure gradient, and downwash might be insignificant. Laboratory experiments have been performed by Overcamp and Hoult ${ }^{57}$ that suggest that this indeed occurs; this is discussed further in Sect. 4.3.

In the computation of the effective height above the tower for large droplets, Rao, Lague, and Egan assume that the effective droplet rise is inversely proportional to the square root of the droplet fall velocity $\left(v_{f}{ }^{1 / 2}\right)$ rather than the square of the fall velocity $\left(v_{f}^{2}\right)$ derived from Brigg's plume rise. Thus, a given droplet's rise can differ by a factor $v_{f}^{1.5}$. For a droplet $600 \mu \mathrm{m}$ in diameter (which has a fall velocity of 2.5 $\mathrm{m} / \mathrm{sec}$ ), the factor is about 4 .

Although atmospheric turbulence is simulated by imposing a Gaussian distribution, the dispersion of small droplets by plume-induced turbulence is entirely neglected in the model. This might be a serious shortcoming of the model because plume-induced turbulence might outweigh ambient turbulence during the initial plume rise. 
3. MODEL COMPARISONS USING A COMMON SET OF INPUT CONDITIONS

A major deficiency in evaluating the models discussed in Chap. 2 is the lack of good field data on drift deposition. In the absence of data, a valuable exercise is to compare the predictions of the various current models using a set of identical input parameters. This was done in the present study. Actual field data, of course, would make possible a better evaluation of the strengths and weaknesses of the various approaches. For simplicity, the models will be compared here in light of only the set of meteorological conditions shown in Table 4, which simulate as closely as possible a natural-draft cooling tower. The drop-size distribution specified in Table 4 was derived from data from environmental reports.

During the course of the study, good cooperation was given by most of the model developers. Some did not participate because of proprietary or other concerns. Even for those participating, the present review does not identify (for various reasons) the results from particular models and, thus, is restricted to demonstration of the differences in predictions.

Given the input data (Table 4), most of the models estimate that the cooling tower plume will level off at an elevation of about $500 \mathrm{~m}$ at a distance of about $550 \mathrm{~m}$ downwind from the tower. Most models applied the plume-rise formula derived by Briggs. Deposition rates predicted by the various models are shown in Fig. 26 (a), (b), (c). In Fig. 26(a) curve $A$ is obtained by using the ballistic method and by assuming that all droplets break away at the tower top and that no evaporation occurs. The resulting deposition pattern has a larger maximum deposition rate than any of the other models. Curve B is obtained by applying the Gaussian model and by assuming that all droplets break away at the height of maximum plume rise (500 $\mathrm{m}$ above the tower) and that they evaporate completely. The resulting deposition pattern has a smaller maximum deposition rate but covers a broader distance than any of the other models. (The predicted deposition rate is $4 \times 10^{-3} \mathrm{~kg} \mathrm{~km}$ month $^{-1}$ at $100 \mathrm{~km}$. This is not shown in Fig. 26 (a) because of the limitation of the scale.) It is felt that any model predicting a maximum deposition rate that was not between the maxima of these two curves would contain an error in representing the physical processes involved. 
Table 4. Parameters used in the calculations

Initially saturated plume

Plume temperature at exit from tower $=\mathrm{T}_{\text {po }}=305^{\circ} \mathrm{K}$

Ambient temperature near exit from tower $=\mathrm{T}_{\text {eo }}=275^{\circ} \mathrm{K}$

Tower height $=100 \mathrm{~m}$

Tower-exit diameter $=60 \mathrm{~m}$

Efflux velocity $=4.3 \mathrm{~m} / \mathrm{sec}$

Amount of circulating water $=31.5 \mathrm{~m}^{3} / \mathrm{sec}$

Drift rate $=2 \times 10^{-5}$

Watcr salinity $=3.45 \%$

Wind speed $=4.3 \mathrm{~m} / \mathrm{sec}$

Salt deposition rate calculated for sector of $22.5^{\circ}$

Frequency of wind direction which blows toward the sector $=1$

Ambient relative humidty $=70 \%$ (constant with varying height)

Isothermal ambient atmosphere (slightly stable atmosphere)

Drop size distribution:

\begin{tabular}{ccc}
$\begin{array}{c}\text { Diameter interval } \\
(\mu \mathrm{m})\end{array}$ & $\begin{array}{c}\text { Mean diameter } \\
\text { for interval } \\
(\mu \mathrm{m})\end{array}$ & $\begin{array}{l}\text { Fraction of } \\
\text { total mass }\end{array}$ \\
\hline $0-100$ & 50 & 0.05 \\
$100-200$ & 150 & 0.3 \\
$200-300$ & 250 & 0.4 \\
$300-400$ & 350 & 0.15 \\
$400-500$ & 450 & 0.075 \\
$500-600$ & 550 & 0.025
\end{tabular}



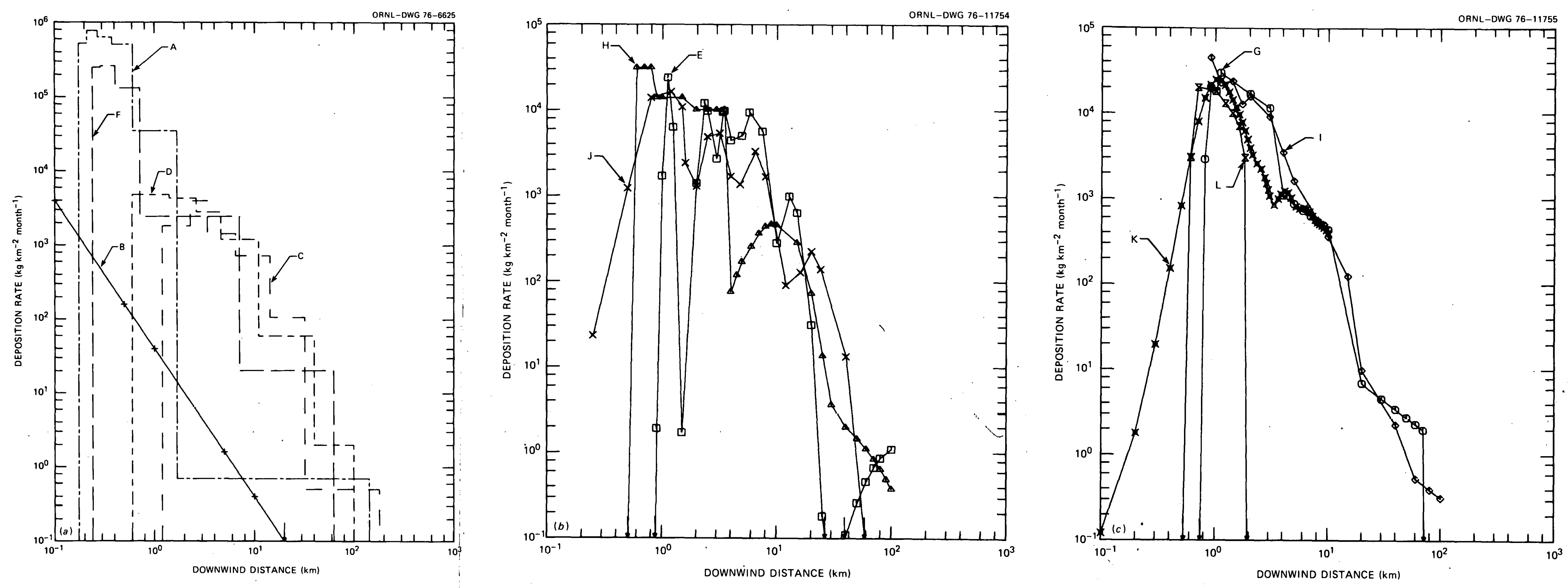

Fig. 26. Model comparison using the input parameters shown in
Table 4. The predicted deposition rate is plotted against the downwind

distance. (a) Models A, B, C, D, and F; (b) Models E, H, and J; (c) Models $G, I, K$, and L. 
The curves in Fig. 26 (a), (b), (c) group into three categories, depending on the assumptions involved in the models: (1) histograms with six steps corresponding to six classes of droplet size (ground deposition is assumed to be uniform over the particle size range); (2) curves representing the superposition of six isolated bell-shaped Gaussian curves (turbulent mixing is assumed to cause overlapping of ground deposition by different particle-size classes and, hence, smearing of the interface); and (3) curves resulting from a combination of the above two methods - the ballistic method for large droplets and the Gaussian model for small droplets. For some models in which the ballistic method without dispersion is applied, the steplike deposition is smoothed by increasing the number of dropletsize groups. In the near field (for example, at about $1 \mathrm{~km}$ ), comparison of the models (with the extreme cases A and B excluded) (Table 5) shows disagreements of up to two orders of magnitude in the predicted deposition rates and a wide range in peak locations. Some of this variation can be attributed to differing assumptions about the effective height of particle emission and/or about the extent of droplet evaporation. Even though the deposition rates fall off rapidly with increasing distance from the tower, the variation in predictions in the far field (for example, at about 100 $\mathrm{km}$ ) shows little improvement. Some of the methods use Pasquill-Gifford $\sigma$ curves to determine the deposition rate in the far field. These results should be viewed cautiously because the $\sigma$ values have been extended to distances greater than those for which they were derived.

One of the essential questions in evaluating a model is whether the salt mass is conserved. For the parameters provided, the total mass emission of $\mathrm{NaCl}$ from the tower is $22 \mathrm{~g} / \mathrm{sec}$. By integrating the sector-averaged deposition rate $\left(\mathrm{kg} \mathrm{km}^{-2}\right.$ month $\left.{ }^{-1}\right)$, it is found that the total salt deposition predicted by models using the ballistic method equals approximately the amount emitted (see Table 5). However, the total salt deposition predicted by models using the Gaussian method is about twice the amount emitted.

More detailed results are given in Figs. 27 through 36 on the maximum deposition, its location, and the extent of the distribution predicted by ten of the models. 
Table 5. Summary of model-predicted maximum deposition rate and ratio of salt deposited to that emitted (with two extremes, cases A and B excluded)

\begin{tabular}{|c|c|c|c|c|}
\hline & Mode1 & $\begin{array}{c}\text { Maximum } \\
\text { deposition rate } \\
\left(\mathrm{kg} \mathrm{km} \text { month }^{-1}\right)\end{array}$ & $\begin{array}{l}\text { Location from } \\
\text { source } \\
(\mathrm{km})\end{array}$ & $\begin{array}{l}\text { Ratio of salt deposited } \\
(\mathrm{g} / \mathrm{sec}) \text { to salt emitted } \\
(\mathrm{g} / \mathrm{sec})^{a}\end{array}$ \\
\hline $\mathrm{C}$ & (Fig. 27) & 4,000 & $2.3-3.4$ & 1.03 \\
\hline $\mathrm{D}$ & (Fig. 28) & 4,800 & $0.6-1.4$ & 1.02 \\
\hline $\mathrm{E}$ & (Fig. 29) & 24,000 & 1.1 & 1.88 \\
\hline $\mathrm{F}$ & (Fig. 30) & 260,000 & $0.29-0.41$ & 0.95 \\
\hline G & (Fig. 31) & 29,400 & 1.1 & 0.87 \\
\hline $\mathrm{H}$ & (Fig. 32) & 31,000 & $0.6-0.8$ & 0.91 \\
\hline I & (Fig. 33) & 44,000 & 0.9 & 0.95 \\
\hline $\mathrm{J}$ & (Fig. 34) & 16,400 & 1.2 & 1.16 \\
\hline $\mathrm{K}$ & (Fig. 35) & 24,500 & 1.0 & 0.41 \\
\hline & (Fig. 36) & 20,000 & 0.7 & 0.11 \\
\hline
\end{tabular}

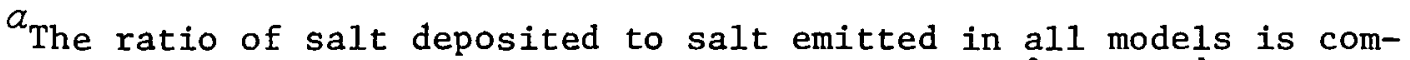
puted by integrating the averaged deposition ( $\mathrm{kg} \mathrm{km}^{-2}$ month-1) over a $22.5^{\circ}$-wide sector from 0.1 to $100 \mathrm{~km}$ away from the tower. The integration interval for model $\mathrm{K}$ is from 0.1 to $10 \mathrm{~km}$, and for model $\mathrm{L}$ is from 0.5 to $2 \mathrm{~km}$.

Figure 27 (Model C) presents results obtained from a model that uses the ballistic method and that gives that method's characteristic histogram. Six step boundaries sharply define the distances traveled by the largest and smallest droplets in the particle size ranges. No turbulence effect is included. The maximum predicted deposition rate is about $4000 \mathrm{~kg} \mathrm{~km}^{-2}$ month $\mathrm{h}^{-1}$ between 2.3 and $3.4 \mathrm{~km}$. The droplets are assumed to evaporate to a saturated solution at $70 \%$ relative humidity.

Figure 28 (Model D) shows a similar result by a model that uses the same method. The predicted deposition rate, with the maximum of $4800 \mathrm{~kg}$ $\mathrm{km}^{-2}$ month ${ }^{-1}$ between 0.6 and $1.4 \mathrm{~km}$, varies by less than a factor of 4 between 0.6 and $11 \mathrm{~km}$ from the tower. All but the 500- and 600- $\mu \mathrm{m}$ drops were predicted to evaporate before striking the ground. 


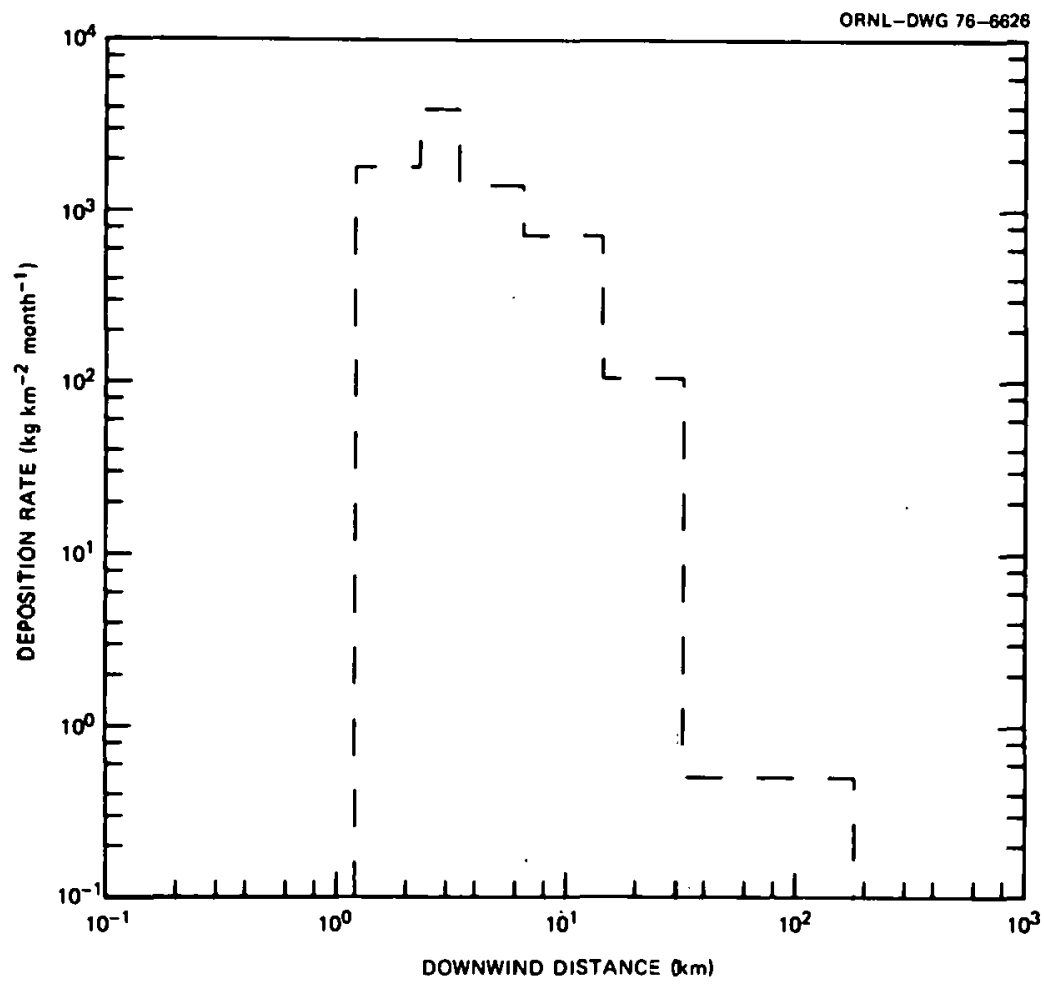

Fig. 27. Deposition histogram predicted by Model C, a ballistic model.

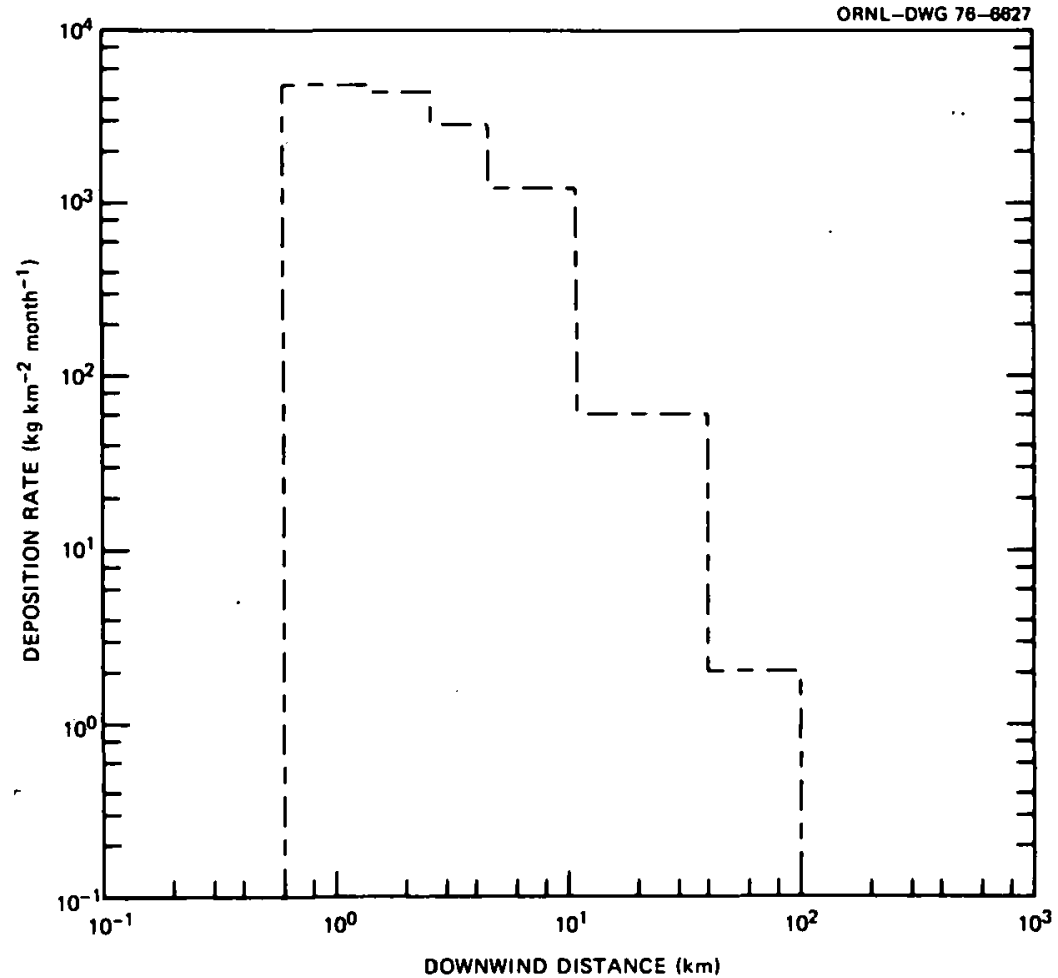

Fig. 28. Deposition histogram predicted by Model D, a ballistic model (different from the model in Fig. 27). 

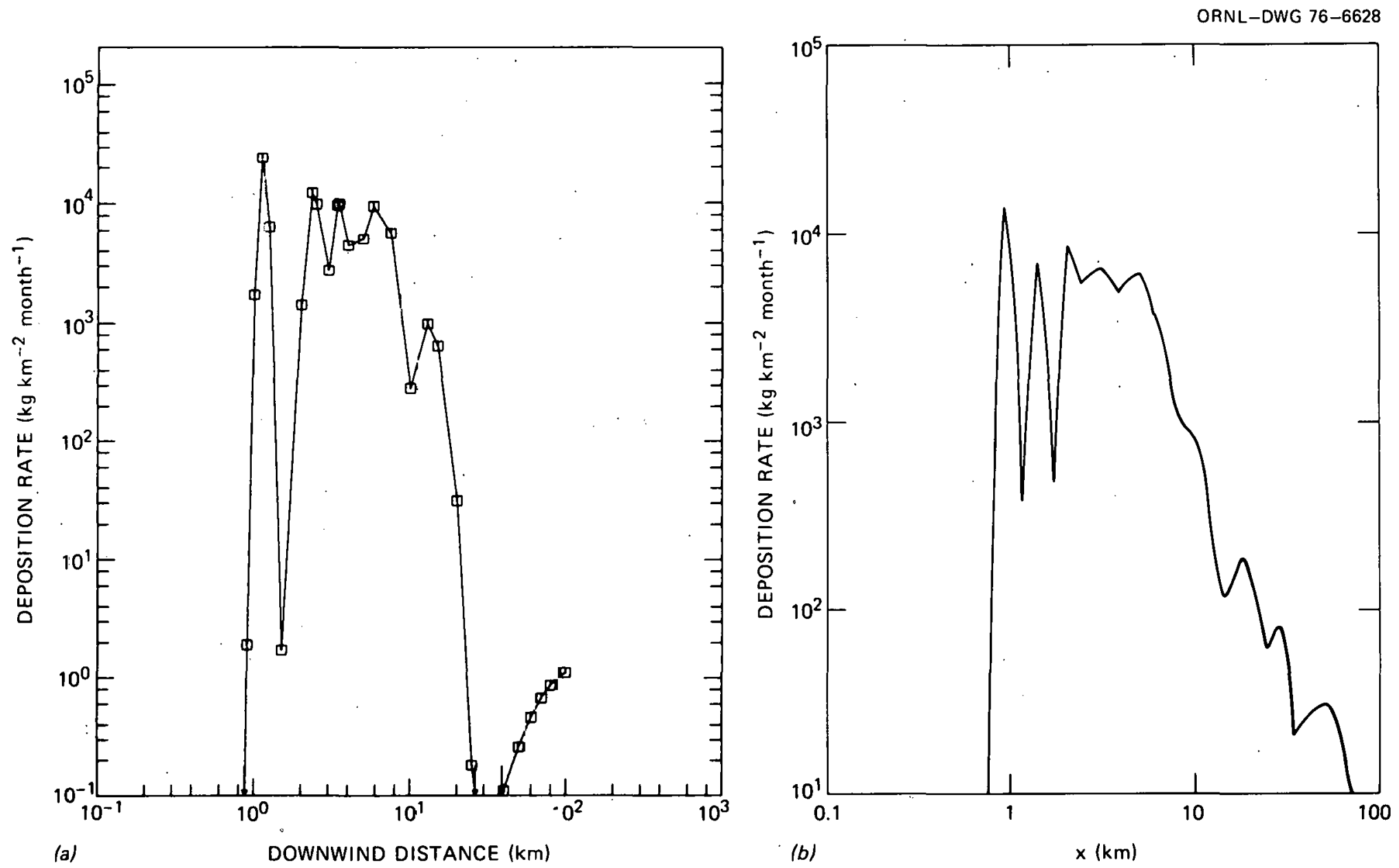

Fig. 29. Deposition predicted by Model E, a modified Gaussian diffusion madel. Note that the scales in $a$ and $b$ are different. 


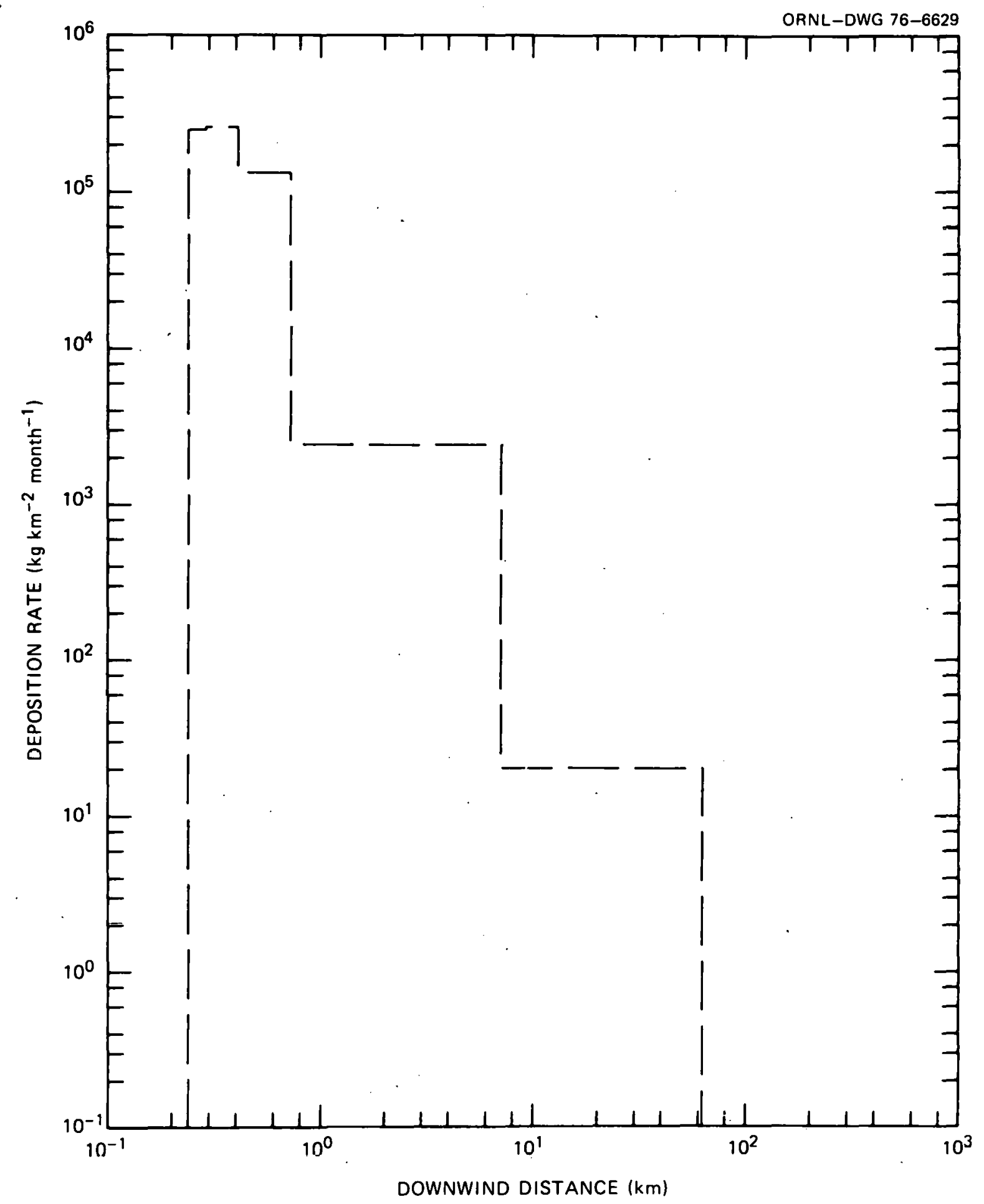

Fig. 30. Deposition histogram predicted by Model F, a ballistic model. 


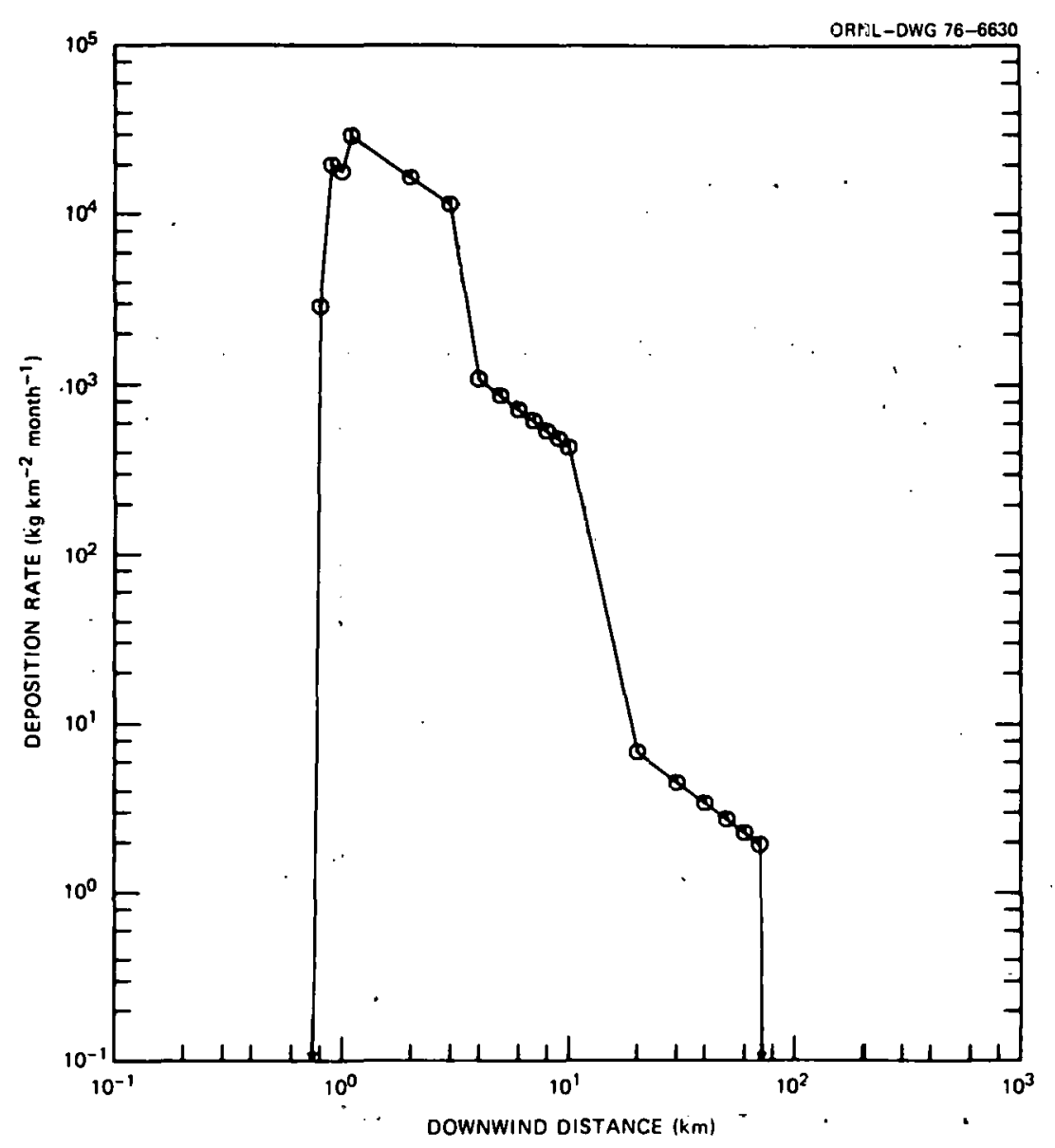

Fig. 31. Deposition predicted by Model G, a ballistic model.

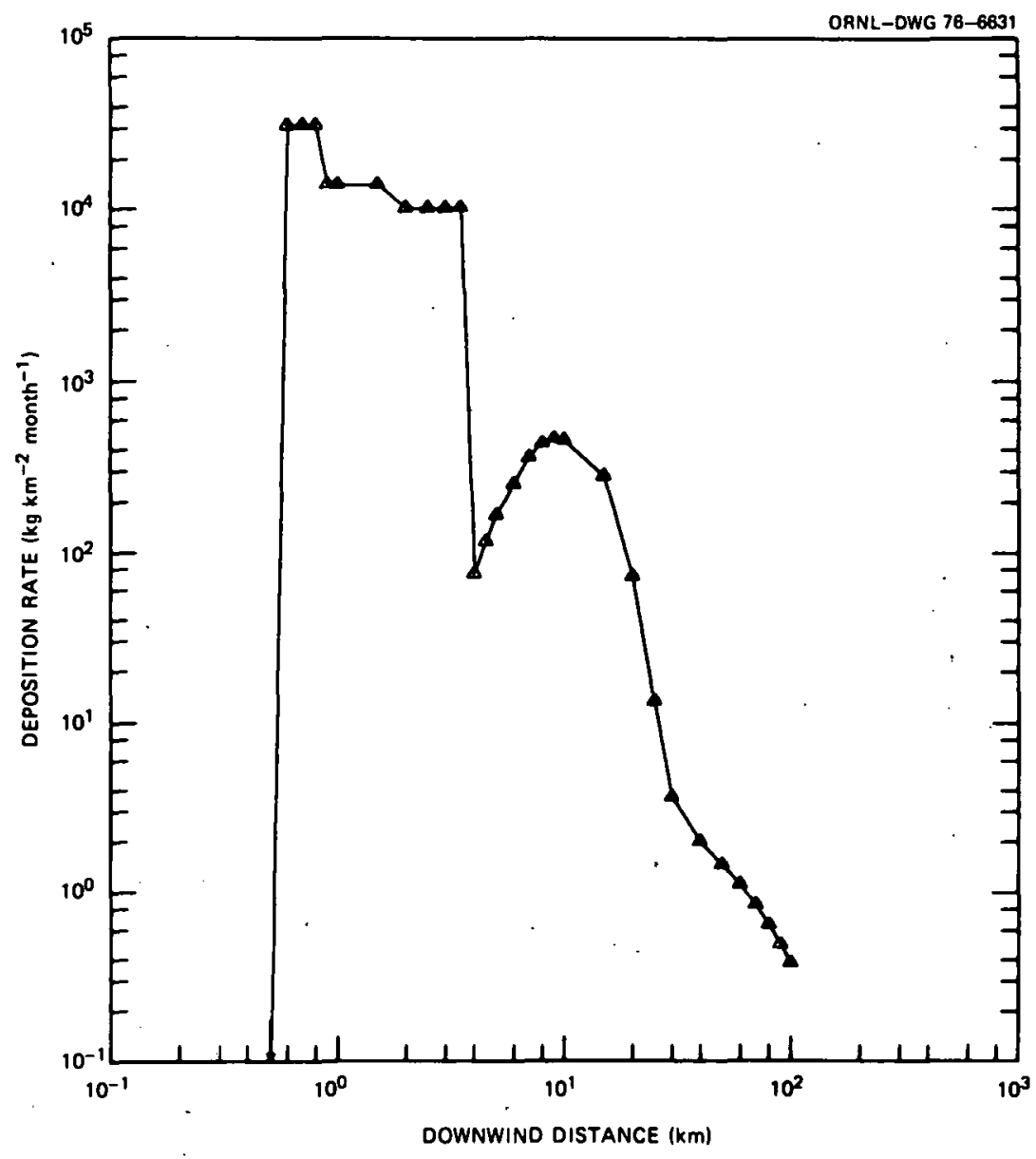

Fig. 32. Deposition predicted by Model H, a ballistic-Gaussian model. 


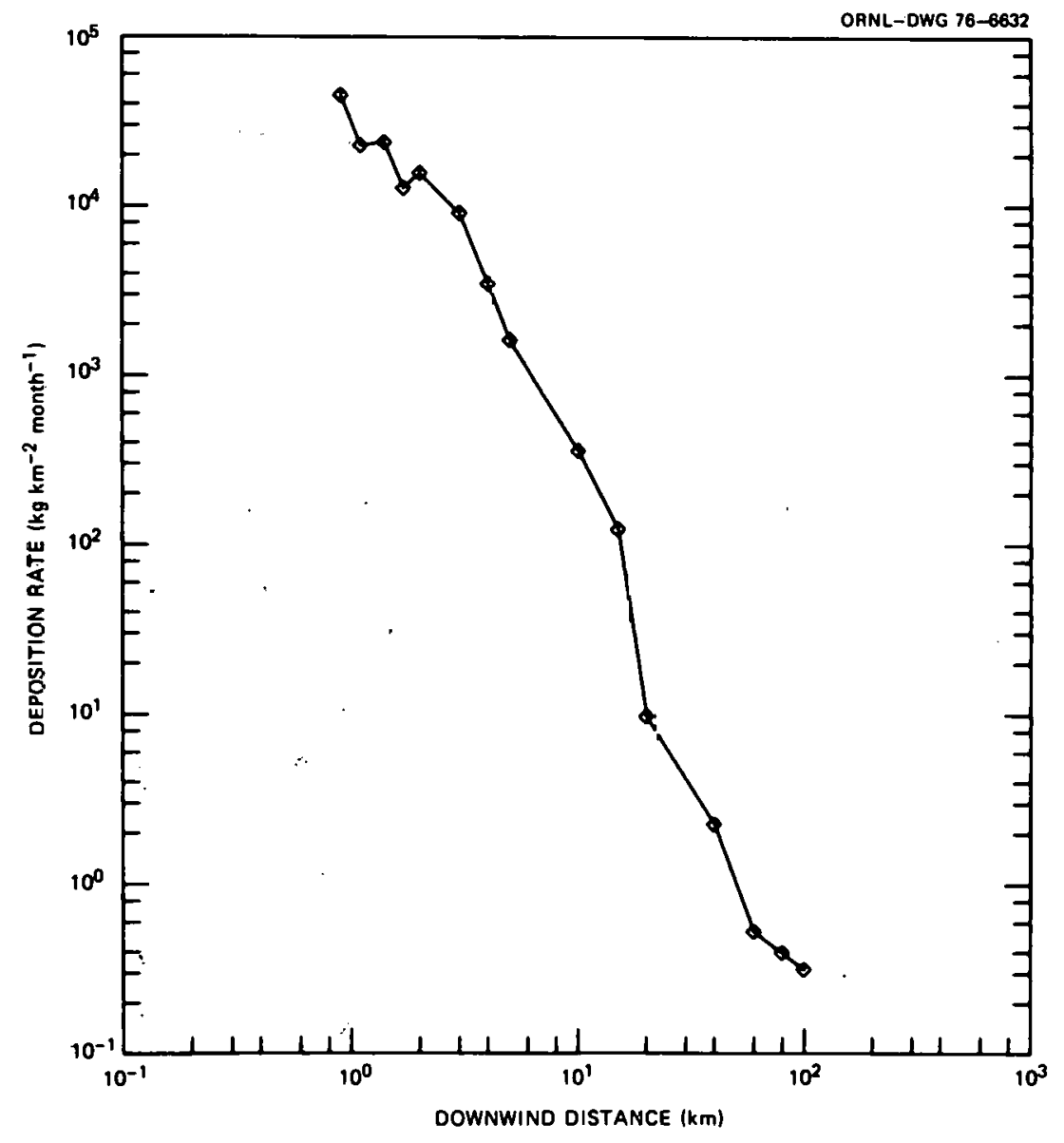

Fig. 33. Deposition predicted by ORFAJ, a modified ballistic model.

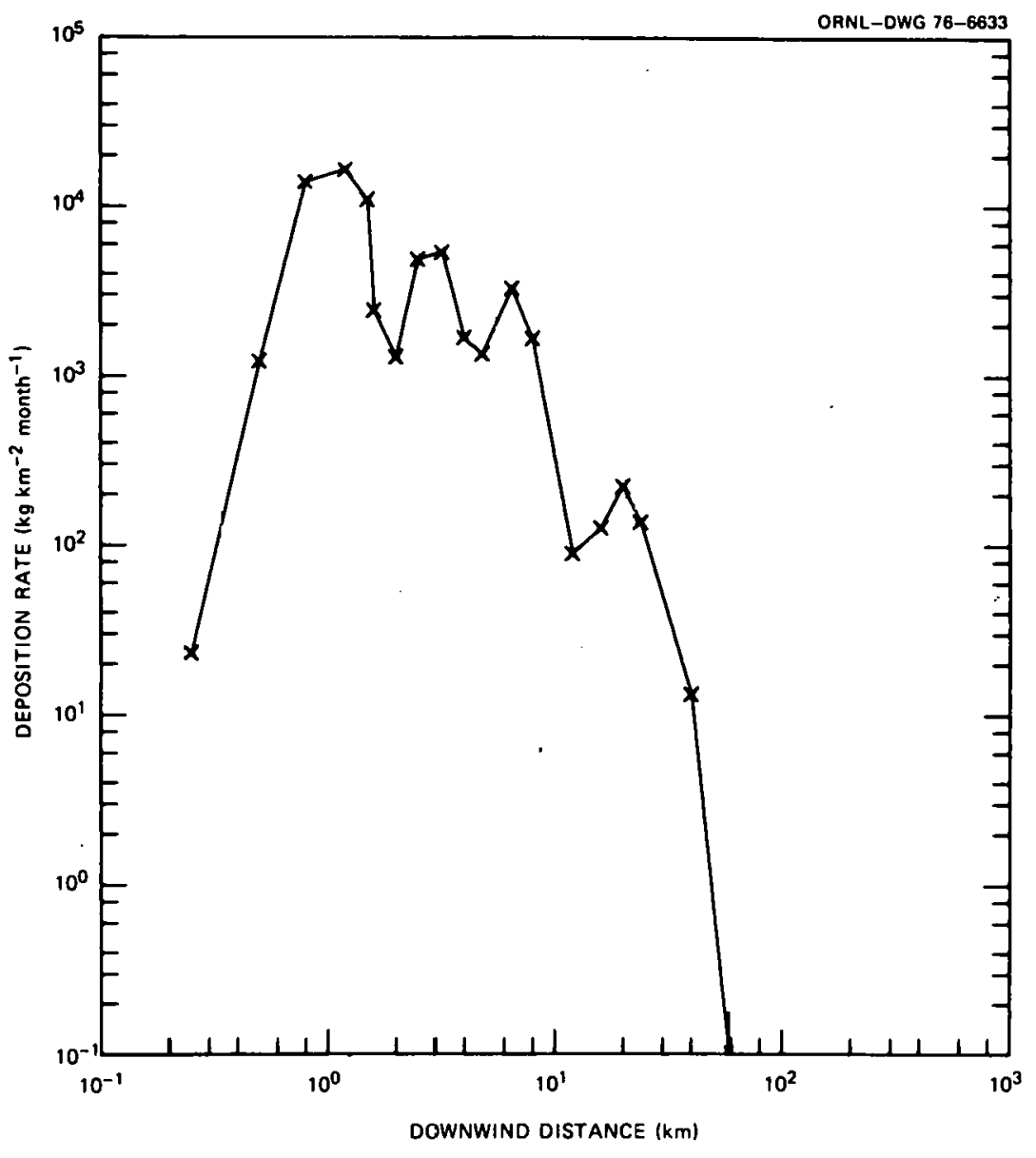

Fig. 34. Deposition predicted by Model J, a ballistic-Gaussian model. 


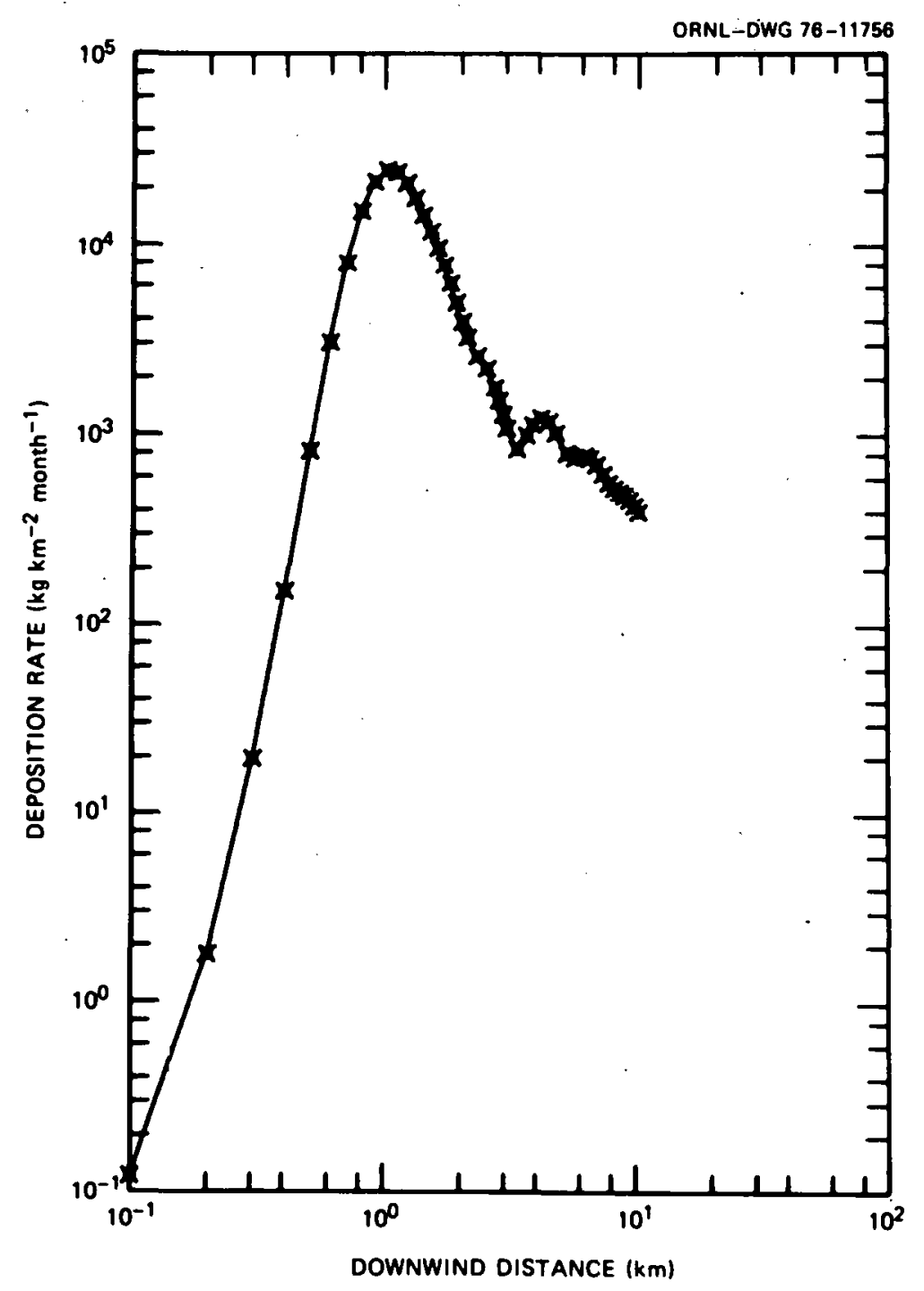

Fig. 35. Deposition predicted by Model $\mathrm{K}$. The method for deposition is not specified.

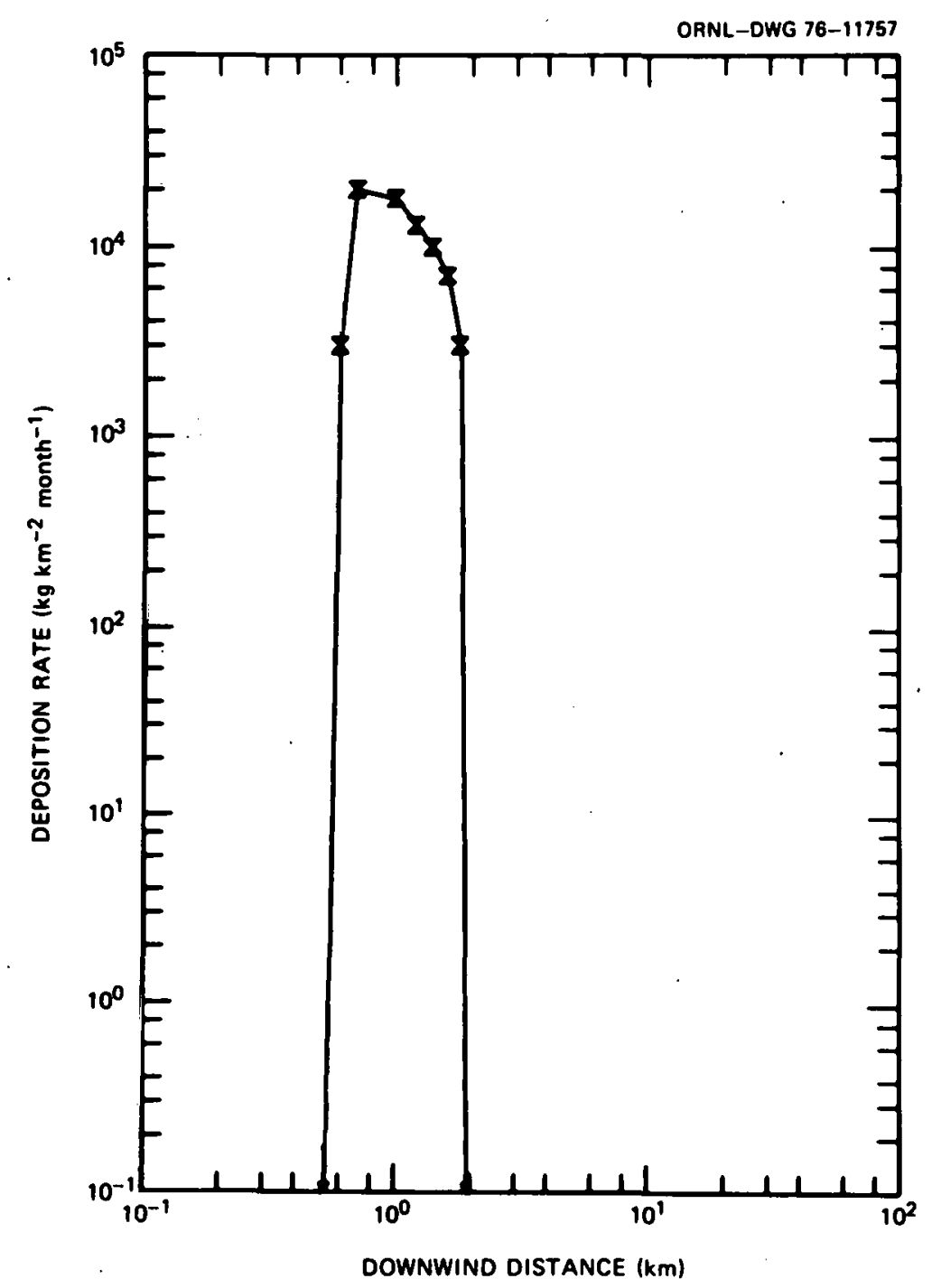

Fig. 36. Deposition predicted by Model L, a ballistic method. Calculation is done for the two largest droplets only. 
Figure 29(a) (Model E) represents results obtained by a model that uses the Gaussian method. A Pasquil1-Gifford class-E turbulent category was chosen as the best representation of the specified isothermal atmosphere. The total deposition is a superposition of six bel1-shaped curves, with the locations of distinguishable peaks being determined largely by the effective height of emission, the fall velocity of each droplet, and the wind speed. The width of each curve, representing the spread caused by turbulence, increases with decreasing droplet size. Note that the largest droplet class is an isolated peak set off by a sizable decrease in the deposition around $1.5 \mathrm{~km}$. Such a gap in the deposition is an obvious physical impossibility and is a peculiarity of this model under stable conditions for droplet-size distributions as the one specified here. The deposition distribution can be improved if the largest droplet size is subdivided further [see Fig. 29(b)]. The maximum deposition rate is about $20,000 \mathrm{~kg} \mathrm{~km}^{-2}$ month ${ }^{-1}$ at $1.1 \mathrm{~km}$.

Figure 30 (Mode1 F) shows another result obtained by a model that uses the ballistic method; these results show a larger deposition rate $(260,000$ $\mathrm{kg} \mathrm{\textrm {km } ^ { - 2 } \text { month }}{ }^{-1}$ ) close to the tower than any other model and a large difference in deposition between steps.

Figure 31 (Model $G$ ) provides the results of a model that uses a modified ballistic method. A peak deposition rate of $29,400 \mathrm{~kg} \mathrm{~km}^{-2}$ month-1 occurs at $1.1 \mathrm{~km}$. No deposition is found within $0.7 \mathrm{~km}$ of the tower or beyond $80 \mathrm{~km}$ from the tower. The normally expected step pattern of deposition is smoothed by a particular sector averaging.

Figure 32 (Model $\mathrm{H}$ ) shows the results of a method that combines (1) the ballistic method for large droplets from $500 \mathrm{~m}$ to $4 \mathrm{~km}$ (with the maximum of $31,000 \mathrm{~kg} \mathrm{~km}^{-2}$ month ${ }^{-1}$ ) with (2) the Gaussian method for small droplets beyond $4 \mathrm{~km}$. The contribution due to downwash is ignored because of the higher initial buoyancy flux imposed in the example.

Figure 33 (Model I), the prediction by ORFAD, shows another example of the ballistic method. The steplike characteristics are smoothed out by increasing the numbers of droplet classes from 6 to 25. The resulting deposition rate drops rapidly (more like a power law, $x^{-2} \cdot{ }^{7}$ ) from its maximum of $44,000 \mathrm{~kg} \mathrm{~km}^{-2}$ month${ }^{-1}$ at $0.9 \mathrm{~km}$ to $0.32 \mathrm{~kg} \mathrm{~km}^{-2}$ month${ }^{-1}$ at $100 \mathrm{~km}$. The ORFAD predictions are found to agree roughly with the values predicted by other models beyond $1 \mathrm{~km}$ for this particular meteorological condition. 
Figure 34 (Model J) presents another example of a combined method. Its results differ somewhat from the features shown in Fig. 32 obtained from a similar (combined) method. The maximum deposition rate in Fig. 34 is 16,400 $\mathrm{kg} \mathrm{km}{ }^{-2}$ month ${ }^{-1}$ at $1.2 \mathrm{~km}$, and there is a finite deposition rate of $20 \mathrm{~kg}$ $\mathrm{km}^{-2}$ month ${ }^{-1}$ at $0.25 \mathrm{~km}$. (Fig. 32 indicates there is no deposition within the first $500 \mathrm{~m}$. )

The data in Fig. 35 were derived from Model $\mathrm{K}$; the theory of this model was not divulged to the author. Because of the shape of the curve and because the amount of salt deposited is only $41 \%$ of that emitted, it is speculated that a modified Gaussian model has been employed with deposition calculations beyond $10 \mathrm{~km}$ discontinued. The maximum deposition rate is about $24,500 \mathrm{~kg} \mathrm{~km}^{-2}$ month ${ }^{-1}$ and is located $1 . \mathrm{km}$ downwind.

The last model for which data are predicted [see Fig. 36 (Model L)] uses a modified ballistic method. The maximum deposition rate is $20,000 \mathrm{~kg}$ $\mathrm{km}^{-2}$ month ${ }^{-1}$ at $0.7 \mathrm{~km}$. The ratio of salt deposited to that emitted is 0.11. Although the calculations of the model are limited to the two heaviest regimes of droplet size (which consist of only about $10 \%$ of the total mass emitted), the magnitude and location of the predicted maximum deposition is within a factor of 2 of the maximum depositions predicted by models $\mathrm{H}, \mathrm{I}, \mathrm{J}$, and $\mathrm{K}$. 


\section{GENERAL SUGGESTIONS TO IMPROVE MODELLING OF DEPOSITION}

A number of processes, effects, and variables were identified in the course of this study that may contribute to deposition from cooling-tower plumes but which are not taken into consideration by any of the current models. A few of these are discussed in some detail in the following sections.

\subsection{Effects of the Centrifugal Force}

Bifurcation of plumes is most often observed on windy days with high relative humidity, not only in stack plumes [(Figs. 37(a) and (b)] but also in plumes from cooling towers. Bifurcation has been observed from plumes of mechanical-draft towers showing vigorous, entangled vortex-induced motion. ${ }^{58}$ Bifurcation is also associated with natural-draft cooling towers although there it is usually comprised of relatively weak, tip-induced vortices at the edge of the tower mouth. Figure $37(\mathrm{c})$, from Meyer, ${ }^{59}$ shows a bifurcated moist plume from a natural-draft cooling tower on a winter morning. Only a light ( 2 to $3 \mathrm{~m} / \mathrm{sec}$ ) southeasterly wind was detected, and the bifurcation was probably caused by a nocturnal temperature inversion that was present.

Observation of such bifurcated plumes indicates that a vortex air motion is present that produces a centrifugal force that might have some significance in removing droplets and in determining the ground deposition rate and its pattern. For instance, the centrifugal force might cause droplets to be thrown out normal to the axis of the plume and enhance the lateral spread of the ground deposition. Field data are needed to verify this prediction. The tower diameter plays an important role not only in determining the effluent velocity, the level of turbulence induced, and the subsequent rate of mixing by entrainment but also in determining the centrifugal force if the plume is bifurcated.

Table 6 shows ratios of centrifugal and gravitational forces for bifurcated plumes from typical cooling towers and smokestacks. The ratio of centrifugal to gravitational forces increases proportionally to the square of the angular speed and is inversely proportional to the diameter 


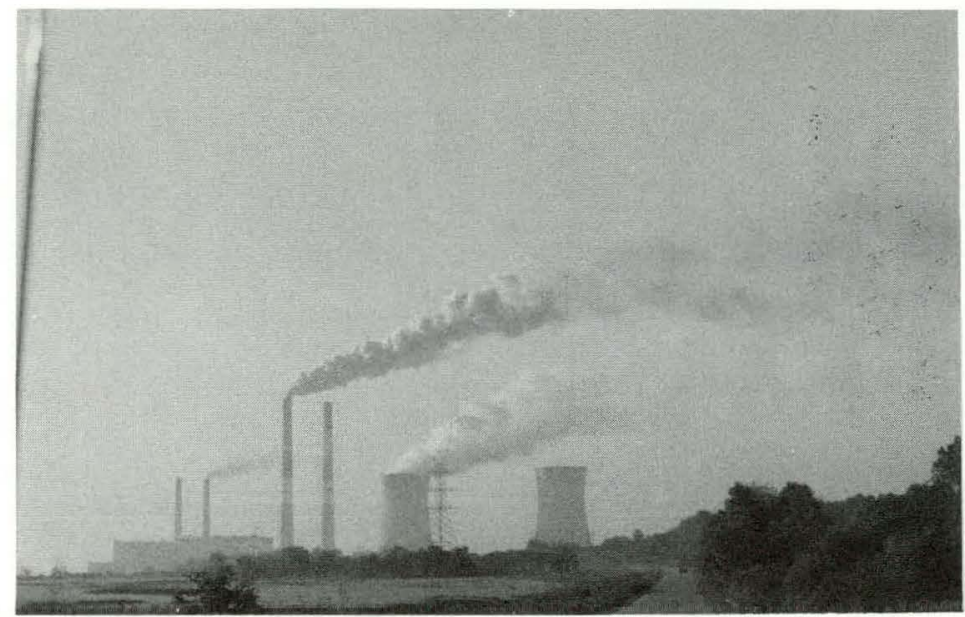

(a)

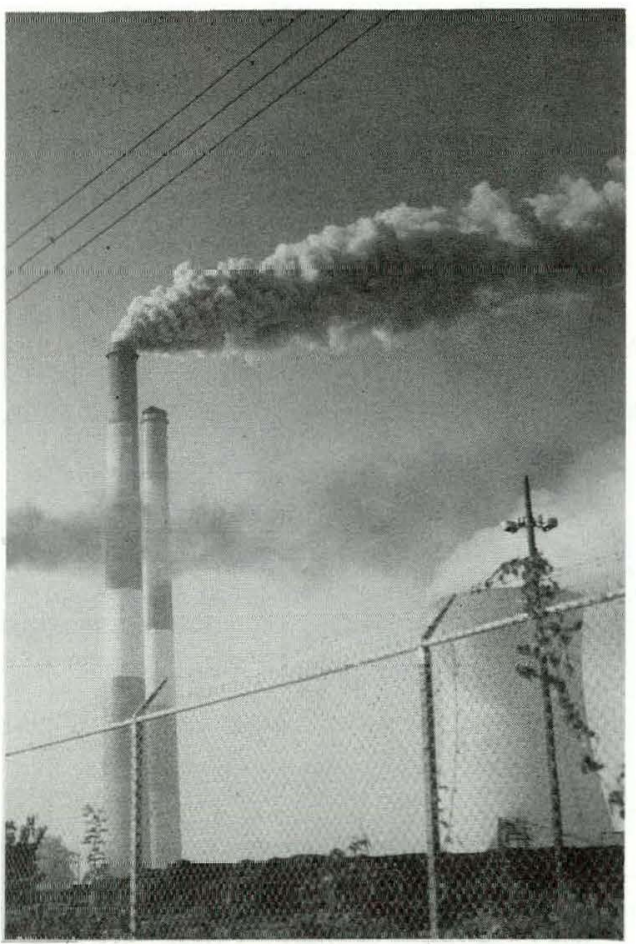

(b)

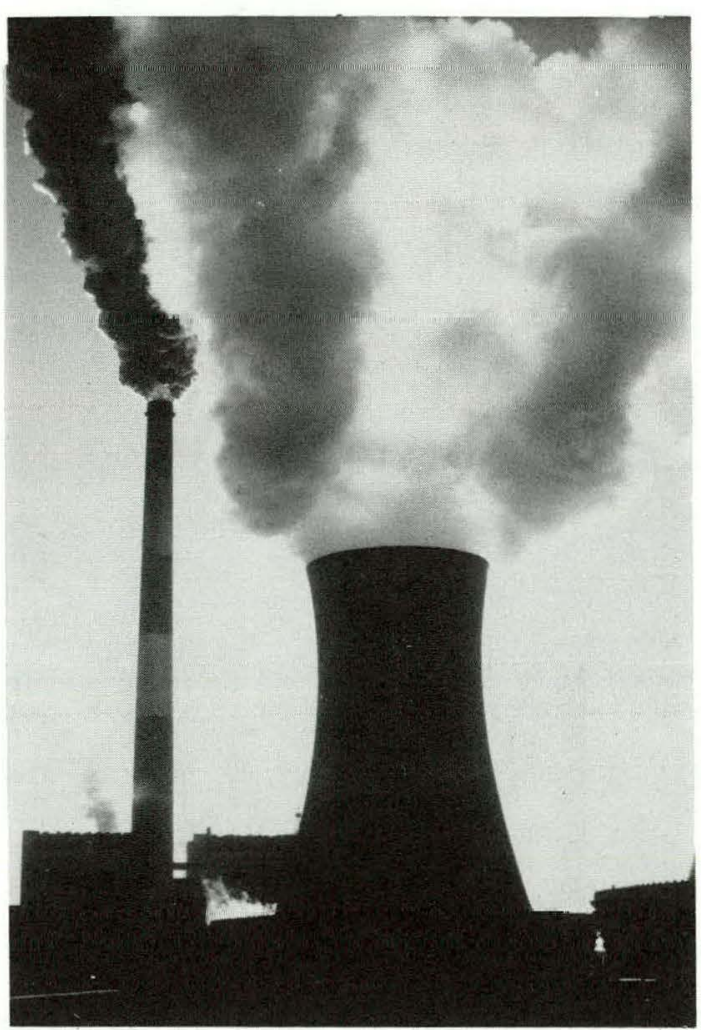

(c)

Fig. 37. Pictures taken by J. Meyer of Applied Physics Laboratory showing bifurcated plumes from a smokestack and a natural-draft cooling tower. (a) A smokeplume and a cooling-tower plume at Chalk Point, Md., are seen to be bifurcated at a crosswind. (b) Closeup of the same smokestack plume. (c) A bifurcated cooling-tower plume at Chalk Point illuminated from behind on a morning with light winds of 2 to $3 \mathrm{~m} / \mathrm{sec}$ out of the southeast. There was a nocturnal temperature inversion, $-5^{\circ} \mathrm{C}$ at the surface warming to $1.7^{\circ} \mathrm{C}$ at 214 meters. The tower heat load at this time was only about half its operating capacity. 
Table 6. Ratios of centrifugal and gravitational forces in bifurcated plumes from cooling towers and smokestacks

\begin{tabular}{lccc}
\hline & $\begin{array}{c}\text { Natural-draft } \\
\text { cooling tower }\end{array}$ & $\begin{array}{c}\text { Mechanical-draft } \\
\text { cooling tower }\end{array}$ & Smokestacks \\
\hline $\mathrm{D}, \mathrm{m}$ & 60 & 10 & 6 \\
$\mathrm{R}_{\mathrm{v}}=\mathrm{D} / 4$ & 15 & 2.5 & 1.5 \\
$\mathrm{w}_{0}, \mathrm{~m} / \mathrm{sec}$ & 5 & 10 & 15 \\
$\mathrm{v}_{\mathrm{t}}^{2} / \mathrm{R}_{\mathrm{v}}$ & & & \\
$\mathrm{g} \cdot$ & & 0.26 & 0.96 \\
$\mathrm{v}_{\mathrm{t}}=\mathrm{w}_{0} / 4$ & 0.011 & 1.04 & 3.84 \\
$\mathrm{v}_{\mathrm{t}}=\mathrm{w}_{0} / 2$ & 0.044 & 4.16 & 15.36 \\
$\mathrm{v}_{\mathrm{t}}=\mathrm{w}_{0}$ & 0.176 & & \\
\hline
\end{tabular}

of the tower. The ratio increases rapidly with angular speed if the vortex angular speed is comparable to the effluent speed. Furthermore, under high-wind conditions, pressure-induced vortex motions (eddy currents) with smaller radii and higher angular speeds are induced in the wake region. The centrifugal force in these currents may very well be dominant and enhance the deposition close to the tower. More theoretical studies of bifurcated plumes and measurements of angular speeds in cooling tower vortices may uncover a significant, additional influence on drift deposition.

\subsection{Multiple Plumes}

There are usually several cooling towers at any site. If mechanicaldraft cooling towers are used, there can be several tower units, each containing 10 or 20 individual cells. Natural-draft cooling towers are grouped together also; three or four such towers are in use, for example, at Paradise, Ky.; at Keystone, Pa.; at the Bowen plant in Georgia; and at the John E. Amos plant in West Virginia. It is important to know how plumes from these multiple sources interact. On the one hand, the merged plume may enhance plume rise and reduce the drift deposition, but on the other hand it might increase the chance of cloud and rainstorm generation. 
Unfortunately, there are no adequate observations of the interaction among cooling-tower plumes. The only method available for estimating the enhancement of plume rise by multiple sources is based on a few observations at TVA smoke stacks. Briggs ${ }^{60}$ suggests that the plume rise from $N$ stacks equals the plume rise from a single stack $H$ multiplied by an enhancement factor $\mathrm{E}_{\mathrm{N}}$ defined by:

$$
E_{N}=[(N+S) /(1+S)]^{1 / 3} \text {, }
$$

where

$$
\mathrm{S}=6\left[(\mathrm{~N}-1) \mathrm{s} / \mathrm{N}^{1 / 3} \mathrm{H}\right]^{3 / 2}
$$

The distance $s$ is the center-to-center spacing between towers. This formula is empirical but has reasonable asymptotes for both large spacing $\left(E_{N}=1\right.$, no enhancement) and very close spacing $\left(E_{N}=N^{1 / 3}\right)$.

Observation programs at multiple cooling towers are needed to verify Eq. (22).

\subsection{Downwash}

Downwash from mechanical-draft towers is a severe problem due to the towers' low height and large cross-sectional area: Hanna ${ }^{37}$ found that downwash occurs if the wind speed exceeds two-third of the efflux speed and observed that downwash (the plume reaching the ground) occurs about $40 \%$ of the time at the mechanical-draft towers in Oak Ridge. However, if the plume is very buoyant, that is if the initial Froude number $F r_{0}=w_{0}^{2} /$ $\mathrm{g}(\Delta \mathrm{T} / \mathrm{T}) \mathrm{D}$ is 1 or less, the buoyant forces are sufficient to balance some of the adverse pressure force. Overcamp and Hoult ${ }^{57}$ carried out laboratory simulations and suggest that the critical value of $\mathrm{w}_{0} / \mathrm{u}$ decreases to 0.5 at $\mathrm{Fr}_{0}=0.25$ and to 0.2 at $F r_{0}=0.01$. The efflux Froude number for cooling towers and smoke stacks is shown in Table 7.

At natural-draft towers, the plume seldom reaches the ground during downwash conditions because of the towers' height and smooth aerodynamic shape. Moore ${ }^{61}$ quotes observations at a tower in England where the plume contacted the ground no more than two or three times a year. At some 
Table 7. Efflux Froude numbers for cooling tower's and smokestacks

\begin{tabular}{|c|c|c|c|c|}
\hline & D (m) & $w_{0}(\mathrm{~m} / \mathrm{sec})$ & $\Delta \mathrm{T}^{a}\left({ }^{\circ} \mathrm{K}\right)$ & $\mathrm{Fr}_{0}^{b}$ \\
\hline $\begin{array}{l}\text { Natural-draft cooling } \\
\text { tower }\end{array}$ & 60 & 5 & 20 & 0.62 \\
\hline $\begin{array}{l}\text { Mechanical-draft } \\
\text { cooling tower }\end{array}$ & 10 & 10 & 6 & 50 \\
\hline Smokestack $^{C}$ & 8 & 15 & 92 & 9 \\
\hline
\end{tabular}

natural-draft towers in the United States, the plume has never been observed to reach the ground. During high winds, some downwash is observed (Slawson, Coleman, and Frey ${ }^{62}$ and Bough $^{63}$ ) at the mouth of a tower, but the major effect of the downwash is to lower the plume centerline. Correction factors are introduced into some of the plume-rise equations to account for the slight downwash and should be included in any future model.

\section{4 'lerrain Effects}

Very little is known about the effects of terrain on cooling-tower plumes and drift deposition. The diffusion of the plume after attaining final rise will be increased by the mechanical mixing generated by rough terrain. This increase will be greater than would be expected from measures of stability, such as the Pasquill-Gifford classes. One (indirect) effect is that the terrain can channel the winds ${ }^{64}$ and thus influence the direction of the plume. If the terrain discontinuity is close enough to the cooling towers (less than about ten tower heights), vertical motions induced by the terrain can influence plume rise. For example, observers at the Indiana, $\mathrm{Pa}$. , towers report that the plume dips toward the ground when the wind blows over a hill upwind of the towers. Furthermore, the plume may contact the side of a hill during stable conditions and cause local fogging and local maximum deposition. Since most terrain is sitespecific and cannot be represented in a general way, it is recoumended that 
terrain effects be studied for each particular site using a physical modeling facility (wind tunnel or water flume). A general discussion of terrain effects is given by Egan in Ref. 65. 


\section{SUMMARY AND RECOMMENDATIONS}

The major characteristics of the ten drift deposition models surveyed are reviewed and summarized in Table 8 . Most of the models use the stackplume-rise formulas derived by Briggs. Whether Brigg's formulas can be appropriately applied to cooling tower plumes has never been satisfactorily proven and requires further experimental verification. In some models, it is assumed that the droplets escape from the plume at a height where the droplet's fall velocity exceeds the updraft. Various updrafts have been assumed, but again this variable needs investigation.

As an interim guideline, the plume centerline vertical velocity derived from the 2/3 law of plume rise derived by Briggs is recommended; also, the effective height of emission used by Israel and Overcamp is recommended. That would bound the effective height of emission by the cooling tower height for the larger droplets and by the maximum plume rise for the smaller droplets. Further, Hosler, Pena, and Pena's method for calculating the rate of droplet evaporation as functions of droplet size, salinity, and ambient relative humidity is recommended. In the absence of adequate verification, the combined ballistic/Gaussian method for deposition calculation is recommended on the basis of physical reasonableness. The ballistic method is more proper for describing the behavior in the rising plume of those droplets that are not affected by turbulence (diam $>100 \mu \mathrm{m})$. The application of the Gaussian model in the rising plume should be limited; it is more appropriate for small droplets in the passive p1ume (diam < $1 \cap n \mathrm{~lm}$ ) that. are, influenced hy turhulence.

The main findings in this study are that the discrepancy in predicted maximum deposition differs by almost two orders of magnitude (from 4000 to $260,000 \mathrm{~kg} \mathrm{~km}^{-2}$ month$^{-1}$, excluding two extreme cases) and by an order of magnitude in the downwind location of peak deposition (from 0.2 to $3 \mathrm{~km}$ ). Some of these discrepancies can be attributed to different assumptions about the variation of the plume vertical velocity with height and the droplets' effective height of emission. Whether or not a given droplet reaches an equilibrium size depends on many factors, such as the plume updraft, original droplet size, salt concentration, and ambient relative humidity. In conjunction with these variables, the assumption of the 
Table $\varepsilon$. Summary of model characteristics for ground-deposition-rate prediction ${ }^{a}$

\begin{tabular}{|c|c|c|c|c|c|}
\hline Investigator & Method & $\begin{array}{l}\text { Atmospheric } \\
\text { turbulent } \\
\text { diffusion }\end{array}$ & $\begin{array}{l}\text { Plume } \\
\text { rise } \\
\text { formula }\end{array}$ & Breakaway point & Evaporation \\
\hline $\begin{array}{l}\text { Hosler et al. } \\
\text { May } 1972\end{array}$ & Ballistic & No & $\mathrm{Ns}^{b}$ & $\begin{array}{l}\text { Drop fall velocity } \\
\text { exceeds updraft }\end{array}$ & $\begin{array}{l}\text { Three categories: no } \\
\text { evaporation, saturated } \\
\text { solution, and dry } \\
\text { particles }\end{array}$ \\
\hline $\begin{array}{l}\text { Roffman and Grímble } \\
\text { Jan. } 1973\end{array}$ & K-theory & $\begin{array}{l}\text { Yes, constant } \\
K \text { assumed }\end{array}$ & Brig̈gs & Maximum plume rise & Same as Hosler et al. \\
\hline $\begin{array}{l}\text { W1strom and Ovard } \\
\text { Jan. } 1973\end{array}$ & $\begin{array}{l}\text { Ballistic - large drops; } \\
\text { Gaussian - small drops }\end{array}$ & les, $\mathrm{PG}^{c}$ & $\mathrm{Ns}^{b}$ & Tower top. & Yes \\
\hline $\begin{array}{l}\text { Slinn } \\
\text { March } 1974\end{array}$ & $\begin{array}{l}\text { Ballistic - large drops; } \\
\text { Gaussian - small drops- }\end{array}$ & Yes, $\mathrm{PG}^{c}$ & Briggs & $\begin{array}{l}\text { Tower top - large } \\
\text { drops; } \\
\text { Max. plume rise - } \\
\text { sma1l drops }\end{array}$ & No \\
\hline $\begin{array}{l}\text { Laskowski } \\
\text { March } 1974\end{array}$ & Ballistic-Gaussian & Hes, $\mathrm{PG}^{c}$ & $\begin{array}{l}\text { Briggs or Slawson } \\
\text { and Csanady }\end{array}$ & $\begin{array}{l}\text { Drop fall distance } \\
\text { exceeds plume } \\
\text { radius }\end{array}$ & Yes \\
\hline $\begin{array}{l}\text { Israel and Overcamp } \\
\text { March } 1974\end{array}$ & Gaussian & $\underset{\text { PG }}{\text { Yes, } \text { BNL }^{d} \text { or }}$ & $\begin{array}{l}\text { Briggs or Slaws on } \\
\text { and Csanady }\end{array}$ & $\begin{array}{l}\text { Drop fall velocity } \\
\text { exceeds updraft }\end{array}$ & Same as Hosler et al. \\
\hline $\begin{array}{l}\text { Hanna } \\
\text { March } 1974\end{array}$ & $\begin{array}{l}\text { Ballistic - large drops } \\
\text { Gaussian }- \text {.small drops }\end{array}$ & des, $\mathrm{PG}^{\mathrm{C}}$ & Briggs & $\begin{array}{l}\text { Drop fall distance } \\
\text { exceeds plume } \\
\text { radius }\end{array}$ & Yes \\
\hline $\begin{array}{l}\text { Wolf }{ }^{e} \\
\text { March } 1974\end{array}$ & Ballistic & No & Briggs & $\mathrm{Ns}^{b}$ & Yes \\
\hline $\begin{array}{l}\text { Tsai and Johnson } \\
\text { April } 1974\end{array}$ & Ballistic & $\mathrm{vs}^{b}$ & $\begin{array}{l}\text { Extension of } \\
\text { Morton, Taylor, } \\
\text { and Turner } \\
\text { models } f\end{array}$ & $\begin{array}{l}\text { Fall velocity } \\
\text { exceeds updraft }\end{array}$ & Yes \\
\hline $\begin{array}{l}\text { ORFAD }^{g} \\
\text { Jan. } 1975\end{array}$ & Ballistic & vo & Briggs & $\mathrm{Ns}^{b}$ & Same as Hosler et al. \\
\hline $\begin{array}{l}\text { Rao et al } \\
\text { May } 1975\end{array}$ & Ballistic-Gaussian & res & $\begin{array}{l}\text { Extension of } \\
\text { Morton, Taylor, } \\
\text { and Turner } \\
\text { models } f\end{array}$ & $\mathrm{Ns}^{b}$ & Empirical formula \\
\hline
\end{tabular}

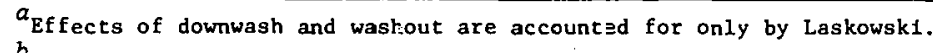

${ }^{b}$ No specification 1 g given ir the model.

cPasquill-Gifford stability class.

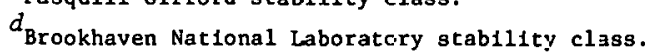

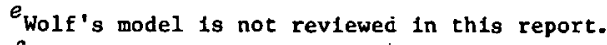

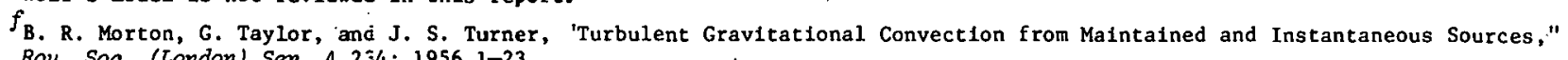
Proc. Roy. Soc. (London) Ser. A 254: 1956 1-23.

goak R1dge Fog and Depositior: model. 
effective height of emission is crucial in determining the impact distances and the deposition rates.

A number of variables and processes were identified as influencing the deposition rate, but little if anything is empirically known about the effects of these. As noted above, the present understanding of droplets' breakaway points is limited. The dispersal of the droplets by the plumeinduced turbulence in the rising plume needs to be considered. Downwash and terrain effects, two very important site-dependent factors, are absent from nearly all of the models. The potential effect of the centrifugal force on deposition from a bifurcated plume should be analyzed. The conservation of the mass of salt emitted should be a major consideration in designing a model of transport and deposition. Finally, the field measurement of droplet-emission-spectrum (both size and mass fraction) should be more accurately determined because all models indicate that the maximum deposition and its location are very sensitive to the mass fraction of larger droplets.

At the present time, given the state of the art, no model can be said to be superior to any other because field data, especially on salt deposition rate, for testing the models are not available. A number of recommendations for the design of research to verify the different deposition models follow. First of all, it must be recognized that there are other sources of deposition besides cooling towers, such as sea-salt spray and nearby smokestacks. Thus, in any research on deposition it is necessary to establish the background and to distinguish between contributions from smokestacks and cooling towers.

Then, simultaneous measurements should be made of the following variables: salt concentration in the tower basin, droplet-size distribution at the tower exit, drift rate, onsite weather conditions, and grounddeposition-rate distribution. Since the amount of salt to be measured is small, the results will be very sensitive to the accuracy and precision of the instruments and methods used. Receptors should be located at suitable intervals (e.g., $500 \mathrm{~m}$ or less) for at least $10 \mathrm{~km}$ in the predominant downwind direction. It is also suggested that more than one receptor (sensor) be placed at each collection station. Because deposition depends 
on, among other things, the distribution of wind vector and humidity, measurements of onsite hourly averaged wind and relative humidity from ground level to the maximum plume rise are necessary.

Because almost all of the models reviewed are of integral, empirical, or phenomenological nature, any sampling period should be longer than the time scale of the plume's meandering. An hourly sampling frequency is reasonable for detailed studies of plume trajectory and its correlation with deposition rates if measurements are obtained only daily. For ecological concerns or environmental-impact assessments, results should include monthly and yearly measurements.

Finally, it is recommended that a time-lapse movie-camera system with high resolution should be used to study the vortex structure of a bifurcated plume, so that the influence of the secondary flow on deposition can be assessed. 


\section{ACKNOWLEDGMENTS}

The preparation of this report was supported by the Energy Research and Development Administration as part of the program on the Atmospheric Effects of Nuclear Energy Centers.

The author is indebted to S. R. Hanna (Atmospheric Turbulence and Diffusion Laboratory, NOAA) and to F. M. O'Hara, Jr. (Oak Ridge National Laboratory) for reviewing the manuscript; J. H. Meyer (Applied Physics Laboratory, The Johns Hopkins University) for photography; L. Jung (Oak Ridge National Laboratory) for calcomp plots; and H. W. Hoffman (Oak Ridge National Laboratory) for constant encouragement.

Contributors to the model comparison (Chapter 3) include the following; their interested participation is appreciated:

M. H. Fuchs (Motor-Columbus Consulting Engineers,. Inc., Switzerland)

S. R. Hanna (Atmospheric Turbulence and Diffusion Laboratory, NOAA)

G. W. Israel (University of Maryland)

S. M. Laskowski (Pickard, Lowe, and Associates, Inc.)

T. J. Overcamp (Clemson University)

J. A. Pena (Pennsylvania State University)

K. S. Rau (Environmental Research and Technology, Inc.)

P. Slawson (University of Waterloo, Canada)

W. G. N. Slinn (Battelle Pacific Northwest Laboratories)

Y. J. Tsai (Stone and Webster Engineering Corp.)

M. A. Wolf (Battelle Pacific Northwest Laboratories) 


\section{REFERENCES}

1. The Chalk Point Cooling Tower Program Steering Group, The Chalk Point Cooling Tower Progrom, Integrated Experimental Design, The Johns Hopkins University, Chalk Point, Md., August 1975.

2. E. Aynsley and J. E. Carson, Environmental Effects of Water Cooling for Power Plants: A Status Report, ANL/ES-20 (Draft, January 1973).

3. A. Roffman et al., State of the Art of Saltwater Cooling Towers for Steam Electric Generating PZants, WASH-1244 (February 1973).

4. The American Society of Mechanical Engineers, Cooling Tower Plume Modeling and Drift Meausrement, A Review of the State-of-the-Art, Research Committee on Atmospheric Emissions and Plume Behavior from Cooling Towers, ASME, New York, 1975. (Original document by G. E. McVehil and K. E. Heikes, issued by Gall Brothers Research Corporation, Boulder, Colo., March 1975.)

5. C. Bosanquet, W. Carey, and F. M. Halton, "Dust Deposition from Chimney Stacks," Proc. Inst. Mech. Eng., London 162: 355-65 (1950).

6. A. C. Chamberlain, Aspects of Travez and Deposition of Aerosol and Vapor Clouds, AERE HT/R-1261 (1955).

7. C. Hosler, J. Pena, and R. Pena, "Determination of Salt Deposition Rates from Drift from Evaporative Cooling Towers," Trans. ASME, Ser. A: J. Eng. Power 96(3): 283 (1974). (Original document issued by Department of Meteorology, Pennsylvania State University, May 1972).

8. J. A. Pena and C. L. Hosler, "Influence of the Choice of the Plume Diffusion Formula on the Salt-Deposition-Rate Calculation," p. 573 in Cooling Tower Environment - 1974, CONF-740302 (1975).

9. J. 2. Holland, A Meteorologiaal Survey of the Oak Ridge Area: Final Report [Covering the Period] 1948-195\%, ORO-99, p. 540 (1953).

10. W. G. N. Slinn, "An Analytical Search for the Stochastic-Dominating Process in the Drift Deposition Problem," p. 483 in Cooling Tower Environment - 1974, CONF-740303 (1975).

11. I. Van der Hoven, "Deposition of Particles and Gases," p. 202 in Meteorology and Atomic Energy - 1968, TID-24190 (1968).

12. A. Roffman and R. E. Grimble, "Predictions of Drift Deposition from Saltwater Cooling Towers," paper presented at the annual meeting of the Cooling Tower Institute, Jan. 29-31, 1973, Houston.

13. A. Roffman and Lowell D. Van Vleck, "The State-of-the-Art of Calculating and Predicting Cooling Tower Drift and Its Deposition," J. Air PolZu. Control Assoc. 24(9): 855-59 (1974).

14. C. Briggs, Plzone Rise, TID-25075 (November 1969).

15. S. R. Hanna, "Rise and Condensation of Large Cooling Tower Plumes," J. App Z. Meteorol. 11(5): 793-99 (1972). 
16. A. Roffman and R. E. Grimble, "Drift Deposition Rates from Wet Cooling Systems," p. 585 in Cooling Tower Environment - 1974, CONF-740302 (1975).

17. F. Pasquill, "Lagrangian Similarity and Vertical Diffusion from a Source at Ground Leve1," Quart. J. Roy. Meteor. Soc., 92, 185-95 (1966).

18 F. Pasquil1, Atmospheric Diffusion, 2d ed., Wiley, New York, 1975.

19. F. Pasquil1, Lectures on Air Pollution and Environmental Impact Analyses, ed. by D. A. Haugen, American Meteorological Society, Boston, 1975.

20. J. Taft, "Numerical Model for Investigation of Moist Buoyant CoolingTower Plumes,' p. 180 in Cooling Tower Environment - 1974, CONF-740302 (1975).

21. G. K. Wistrom and J. C. Ovard, "Cooling Tower Drift; Its Measurements, Control, and Environmental Effects." paper presented at the annual meeting of the Cooling Tower Institute, Jan. 29-31, 1973, Houston.

22. N. H. Fletcher, "The Physics of Rainclouds, Cambridge University Press, Cambridge, 1962.

23. A. H. Woodcock, "Atmospheric Salt Particles and Raindrops," J. Meteorol. 9: 200-12 (1952).

24. S. M. Laskowski, "A Mathematical Transport Model for Salt Distribution from a Saltwater Natural-Draft Cooling Tower," p. 598 in Cooling Tower Environment - 1974, CONF-740302 (1975).

25. P. R. Slawson and G. T. Csanady, "The Effect of Atmospheric Conditions on Plume Rise," J. Fluid Mech. 47(1): 33-44 (1971).

26. R. B. Bird, W. E. Stewart, and E. N. Lightfoot, Transport Phenomena, Wiley, New York, 1960.

27. B. J. Mason, The Physics of Clouds, Clarendon Press, Oxford, 1959.

28. S. M. Laskowski, "A Mathematical Transport Model for Salt Distribution from a Sa1twater Natural-Draft Cooling Tower, Part II," paper presented at the Symposium on Atmospheric Diffusion and Air Pollution, American Meteorological Society, Sept. 9-13, 1974, Santa Barbara, Calif.

29. P. M. Foster, "Droplet Growth Inside and Outside Cooling Towers," Atmos. Environ. 8(4): 393-402 (April 1974).

30. G. W. Israel and T. J. Overcamp, "Drift Deposition Model for NaturalDraft Cooling Towers, p. 614 in Cooling Tower Environment - 1974, CONF-740302 (1975).

31. G. T. Csanady, "Dispersal of Dust Particles from Elevated Sources," Aust. J. Phys. 8: 545-50 (1955).

32. G. T. Csanady, "Deposition of Dust Particles from Industrial Stacks," Aust. J. Appl. Sci. 9: 1-8 (1958).

33. M. E. Smith and I. A. Singer, "An Improved Method of Estimating Concentration and Related Phenomena from a Point Source Emission," J. Appl. Meteorol. 5: 631-69 (1966). 
34. D. B. Turner, "A Diffusion Model for an Urban Area," J. Appl Meteorol. 3, 83-91 (Feb. 1964).

35. T. J. Overcamp and G. W. Israel, "Salt Deposition Calculations for Oak Ridge National Laboratory," October 1975. (An unpublished report available from T. J. Overcamp, Environmental Systems Engineering, Clemson University, Clemson, S.C. 29631.)

36. T. J. Overcamp, "A General Gaussian Diffusion-Deposition Model for Elevated Point Sources," J. Appl. Meteorol. 15(11): 1167-1171 (1976).

37. S. R. Hanna, "Meteorological Effects of the Mechanical-Draft Cooling Towers of the Oak Ridge Gaseous Diffusion Plant," p. 291 in Cooling Tower Environment - 1974, CONF-740302 (1975).

38. G. A. Briggs, Some Recent Analysis of Plume Rise Observations, Atmospheric Turbulence and Diffusion Laboratory Contribution No. 38, Oak Ridge, Tenn. (1970).

39. R. J. Engelmann, "The Calculation of Precipitation Scavenging," p. 208 in Meteorology and Atmoic Energy 1968, ed. by D. Slade, TID-24190 (1968).

40. R. Gunn and G. D. Kinzer, "The Terminal Velocity of Fall for Water Droplets in Stagnant Air," J. Meteorol. 6(4): 243-84 (1969).

41. S. R. Hanna, "Fog and Drift Deposition from Evaporative Cooling Towers," Nucl. Saf. 15(2): 190-96 (1974).

42. Y. J. Tsai and D. H. Johnson, "Cooling Tower Drift Mode1," paper presented at the Fifth Annual Pittsburgh Conference on Modeling and Simulation, April 24-26, 1974, Pittsburgh.

43. L. N. Fan, Turbulent Buoyant Jets into Stratified or Flowing Ambient Fluid, Report KH-R-15, California Institute of Technology, Pasadena, Calif. (1967).

44. G. Abraham, "The Flow of Round Buoyant Jets Issuing Vertically into Ambinet Fluid Flowing in a Horizontal Direction," paper presented at the Fifth International Water Pollution Research Conference, July-August 1970,

45. R. J. List, Smithsonian Meteorological Tables, Smithsonian Institution No. 4014, Washington, D.C., 1966.

46. Y. J. Tsai, private communication.

47. J. M. Dallavalle, Micrometrics, 2nd ed., Pitman, New York, 1948.

48. J. V. Wilson, ORFAD, A Computer Program to Estimate Fog and Drift from Wet Cooling Towers, ORNL/TM-4568 (January 1975).

49. M. E. LaVerne, The Oak Ridge Fog and Drift Code (ORFAD) User's Manual, ORNL/TM-5021, 1977.

50. F. G. Taylor, JR., D. D. Gray, and P. D. Parr, "Interception and Retention of Cooling Tower Drift on Vegetation," TP-15la (January 1976). 
51. P. A. Jallouk, G. J. Kidd, Jr., and T. Shapiro, Environmental Aspects of Cooling Tower Operation: Survey of the Emission, Transport, and Deposition of Drift from the $K-31$ and $K-33$ Cooling Towers at ORGDP, K-1869 (February 1974).

52. K. S. Rao, J. S. Lague, and B. A. Egan, "Cooling Tower Drift Model Description," Appendix B of A Study of Environmental Impacts Associated with Cooling Tower Operation at the Proposed Pleasant Prairie, Wisconsin, Power Plant, ERT/P-1235 (1975).

53. K. S. Rao, J. S. Lague, B. A. Egan, and Y. H. Chu, "A Dynamic Plume Model for the Prediction of Atmospheric Effects Associated with Cooling Tower. Operation," paper presented at the 68 th annual meeting of the Air Pollution Control Association, 1975, Boston.

54. G. A. Briggs, Diffusion Estimation of Small Emissions, Atmospheric Turbulence and Diffusion Laboratory Contribution No. 79, Oak Ridge, Tenn. (1973).

55. D. B. Turner, Workbook of Atmospheric Diffusion Estimates, U.S. Department of Health, Education; and Welfare, Public Health Service, Cincinnati, 1970.

56. J. Halitsky, Gas Diffusion near Buildings in Meteorology and Atomic Energy, TID-24190 (1968).

57. T. J. Overcamp and D. P. Hoult, "Precipitation in the Wake of Cooling Towers," Atmos. Environ. 5: 751-65 (1971).

58. S. R. Hanna, private communication.

59. J. H. Meyer, private communication.

60. G. A. Briggs, "Plume Rise From Multiple Sources," p. 161 in Cooling Tower Environment - 1974, CONF-740302 (1975).

61. D. J. Moore, "Recent Central Electricity Generating Board Research on Environmental Effects of Wet Cooling Towers," p. 205 in Cooling Tower Environment - 1974, CONF-740302 (1975).

62. P. R. Slawson, J. H. Coleman, and J. W. Frey, "Some Observations on Cooling-Tower Plume Behavior at the Paradise Steam Plant," p. 147 in Cooling Tower Environment - 1974, CONF-740302 (1975).

63. P. Bogh, "Experience With Combined Wind Tunnel-Plume Model Analysis of Cooling-Tower Environmental Impact," p. 265 in Cooling Tower Environment - 1974, CONF-740302 (1975).

64. D. H. Slade, Ed., Meteorology and Atomic Energy 1968, TID-24190 (1968).

65. D. A. Haugen, Ed., "Lectures on Air Pollution and Environmental Impact Analyses," American Meteorological Society, Boston, 1975. 
THIS PAGE

\section{WAS INTENTIONALLY LEFT BLANK}


Internal Distribution

ORNL/TM-5357

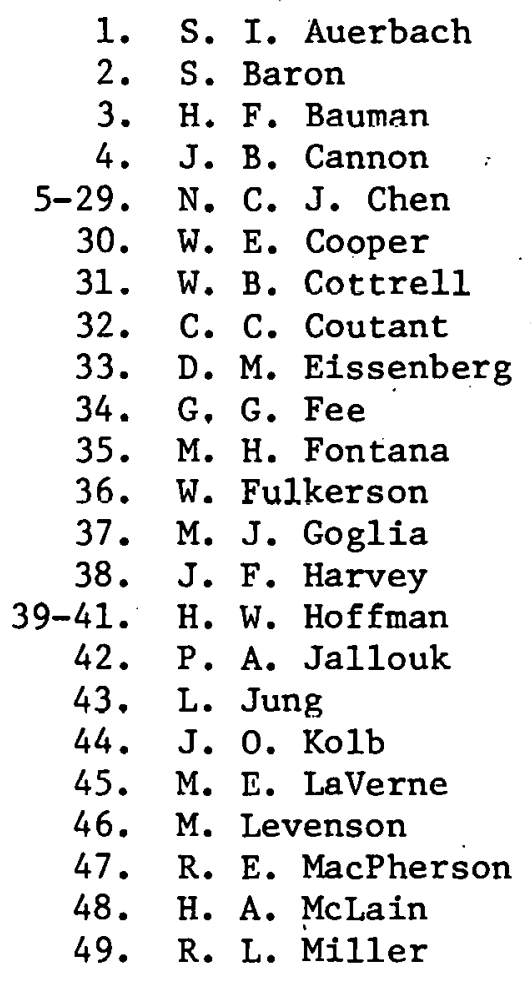

50. F. M. O':Hara, Jr.

51. A. A. N. Patrinos

52. H. Postma

53. R. C. Robertson

54. M. W. Rosenthal

55. T. H. Row

56. R: M. Rush

57. M. R. Sheldon

58. I. Spiewak

59. F. G. Taylor, Jr.

60. D. G. 'lhomas

61. D. B. Trauger

62. G. D. Whitman

63. W. J. Wilcox

64. J. V. Wilson

65. A. J. Witten

66. ORNL Patent Office

67. Central Research Library

68. Document Reference Section

69-70. Laboratory Records Department

71. Laboratory Records (RC)

72. Nuclear. Information Center

73. EISO Library (B1dg. 2028)

\section{External Distribution}

74. R. F. Abbey, Jr., NRC, Office of Nuclear Regulatory Research, Washington, DC 20555

75. D. S. Ballentine, Division of Biomedical and Environmental Research, U.S. Energy Research and Development Administration, Washington, DC 20545

76. P. Bogh, Motor-Columbus, Consulting Engineers, Inc., Baden, Switzerland

77. G. A. Briggs, Atmospheric Turbulence Diffusion Laboratory, P.O. Box E, Oak Ridge, TN 37830

78. J. H. Coleman, Air Quality Branch, Tennessee Valley Authority, River Oaks Building, Muscle Shoals, AL 35660

79. W. R. Cotton, Department of Atmospheric Science, Colorado State University, Fort Collins, CO 80523

80. T. V. Crawford, Savannah River Laboratory, Alken, SC 29801 
81. J. W. Deardorff, National Center for Atmospheric Research, Boulder, CO 80302

82. N. Dingle, Department of Atmospheric and Oceanic Science, University of Michigan, Ann Arbor, MI 48109

83. R. A. Dirks, National Science Foundation, $1800 \mathrm{G}$ Street, NW, Washington, DC 20550

84. R. L. Drake, Battelle Pacific Northwest Laboratorles, Battelle Boulevard, Richland, WA 99352

85. W. E. Dunn, Argonne National Laboratory, 9700 South Cass Avenue, Argonne, IL 60439

86. A. D'zmura, Division of Reactor Research and Development, U.S. Energy Research and Development Administration, Washington, DC 20545

87. B. A. Egan, Environmental Research and Technology, Inc., 696 Virginia Road, Concord, MA 01742

88. C. Elderkin, Battelle Pacific Northwest Laboratories, Battelle Boulevard, Richland, WA 99352

89. J. E. Fairobent, Office of Nuclear Reactor Regulation, U.S. Nuclear Regulatory Commisston, Washington, DC 20555

90. G. Fisher, NUS Corporation, 4 Research Place, Rockville, MD 20850

91. P. M. Foster, Central Electricity Generating Board, Central Electricity Research Laboratories, Leatherhead, Surrey, England KT 22 7SE

92. P. Frenzen, Argonne National Laboratory, 9700 South Cass Avenue, Argonne, IL 60439

93. M. H. Fuchs, Motor-Columbus Consulting Engineers, Inc., Baden, Switzerland

94. A. Gakner, Bureau of Power, Federal Power Commission, Washington, DC 20426

95. F. A. Gifford, Atmospheric Turbulence Diffusion Laboratory, P.O. Box E, Oak Ridge, TN 37830

96. C. H. Goodman, Southern Company Services, Inc., P.0. Box 2625, Birmingham, AL 35202

97. D. D. Gray, School of Civil Engineering, Purdue University, West Lafayette, IN 47907 
98. C. Hakkarinen, Electric Power Research Institute, P.0. Box 10412, Palo Alto, CA 94303

99. S. R. Hanna, Atmospheric Turbulence Diffusion Laboratory, P.O. Box E, Oak Ridge, TN 37830

100. P. Harrison, Meteorology Research, Inc., P.0. Box 637, Altadena, CA 91001

101. B. B. Hicks, Argonne Nattonal Laboratory, 9700 South Cass Avenue, Argonne, IL 60439

102. P. Hobbs, Department of Atmospheric Sciences, University of Washington, Seattle, WA 98195

103. R. P. Hosker, Atmospheric Turbulence Diffusion Laboratory, P.O. Box E, Oak Ridge, TN 37830

104. G. Israel, Department of Meteorology, University of Maryland, College Park, MD 20740

105. A. L. Kistler, Department of Mechanical Engineering and Astronautical Sciences, Northwestern University, Evanston, IL 60201

106. L. R. Koenig, The Rand Corporation, Santa Monica, CA 90406

107: R. Kornasiewicz, Office of Standards Development, U.S. Nuclear Regulatory Commission, Washington, DC 20555

108. M. L. Kramer, Smith-Singer Meteorologists, Inc., 134 Broadway, Amityville, NY 11701

109. S. M. Laskowski, Pickard, Lowe \& Associates, Inc., 1200 18th Street, NW, Suite 612, Washington, DC 20036

110. J. Lee, Department of Meteorology, The Pennsylvania State University, University Park, PA 16802

111. D. Lenschow, National Center for Atmospheric Research, Boulder, CO 80302

112. P. S. Lykoudis, Department of Nuclear Engineering, Purdue University, West Lafayette, IN 47907

113. G. E. McVeh11, P.O. Box 4480, Boulder, Co 80302

114. J. H. Meyer, Applied Physics Laboratory, The Johns Hopkins University, Silver Spring, MD 20900 
115. H. Moses, Biomedical and Environmental Research Division, U.S. Energy Research and Development Administration, Washington, DC 20545

116. F. W. Murray, Rand Corporation, 1700 Main Street, Santa Monica, CA 90406

117. C. J. Nappo, Atmospheric Turbulence Diffusion Laboratory, P.O. Box E, Oak Ridge, TN 37830

118. C. Newton, National Center for Atmospheric Research, Boulder, CO 80302

119. R. S. Nietubicz, Chalk Point Cooling Tower Project, c/o Bureau of Air Quality and Noise Control, O'Conor Bullding, 201 West Preston Street, Baltimore, MD 21201

120. J. M. Norman, Department of Meteorology, The Pennsylvania State University, University Park, PA 16802

121. Y. Onishi, Battelle Pacific Northwest Laboratories, Battelle Boulevard, Richland, WA 99352

122. H. D. Orville, Institute of Atmospheric Sciences, South Dakota School of Mines and Technology, Rapid City, SD 57701

123. T. J. Overcamp, Environmental Systems Engineering, Clemson University, Clemson, SC 29631

124. J. Pell, Director, Office of Environmental Regulations, Office of Encrgy Conocrvation and Enviruinitiet, Federal Enelgy Adinlnisstration, Room 7116, 12 th Street and Pennsylvania Avenue, NW, Washington, DC 20461

125. J. Pena, Department of Meteorology, The Pennsylvania State University, University Park, PA 16802

126. R. Perhac, Electric Power Research Institute, P.0. Box 10412, Palo Alto, CA 94303

127. A. J. Policastro, Argonne National Laboratory, 9700 South Cass Avenue, Argonne, IL 60439

128. K. S. Rao, Atmospheric Turbulence Diffusion Laboratory, P.o. Box E, Oak Ridge, TN 37830

129. A. Roffman, Westinghouse Electric Corporation, Environmental Systems Department, Pittsburgh; PA 15230

130. E. Ryzner, Department of Atmospheric and Oceanic Science, University of Michigan, Ann Arbor, MI 48109 
131-155. W. F. Savage, Advanced Concepts Evaluation Branch, Division of Reactor Research and Development, U.S. Energy Research and Development Administration; Washington, DC 20545

156. G. L. Sherwood, Division of Reactor Research and Development, U.S. Energy Research and Development Administration, Washington, DC 20545

157. D. H. Slade, Division of Biomedical and Environmental Research, U.S. Energy Research and Development Administration, Washington, DC 20545

158. P. Slawson, Department of Mechanical Engineering, University of Water1oo, Waterloo, Ontario, Canada

159. W. G. N. Slinn, Precipitation Physics Section, Atmospheric Resources Department, Battelle Pacific Northwest Laboratories, R1chland, WA 99352

160. S. Strauch, Division of Nuclear Research and Applications, U.S. Energy Research and Development Administration, Washington, DC 20545

161. D. W. Thomson, Department of Meteorology, The Pennsylvania State University, University Park, PA 16802

162. Y. J. Tsai, Stone \& Webster Engineering Corporation, P.0. Box 2325, Boston, MA 02107

163. J. L. Vogel, Illinois State Water Survey, Box 232, Urbana, IL 61801

164. J. C. Weil, Martin-Marietta Corporation, Baltimore, MD 21240

165. M. L. Wesely, Argonne Natfonal Laboratory, 9700 South Cass Avenue, Argonne, IL 60439

166. G. K. Wistrom, Advanced Engineering Department, Ecodyne Cooling Products, Inc., P.0. Box 1267, Santa Rosa, CA 9.5403

167. M. A. Wolf, Atmospheric Sciences Department, Battelle Pacific Northwest Laboratories, Battelle Boulevard, Richland, WA 99352

168. Director, Research and Technical Support Division, U.S. Energy Research and Development Administration, P.O. Box E, Oak Ridge, TN 37830 
169. Director, Reactor Division, U.S. Energy Research and Development Administration, P.O. Box E, Oak Ridge, TN 37830

170-196. Technical Information Center, U.S. Energy Research and Development Administration, Oak Ridge, TN 37830 